(C) 2014

Fanhui Jiang

ALL RIGHTS RESERVED 


\title{
REAL-TIME OPTICAL AND MECHANO-OPTICAL STUDIES DURING DRYING AND UNIAXIAL STRETCHING OF POLYETHERIMIDE FILMS FROM SOLUTION
}

\author{
A Thesis \\ Presented to \\ The Graduate Faculty of The University of Akron \\ In Partial Fulfillment \\ of the Requirements for the Degree \\ Master of Science
}

Fanhui Jiang

May, 2014 


\title{
REAL-TIME OPTICAL AND MECHANO-OPTICAL STUDIES DURING DRYING AND UNIAXIAL STRETCHING OF POLYETHERIMIDE FILMS FROM SOLUTION
}

\author{
Fanhui Jiang
}

Thesis

Approved:

Advisor

Dr. Mukerrem Cakmak

Committee Member

Dr. Mark D. Soucek

Committee Member

Dr. Kevin Cavicchi
Accepted:

Dean of the College

Dr. Stephen Z. D. Cheng

Dean of the Graduate School

Dr. George R. Newkome

Department Chair

Dr. Robert Weiss 


\begin{abstract}
Polyetherimide (PEI) exhibits excellent thermal, chemical, and mechanical stabilities as well as good film forming behavior. These characteristics allow it to be used in harsh industrial applications including electronics, automotive and aerospace.

In order to have a fundamental understanding of the temporal evolution of physical characteristics of PEI film and processing parameters, real time measurements are essential. Because drying process of solvent-cast polymer film is complex, off line measurements unable to reveal the temporally varying detailed information, especially for fast "transient events". To solve this problem, two measurement systems, one for drying that tracks real time thickness, weight, surface temperature, in-plane and out-of-plane birefringence of solution casting film, and another for uniaxial stretching that tracks real time true stress, true strain and birefringence while subjecting film to heating and stretching were used. These allowed systematic investigation of development of optical anisotropy through in and out of plane birefringence monitoring drying of solution cast films and their mechano-optical behavior during stretching, and quantify the influence of solvent N-methyl-2-pyrrolidinone (NMP) on these relationships.
\end{abstract}


In drying, the thickness and weight of PEI solution casting film reduce rapidly at the initial stage due to solvent evaporation, while both in and out of plane birefringence remain zero. Beyond a critical time, while the in-plane birefringence remains very close to zero, the out-of-plane birefringence shows an increase then leveling off. This indicates that the polymer chain axes rotate to preferentially lie in the film plane while exhibiting random in-plane orientation. The decrease of solid content in solution leads to increase in ultimate out-of-plane birefringence as a result of higher chain orientation in the plane. Mixing with low boiling-point solvent, casting at small thickness, drying at low temperature and fast surface air speed, all lead to increases in final value of out-of-plane birefringence due to this alignment.

The presence of NMP solvent decreases the glass transition temperature of PEI that allows the PEI film to be stretched at relatively low temperatures. This offers an alternative to high temperature $\left(\mathrm{Tg}=216^{\circ} \mathrm{C}\right)$ stretching of pristine PEI. The PEI films with various NMP solvent contents all exhibit three regimes of non-linear stress and strain-optical behavior. The addition of solvent content brings a transition from plastic-like behavior to rubber-like behavior, and reduces the final birefringence due to relaxation. Rising stretching temperature and reducing stretching rate play a very similar role with increasing the solvent content that decrease the true stress value at given true strain and the birefringence because of relaxation. 


\section{ACKNOWLEDGEMENTS}

I owe my deepest gratitude to my advisor, Distinguished Professor Mukerrem

Cakmak, for his patience, guidance, support and encouragement throughout this work.

Also I would like to thank all the members in Professor Cakmak's research group. It is a very enjoyable journey working with all of you. I will always remember the wonderful times we spent together.

Finally, I would like to dedicate this work to my mother, father and my girlfriend, who supported me in every decision I took with great patience and understanding. 
TABLE OF CONTENTS

Page

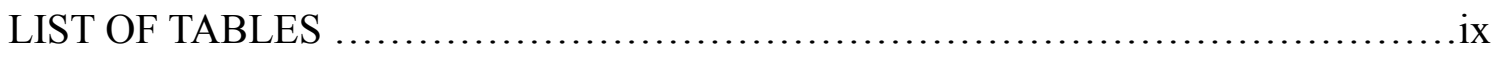

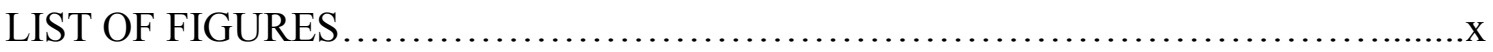

CHAPTER

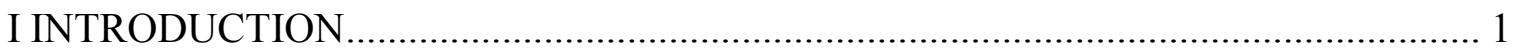

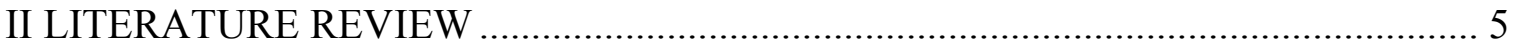

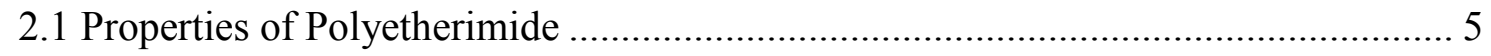

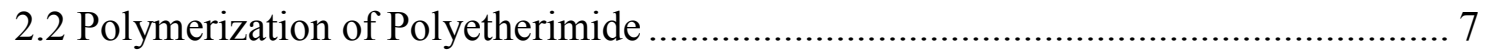

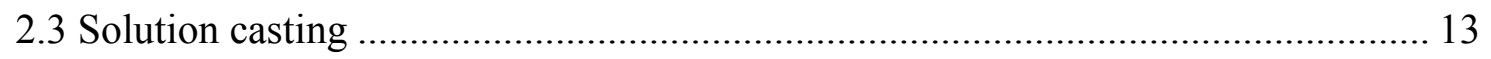

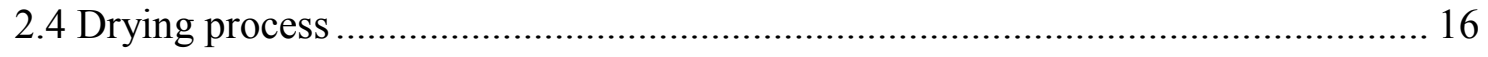

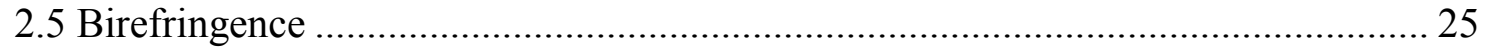

2.6 Mechanical Behavior during Uniaxial Stretching .............................................. 29

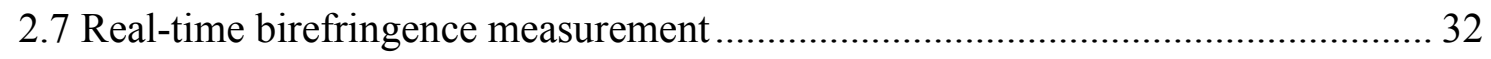

III REAL-TIME OPTICAL AND MECHANO-OPTICAL STUDIES DURING DRYING AND UNIAXIAL STRETCHING OF POLYETHERIMIDE FILMS FROM SOLUTION 


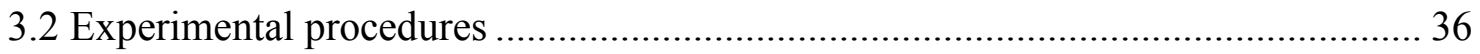

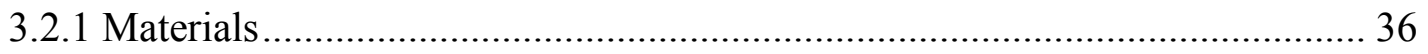

3.2.2 Solution casting by Dr. Blade ………………............................................. 37

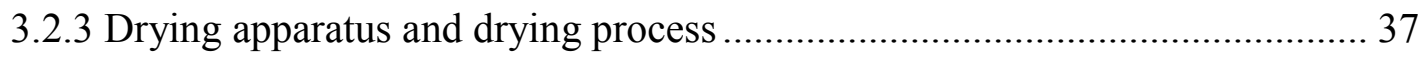

3.2.4 Dumbbell shape film preparation and stretching apparatus ............................ 39

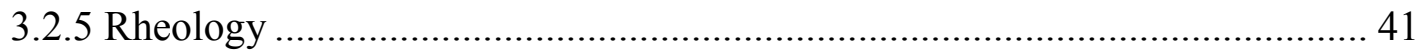

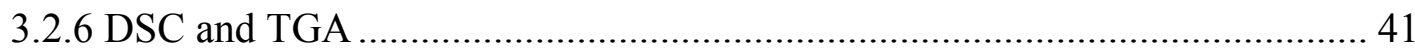

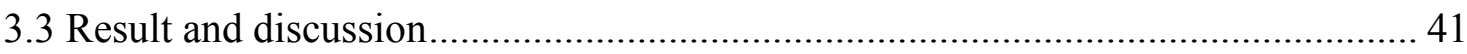

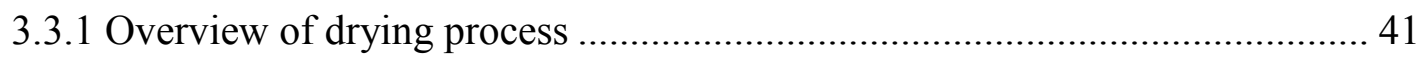

3.3.2 Solid content effect in drying process .......................................................... 45

3.3.3 Drying temperature effect in drying process.................................................. 46

3.3.4 Casting thickness effect in drying process ................................................... 53

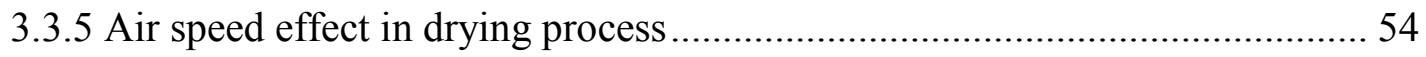

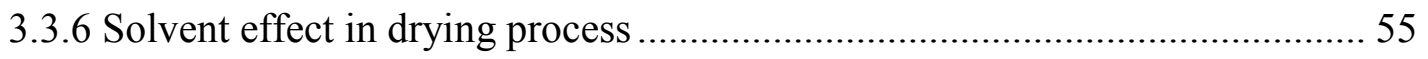

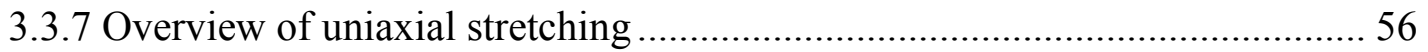

3.3.8 Solvent content effects on mechano-optical properties................................... 57 
3.3.9 Temperature effects on mechano-optical properties

3.3.10 Stretching speeding effects on mechano-optical properties ....................... 67

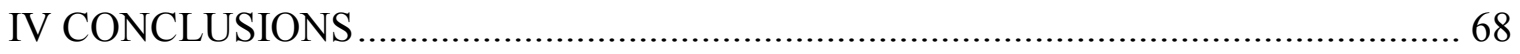

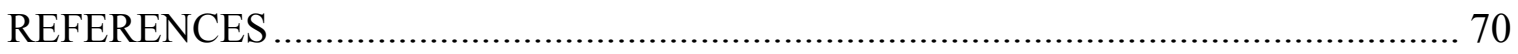




\section{LIST OF TABLES}

Table

Page

2.1 Limiting oxygen index of polyetherimide and selected

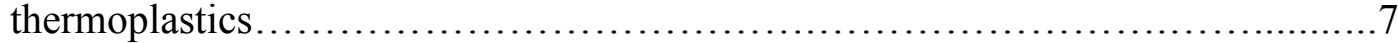

3.1 The ultimate values of out-of-plane birefringence, solid content, $\mathrm{Tg}$ and different value of PEI film with $17 \%$ initial solid content drying at $0.5 \mathrm{~m} / \mathrm{s}$ air speed........51 


\section{LIST OF FIGURES}

Figure Page

2.1 Regular repeat units of PEI chemical structure................................................. 5

2.2 Two steps polymerization of PEI. ............................................................ 8

2.3 The melting polymerization of PEI by tetracarbooxylic acid and diamine. ........... 10

2.4 Synthesis of PEI via nucleophilic aromatic sostitution reaction............................11

2.5 Synthesis of bisetherimides by nitro displacement reaction. .................................11

2.6 Synthesis of PEI by amine-exchange reaction............................................. 12

2.7 Synthesis of PEI by ether-exchange reaction................................................. 13

2.8 Transverse birefringence vs. dry film thickness, showing the effect of casting method for PCl cast from DCM: ○BC method; •FC method.............................. 15

2.9 Transverse birefringence vs. dry film thickness showing the effect of casting method. TMBPA: $\circ$ BC method, $\square$ FC method. PS: $\bullet$ BC method, $\square$ FC method. ... 16

2.10 Operating window of drying for PET substrate. ........................................... 17

2.11 Operating window of drying for glass substrate. ............................................ 18

2.12 Surface appearance of "orange peel". The wet coated film with the thickness $300 \mu \mathrm{m}$ was dried at $80^{\circ} \mathrm{C}$ on glass substrate.

2.13 Schematic description of polyimide gel film and condensed film formations from its solution. (Three-dimensional axes show macromolecular size comparatively. The slight dark bar depicts anisotropic unit, and the possibility of its position in space is outlined.) 
2.14 Transverse birefringence vs. casting temperature, showing the effect of solvent

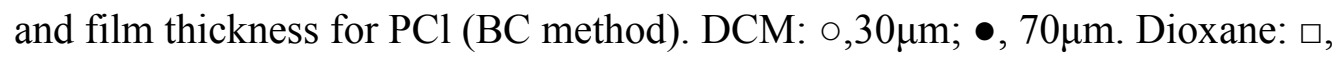
$25 \mu \mathrm{m} ; \boldsymbol{m}, 50 \mu \mathrm{m}$.

2.15 Birefringence of the 3- $\mu \mathrm{m}$-thick polystyrene films as a function of the weight average of molecular weight

2.16 Transverse birefringences dry film thickness, showing the effect of casting solvent for $\mathrm{PCl}$. •DCM; o tetrahydrofuran; $\square$ p-dioxane; cyclohexanone.

2.17 Birefringence vs. dry film thickness showing the effect of casting substrate for $\mathrm{PCl}$ casted from $\mathrm{DCM} \circ$ polyethylene, $\square$ glass, $\bullet$ aluminum, $\bullet$ Teflon substrate. .... 24

2.18 Transverse birefringence vs. dry film thickness, showing the effect of film removal from casting substrate for $\mathrm{PCl}, \circ$, removed after complete drying at elevated temperature; $\bullet$, removed after $24 \mathrm{~h}$ at ambient; $\square$, removed after $1.5 \mathrm{~h}$ at ambient; $\mathbf{n}$,removed after $0.5 \mathrm{~h}$ at ambient.

2.19 Schematic diagram of the set-up for measuring birefringence: (1) He-Ne laser, $632.8 \mathrm{~nm}$; (2) analyser; (3) sample holder; (4) polarizer; (5) photodetector.

2.20 Experimental uniaxial compression stress-strain curves for PC, PMMA and PAI at the temperature $25^{\circ} \mathrm{C}$ over a wide range of strain rates.

3.1 Casting procedure with casting blade apparatus: before (1) and after casting (2).. 37

3.2 Real-time solution drying measurement instrument (1 Hot air blower, 2 connection of blower to the tunnel, 3 vertical baffles, 4 drying sample and sensor location, 5. open end of the tunnel).

3.3 (a) Dumbbell shape of testing sample, and 3.3 (b) Scheme of uniaxial stretch-birefringence machine.

3.4 Rheology behavior of PEI-NMP with various solid contents at room temperature. (Inset figure: $\log \left(\right.$ viscosity) vs. solid content at shear rate $0.0825 \mathrm{~s}^{-1}$.) 42

3.5 Temperature of glass transition vs. solvent content of PEI-NMP. 43 
3.6 (a)The whole drying process traced by real-time measurements system of PEI-NMP with $17 \%$ solid content and $750 \mu \mathrm{m}$ initial thickness drying at $65{ }^{\circ} \mathrm{C}$ and $0.5 \mathrm{~m} / \mathrm{s}$ air speed, and 3.6 (b) $30 \%$ solid content.

3.7 Solid content effects on in-plane and out-of-plane birefringence behavior of PEI-NMP with $750 \mu \mathrm{m}$ initial thickness drying at $65^{\circ} \mathrm{C}$ and $0.5 \mathrm{~m} / \mathrm{s}$ air speed....... 46

3.8 (a) Temperature effects on in-plane and out-of-plane birefringence behavior of PEI-NMP with $17 \%$ solid content and $300 \mu \mathrm{m}$ initial thickness drying at $0.5 \mathrm{~m} / \mathrm{s}$ air speed, and 3.8 (b) $750 \mu \mathrm{m}$ initial thickness.

3.9 (a) The changes of out-of-plane birefringence, solid content and glass transition temperature of PEI-NMP with 17\% solid content and 300 $\mu \mathrm{m}$ initial thickness drying at $0.5 \mathrm{~m} / \mathrm{s}$ air speed and various temperatures, and 3.9(b) $750 \mu \mathrm{m}$ initial thickness..

3.10 (a) The out-of-plane birefringence vs. solid content of PEI-NMP with $17 \%$ solid content and $300 \mu \mathrm{m}$ initial thickness drying at $0.5 \mathrm{~m} / \mathrm{s}$ air speed and vary temperatures, and 3.9 (b) $750 \mu \mathrm{m}$ initial thickness

3.11 Temperature vs. time of out-of-plane birefringence begin to increase of PEI-NMP with $17 \%$ solid content and different initial thickness drying at $0.5 \mathrm{~m} / \mathrm{s}$ air speed.

3.12 Thickness effects on in-plane and out-of-plane birefringence behavior of PEI-NMP with $17 \%$ solid content drying at $65^{\circ} \mathrm{C}$ and $0.5 \mathrm{~m} / \mathrm{s}$ air speed.

3.13 Air speed effects on in-plane and out-of-plane birefringence behavior of PEI-NMP with $17 \%$ solid content and $750 \mu \mathrm{m}$ initial thickness drying at $65^{\circ} \mathrm{C} . \ldots .55$

3.14 Solvent effects on in-plane and out-of-plane birefringence behavior of PEI-NMP with $17 \%$ solid content and $750 \mu \mathrm{m}$ initial thickness drying at $65^{\circ} \mathrm{C}$ and $0.5 \mathrm{~m} / \mathrm{s}$ air speed. 56

3.15 The change of solvent content and Tg during stretching for PEI film with 17\% initial solvent contents stretched at $130{ }^{\circ} \mathrm{C}$ and $10 \mathrm{~mm} / \mathrm{min}$ stretching speed. 58

3.16 True stress-strain plots of PEI films with various solvent contents stretched at $130^{\circ} \mathrm{C}$ and $10 \mathrm{~mm} / \mathrm{min}$ stretching speed. 
3.17 True stress at yield point and strain hardening onset at various solvent contents. 60

3.18 Birefringence-true stress plot for PEI film with various solvent contents stretched at $130{ }^{\circ} \mathrm{C}$ and $10 \mathrm{~mm} / \mathrm{min}$ stretching speed. (Inset figure: magnification of initial regime)

3.19 Birefringence-true strain plot for PEI film with various solvent contents stretched at $130{ }^{\circ} \mathrm{C}$ and $10 \mathrm{~mm} / \mathrm{min}$ stretching speed. (Inset figure: magnification of initial regime)

3.20 Photoelastic constant and strain optical constant of Regime i at various solvent contents.

3.21 True stress-true strain plots for PEI films with $17 \%$ solvent content stretched at $10 \mathrm{~mm} / \mathrm{min}$ stretching speed with various temperatures.

3.22 Birefringence-true stress plots for PEI films with $17 \%$ solvent content stretched at $10 \mathrm{~mm} / \mathrm{min}$ stretching speed with various temperatures.

3.23 Birefringence-true strain plots for PEI films with $17 \%$ solvent content stretched at $10 \mathrm{~mm} / \mathrm{min}$ stretching speed with various temperatures.

3.24 True stress-true strain plots for PEI films with $12 \%$ solvent content stretched at $140{ }^{\circ} \mathrm{C}$ with various stretching speeds.

3.25 Birefringence-true stress plots for PEI films with $12 \%$ solvent content stretched at $140{ }^{\circ} \mathrm{C}$ with various stretching speeds.

3.26 Birefringence-true strain plots for PEI films with $12 \%$ solvent content stretched at $140{ }^{\circ} \mathrm{C}$ with various stretching speeds. 


\section{CHAPTER I}

\section{INTRODUCTION}

To obtain an ideal polyimide which assembles both good solubility characteristics and excellent mechanical and thermal properties with chemical resistance, polyetherimide (PEI) is prepared by polycondensation via dianhydride and diamine. ${ }^{1-5}$ Since PEI has a unique combination of characteristics, including high specific strength, exceptional dimensional stability, good insulative capability and flammability resistance, it is able to compete with metals and other high performance engineering plastics such as polysulfone (PSU), polyphenylene sulfide (PPS), and polyetherether keone (PEEK). Due to the potential wide applicability, studies continuously report concerning new methods of PEI synthesis, ${ }^{6-8}$ structural and surface modification of PEI, ${ }^{9-15}$ and PEI composites. ${ }^{16}$ All of these further widen the application of PEI in membranes (separation and filtration), electronics, automotive, medical and aerospace areas.

PEI processing methods involve conventional injection molding, extrusion and blow molding due to its high melt strength. In a large scale in industry, extrusion is the most common processing way to prepare PEI film and sheet. Comparing with the crystalline thermoplastic, the uniformity in shrinkage can be maintained over a fairly 
wide processing range so that the precise dimensional control of PEI film and sheet are achieved relatively easily. Solution-casting, another process method, which casts solution by doctor blade on a moving substrate, such as glass plane and polyethylene terephthalate (PET) films, and then strip the solvent, is also able to generate a defect-free polymer film with uniform surface.

Considering the processing conditions bring significant influence on the final properties of polymer products, establishing a fundamental understanding between the processing parameters, such as temperature, casting thickness, solvent type and structural characteristics is essential important. Rickert et al. ${ }^{17}$ studied that the alignment behavior of polymer chains was controlled by substrate properties, solution properties and interfacial properties. Cherkasov et al. ${ }^{18}$ investigated the orientation phenomena of polymer molecules by free casting. Also, the molecular weight, polydispersity, film thickness, solvent, plasticizer content and temperature were of great factors affecting the optical properties of solution-casting polymer film. $^{19-21}$

However, solution-casting is rarely used in PEI processing mainly as it is an expensive path to film formation due to the use of expensive solvents and needs to recover the solvent. Since film formation involves a series of complex events, including solvent loss, thickness reduction, shrinkage and orientation, off-line measurements are unable to give complete information, especially for those rapid “transient events". Hence, a new designed real-time instrument, which simultaneously captures thickness, weigh, surface temperature, in-plane and 
out-of-plane birefringence of solution-casting film, is used to investigate the relationship between processing conditions and structure development of PEI film.

In the case of mechanical properties, the deformation behavior of PEI in the stretching process has been investigated. ${ }^{22,23}$ Since polymer material generally goes through series of changes, such as solvent loss (if it contains solvent), orientation and relaxation, and these changes might take place simultaneously or in a complicated sequence, a real-time apparatus that includes structural sensors such as birefringence is essential for comprehensive analysis. What's more, the cross-section of the sample becomes non uniform during stretching, so that engineering stress and strain described in those former studies may not accurately reflect the real situation of the deformation. Therefore, instrumentation with real time cross-sectional area determination (laser micrometer, fast video strain measurement system) that allows for determination of real-time birefringence-true stress-true strain is applied. ${ }^{16}$

As a high performance engineering plastics, PEI should be processed at a high temperature due to its high glass transition temperature (about $216^{\circ} \mathrm{C}$ ). To decrease the cost and instabilities induced by high processing temperature, solvent can work as a plasticizer to reduce the glass transition temperature and thus allows films to be stretched at lower temperature. Among the process parameters in film stretching of PEI, various temperatures and stretching rates also potentially influence the structure development, mechanical and optical properties of PEI.

The main goal of this study is to establish a fundamental understanding of structural development and mechano-optical properties of PEI during the whole 
processing, including the initial film formation and the final deformation. By measuring a real time birefringence in drying and stretching process, the optical anisotropy changes and structure develops. A fundamental research about the effects of drying conditions, including drying temperature, air speed on the film surface, casting thickness, solid concentration, and solvent type, and the effects of stretching parameters, such as stretching temperature, stretching rate and solvent content on the PEI solution-casting film is included in this work.

Two powerful on-time measurement techniques, which provide real-time drying-birefringence and real-time stretching-birefringence, will be utilized in this study for revealed the structural development during drying and stretching process.

Therefore, a systematical and consecutive study of the structure development and optical properties changes from PEI solution-casting film preparation to stretching will be demonstrated. The relationship between film properties and process conditions will be discussed in detail. 


\section{CHAPTER II}

\section{LITERATURE REVIEW}

\subsection{Properties of Polyetherimide}

Polyetherimide (PEI) is an amorphous, high performance, thermoplastic resin and its commercial product named Ultem resin has an amber color and transparen The regular repeat units of chemical structure is showed in Figure 2.1

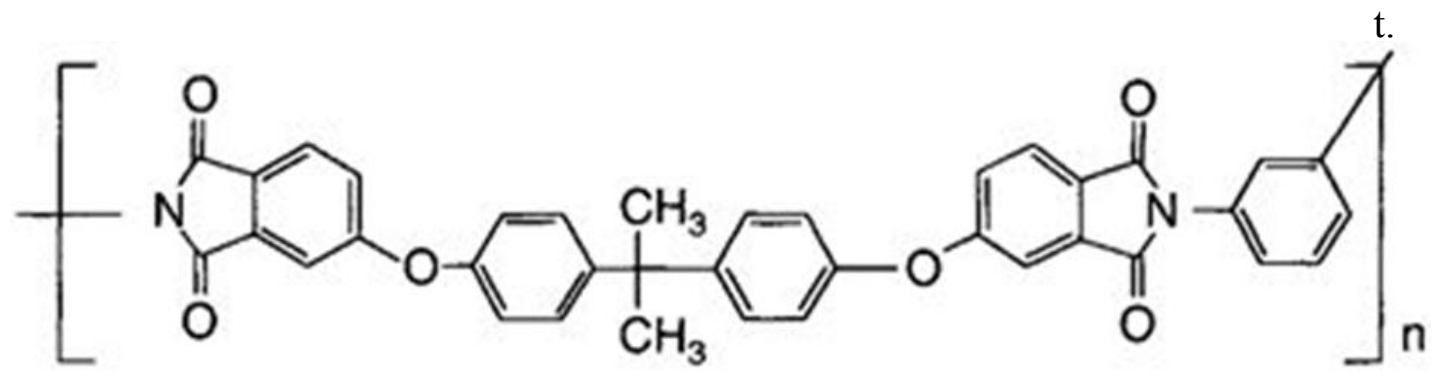

Figure 2.1 Regular repeat units of PEI chemical structure.

Because of the polarity, PEI has a good solubility in polar and chlorinated solvent, including Dimethylacetamide (DMAc), Dimethylformamide (DMF), N-Methyl-2-pyrrolidone (NMP), Methylene Chloride, Chloroform, and Dichlorobenzene. 
This material has a high glass transition temperature around $215-217^{\circ} \mathrm{C}$. It retains physical properties at elevate temperatures ${ }^{24}$ and its linear thermal expansion coefficient is similar to some metals. ${ }^{25}$

The repeating ether and imide units provide material with excellent creep resistance, dimensional stability, impact resistance and relatively fair flexibility. PEI exhibits high tensile strength of 14,000 psi in unfilled grades, 28,000 psi in glass-filled grades, 34,000 psi in carbon-filled grades, tensile modulus of $450,000-1,300,000$ psi, flexural strength of 22,000-45,000 psi and flexural modulus of $500,000-1,700,000 \mathrm{psi}^{26}$

The special structure, that is the asymmetry of the imide groups compared with the central ether groups, also gives the specific dipolar charges and interesting electrical properties to the materials. PEI has good insulation capabilities of high volume resistivity of $1017 \mathrm{ohm}-\mathrm{cm}$ and dielectric strength of $830 \mathrm{~V} / \mathrm{mm} .{ }^{27}$ The dielectric constant is stable over a wide range of temperatures and frequencies. The structural and electrical properties do not show a decreased relaxation frequency until the material is heated up to $190{ }^{\circ} \mathrm{C} .^{28}$

Good stabilities, including hydrolytic stability, thermal stability, thermo-photo oxidative stability, and chemical stability are found in this material. PEI retains around $93 \%$ of tensile properties after 10,000 hours in boiling water. Some studies revealed that the water equilibrium concentration of PEI $(1.4 \%)$ is quite stable in the range of temperatures between 20 to $100^{\circ} \mathrm{C}$ and not affects the glass transition temperature. ${ }^{24,29-30}$ The commercial product, Ultem, starts decomposing at $450{ }^{\circ} \mathrm{C}$ 
and only $1 \%$ weight loss at $460^{\circ} \mathrm{C}$. A wide continuous use temperature range of $170-180^{\circ} \mathrm{C}$ ensures its application at high temperature. ${ }^{26} \mathrm{PEI}$ shows a superior resistance to thermo-oxidation processes up to $300{ }^{\circ} \mathrm{C}$ and an outstanding $\mathrm{UV}$ and ionizing radiation resistance with retaining $94 \%$ strength after $400 \mathrm{mrad}$ of cobalt irradiation. In the case of chemical resistance, it's resistant to most hydrocarbons, alcohols, fully halogenated solvents, mineral acids, and mild alkali. ${ }^{26}$

Besides, PEI also has inherent ignition resistance without the use of phosphorous or halogen additives due to its limiting oxygen index (47) and low smoke. ${ }^{31}$ Table 2.1 shows a comparison of limiting oxygen index of PEI and selected thermoplastics.

Table 2.1 Limiting oxygen index of polyetherimide and selected thermoplastics.

\begin{tabular}{|c|c|c|c|c|c|c|c|c|}
\hline Material & PEI & Ryton & PVC & PEEK & Polysulfone & PC & PPO & Nylon \\
& & & & & & & & \\
(FRG) & $6 / 6(F G R)$ \\
Oxygen & 47 & $47-53$ & 47 & 35 & $32-36$ & 32.5 & 30 & 28 \\
\hline
\end{tabular}

\subsection{Polymerization of Polyetherimide}

There are two kinds of method of PEI syntheses: one step processes which is widely used, and two steps polymerization. ${ }^{13,32-33}$

The two-step processing of polymerizing PEI, as well as other polyimides, is conducted by preparing of high molecular weight soluble poly poly(amic acid) by 
reaction of dianhydride with diamine (shown in Figure 2.2). ${ }^{31}$ The reaction takes place in the polar aprotic solvents at the room temperature. The poly(amic acid) film is formed by solution casting on a substrate and then transform to polyetherimide by heating or using dehydrating agents. However, the difficulty is hard to control the molecular weight since there are numerous amounts of various monomers with different solubilities and reactivities. This method only adapt for preparing PEI film when not too many reactants are required.

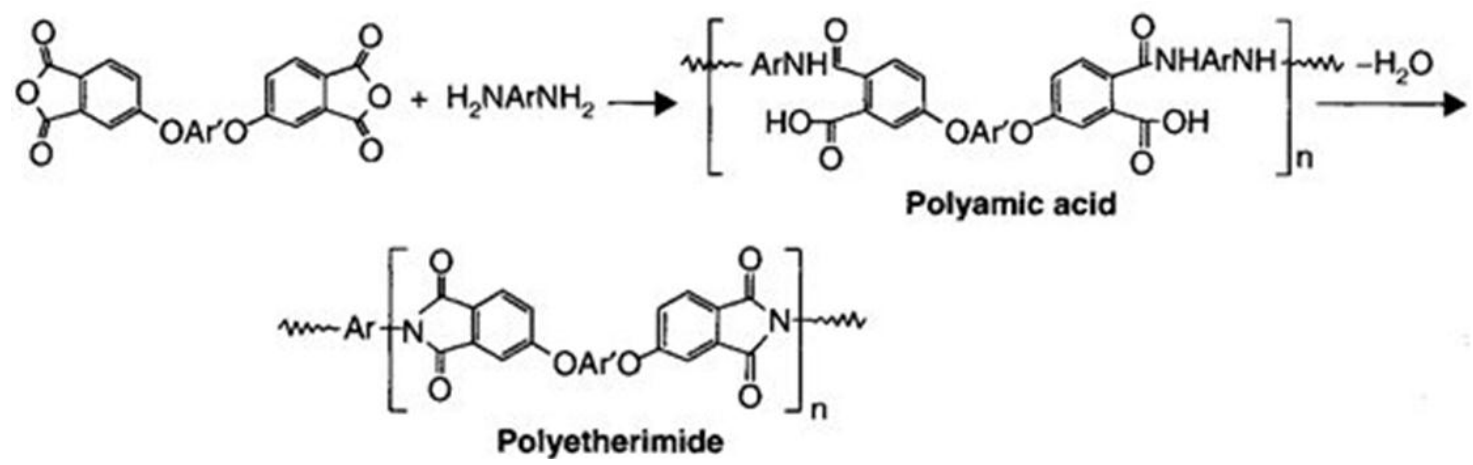

Figure 2.2 Two steps polymerization of PEI.

There are several kinds of one step processes of PEI, including solution polymerization, melt polymerization, synthesis via nucleophilic substitution reaction, and synthesis via exchange reactions. ${ }^{27}$

Solution polymerization involves the reaction of an aromatic bis(ether anhydride) and an organic diamine or diisocyanates in an inert solvent at 150-250 ${ }^{\circ} \mathrm{C} .{ }^{34}$ Even though the concentration of amid acid groups in reaction is very low, the imidization still proceeds by amic acid intermediate. The amine and anhydride are formed very instantly due to the low stability of amic acid at high temperature. Generally, high-boiling nonpolar organic solvent are preferred for solution 
polymerization due to its good compatibility with reactants and products.

Alternatively, dipolar aprotic solvent and phenolic solvent are also selected when the starting material is aromatic bis-etherdicarboxylic acid since the acidic and the intrinsic radical inhibitor solvent significantly decreases the oxidation of air sensitive diamine. ${ }^{34}$ By using toluene as co-solvent, the water formed during the polymerization reaction can be removed. The polycondensation of PEI is realized by using catalysts, such as alkali metals, salts of organo-phosphorus compound or zinc salts of carboxylic acid. ${ }^{35-38}$ Although the reaction time of solution polymerization is relatively long, it accurate controls over the stoichiometry of reaction mixture.

The melt polymerization is conducted by reaction of bis(etherdicarbonyl) compounds with aromatic diamine or diisocyanates. ${ }^{39-40}$ In order to prevent to form high molecular weight polyamic acid intermediates during the initial heating up stages, tetracarboxylic acid is prefer to use (Figure 2.3). Another reason of using this acid is stability and purification. However, the main difficulty of the melt polymerization is control the stoichiometric ratio of reactants in the reaction due to different volatilities of monomers induced by the high melting temperature. 

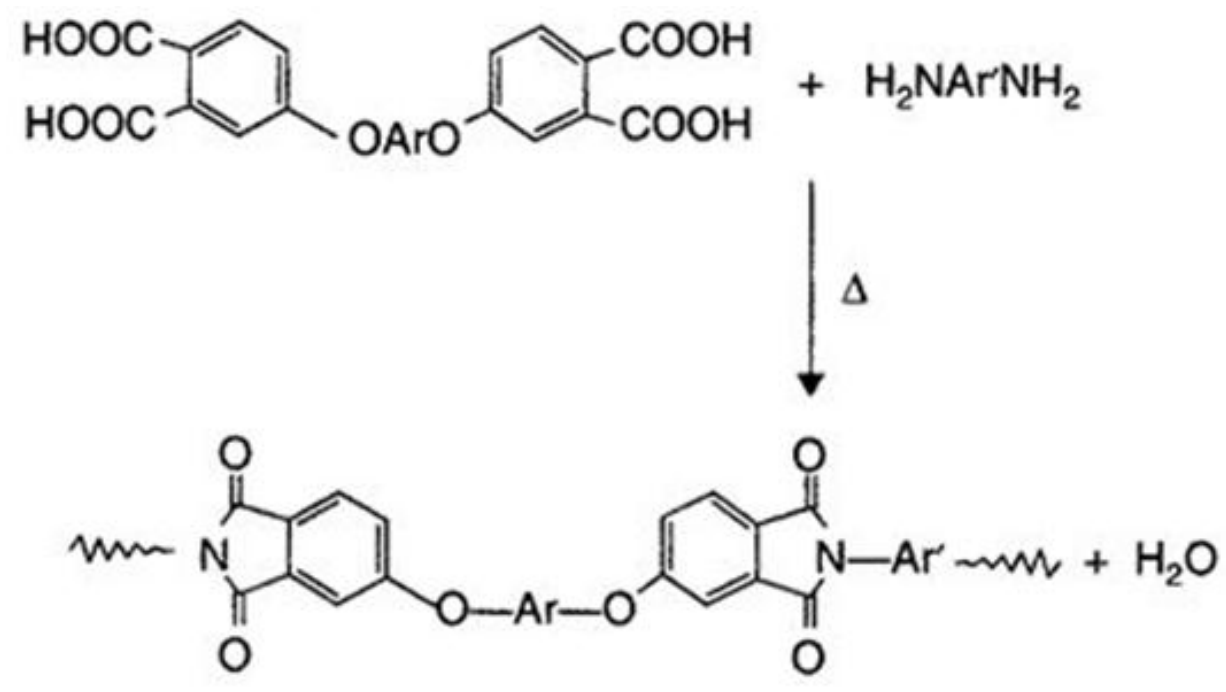

$\operatorname{Ar}=$
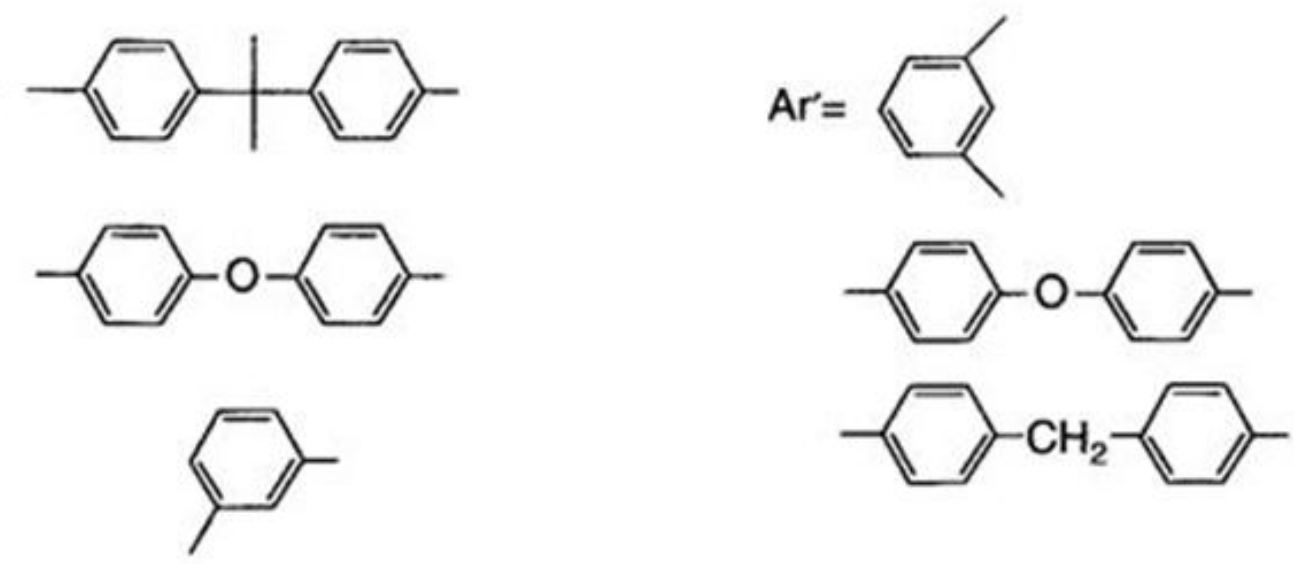

Figure 2.3 The melting polymerization of PEI by tetracarbooxylic acid and diamine.

There are two synthetic strategies of synthesis PEI via nucleophilic substitution reaction. ${ }^{41}$ The first one is the reaction of bishaloimide ${ }^{42-43}$ or bisnitroimides ${ }^{44-46}$ with anhydrous bisphenol salts in dipolar aprotic solvent shown in Figure 2.4. Another way is the reaction of bisetheranhydrides and various aromatic diamines ${ }^{5}$ shown in Figure 2.5. 

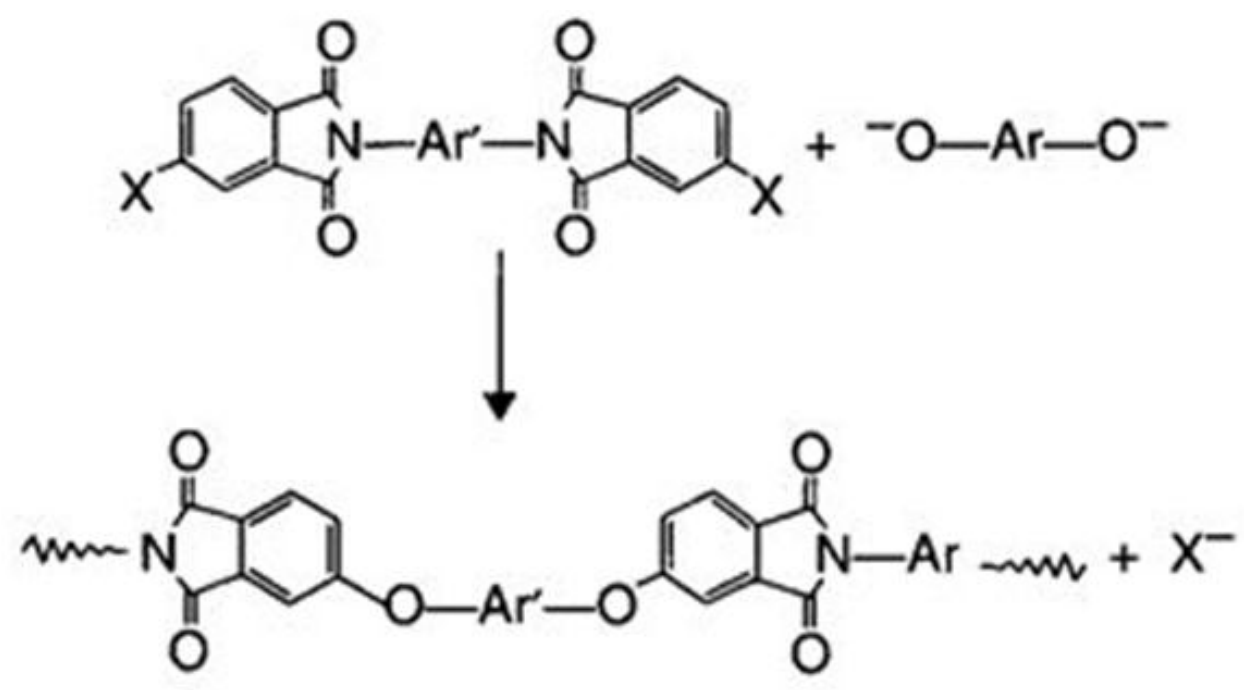

\section{$\mathrm{X}=$ Halogen, $\mathrm{NO}_{2}^{-}$}
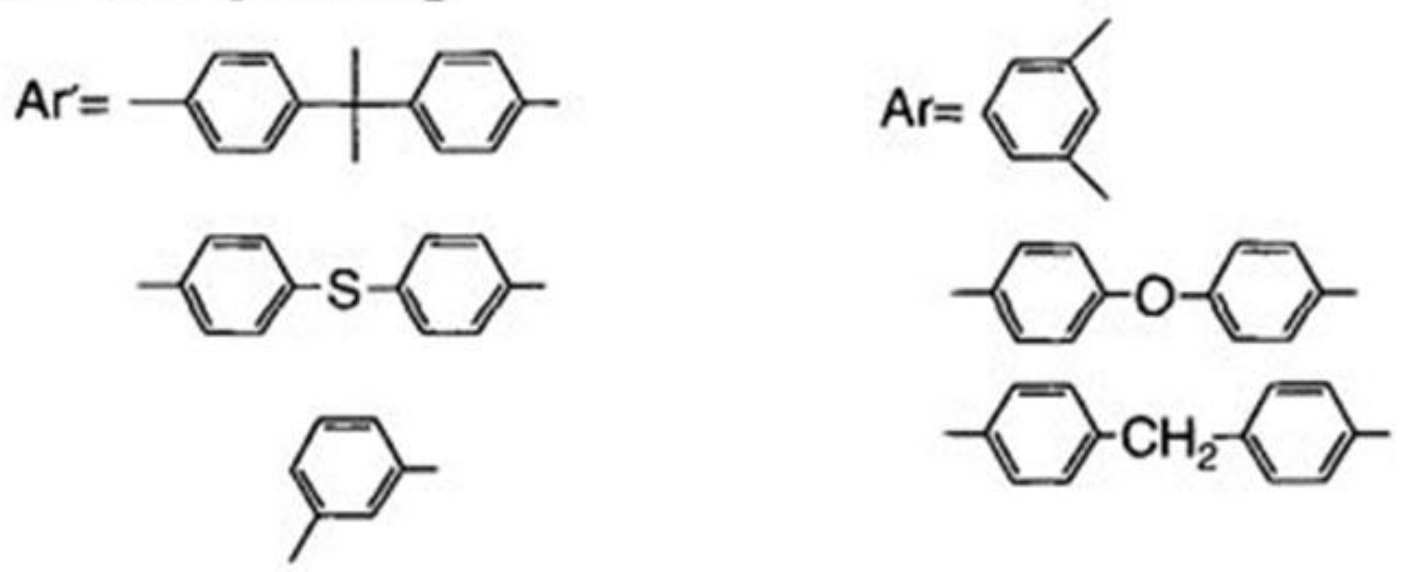

Figure 2.4 Synthesis of PEI via nucleophilic aromatic sostitution reaction.<smiles>[R]N1C(=O)C2CCC([N+](=O)[O-])CC2C1O</smiles>

Figure 2.5 Synthesis of bisetherimides by nitro displacement reaction.

PEI can also be obtained by exchange reactions imide-amines and ether-phenols. ${ }^{47-48}$ Particularly, the transimidization reaction occurs between bis(etherimide) and diamine is shown in Figure 2.6. The bis(ether anhydride) can be eliminated from bis(etherimide) by hydrolysis, neutralization and dehydratation. 
Catalysts, including lead, cadmium and carboxylate salts of zinc, are used to accelerate the reaction rate. Additionally, ether-exchange reaction of bis(aryloxophthalimide) and bisphenol at temperature above $200^{\circ} \mathrm{C}$ with phenoxides as catalyst works another way to synthesize the PEI (shown in Figure 2.7). ${ }^{49}$<smiles>[R]N1C(=O)c2ccc(O[Ga]Oc3ccc4c(c3)C(=O)N([PH2+])C4=O)cc2C1=O</smiles>

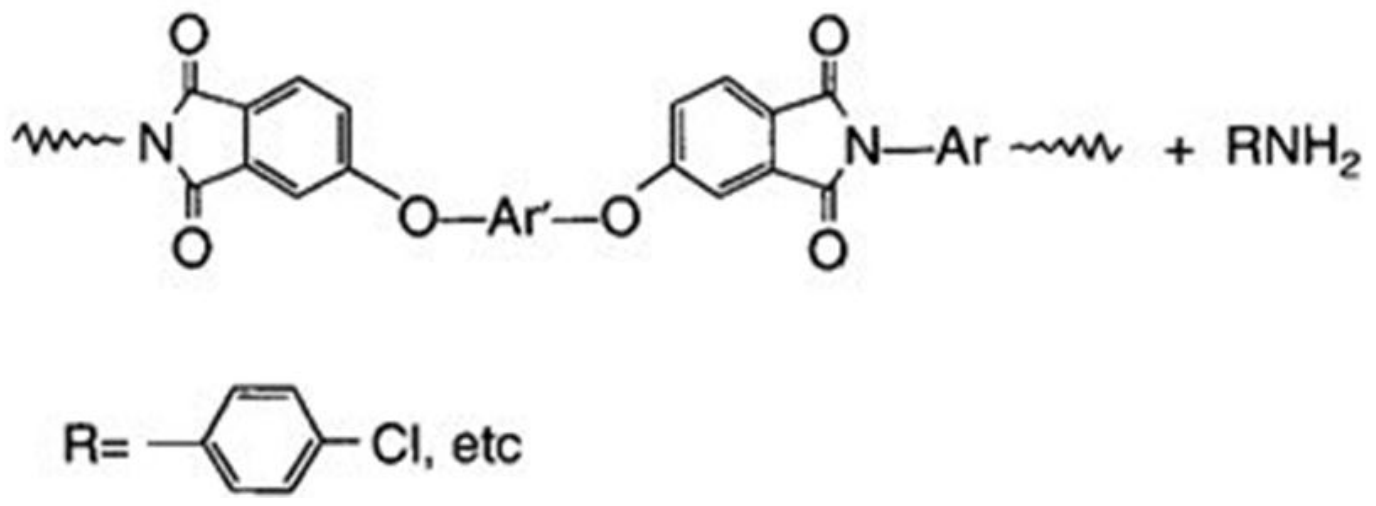

Figure 2.6 Synthesis of PEI by amine-exchange reaction. 

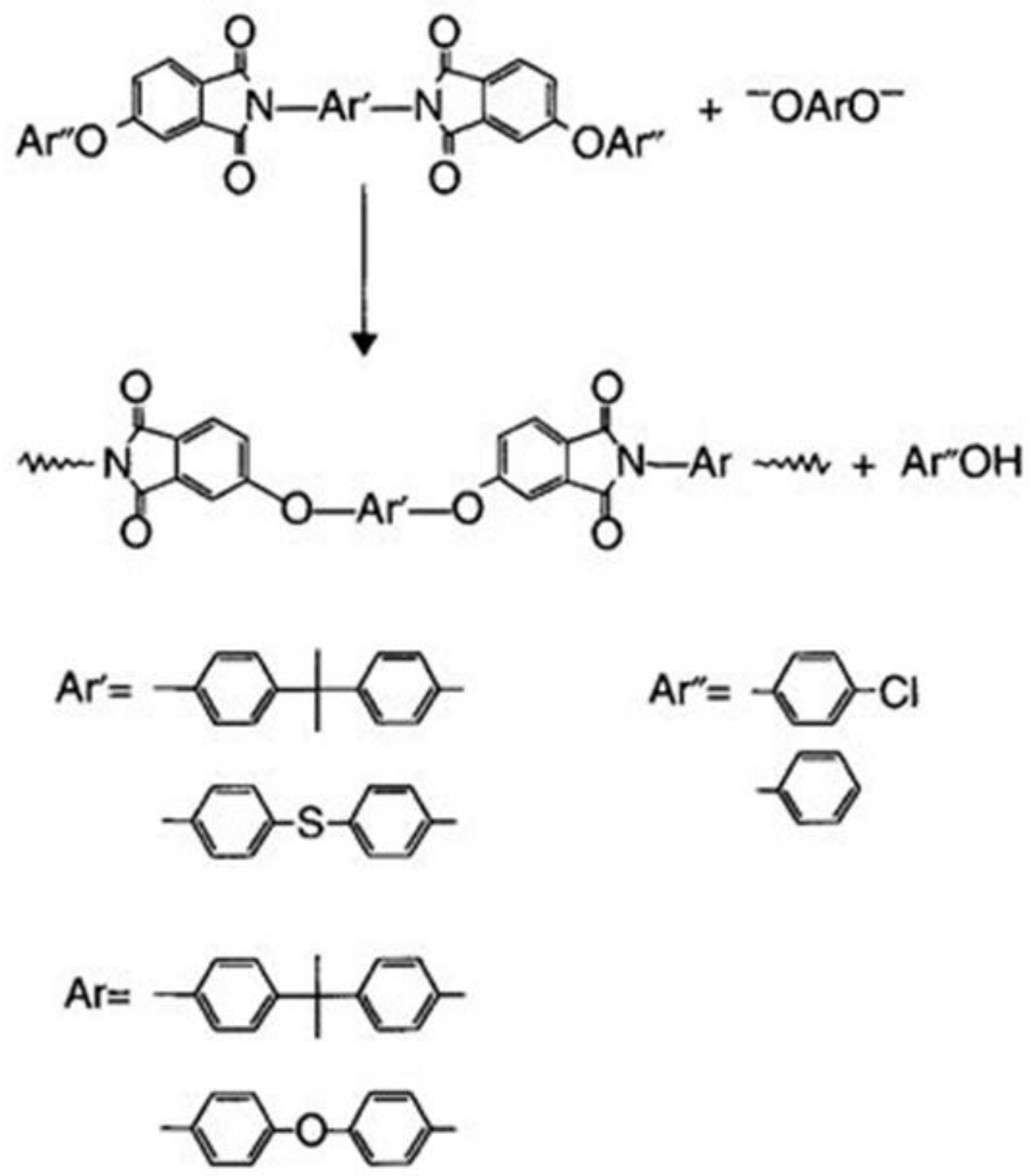

Figure 2.7 Synthesis of PEI by ether-exchange reaction.

\subsection{Solution casting}

There are various methods of providing a uniform and defect-free polymer layer onto a substrate, such as spin coating, spray coating, dip coating and solution casting.

Generally, solution casting, including free casting and blade casting, is often used to prepare samples in the laboratory due to manufacturing films with more 
uniform thickness distribution. ${ }^{50}$ Free casting (FC) pushes polymer solution onto a flat-bottomed substrate without imposing hydrodynamic stress on the liquid. The thickness of a film made by this method usually cannot exceed $200 \mu \mathrm{m}$ due to the difficulties in producing self-supporting film with uniform thickness. Blade casting spreads the polymer solution over a substrate by motor-driven blade at a constant speed with producing hydrodynamic stress. ${ }^{50-51}$ It has been reported that an orientation development occurs on the air-solution interface and solution-substrate interface by blade casting since the movement of Dr. Blade induces shearing effect on the polymer solution. ${ }^{52}$ Later, Greener et al. found that the polymer films, no matter manufactured by free casting or blade casting, all exhibit an isotropic behavior in plane direction( $\mathrm{x}-\mathrm{y}$ direction) and an anisotropic behavior in the out-of-plane direction (y-z direction). Meanwhile, this research agrees that the stress induced by the movement of Dr. Blade did not affect the orientation in y-z direction. However, the out-of-plane birefringence is different by using different solution casting methods. The bisphenol A polycarbonate $(\mathrm{PCl})$ casted from dichloromethane (DCM) by blade casting has higher birefringence than that by free casting, especially for at higher thickness (Figure 2.8). The similar situation also occurred both in Polystyrene (PS) and tetramethyl polycarbonate (TMBPA) films when manufactured by these two solution casting methods in Figure 2.9. The conclusions can be obtained as the following: comparing with free casting, blade casting produced polymer film with higher birefringence; a relationship between out-of-plane 
birefringence and film's thickness exists that increasing the thickness decreases the birefringence.

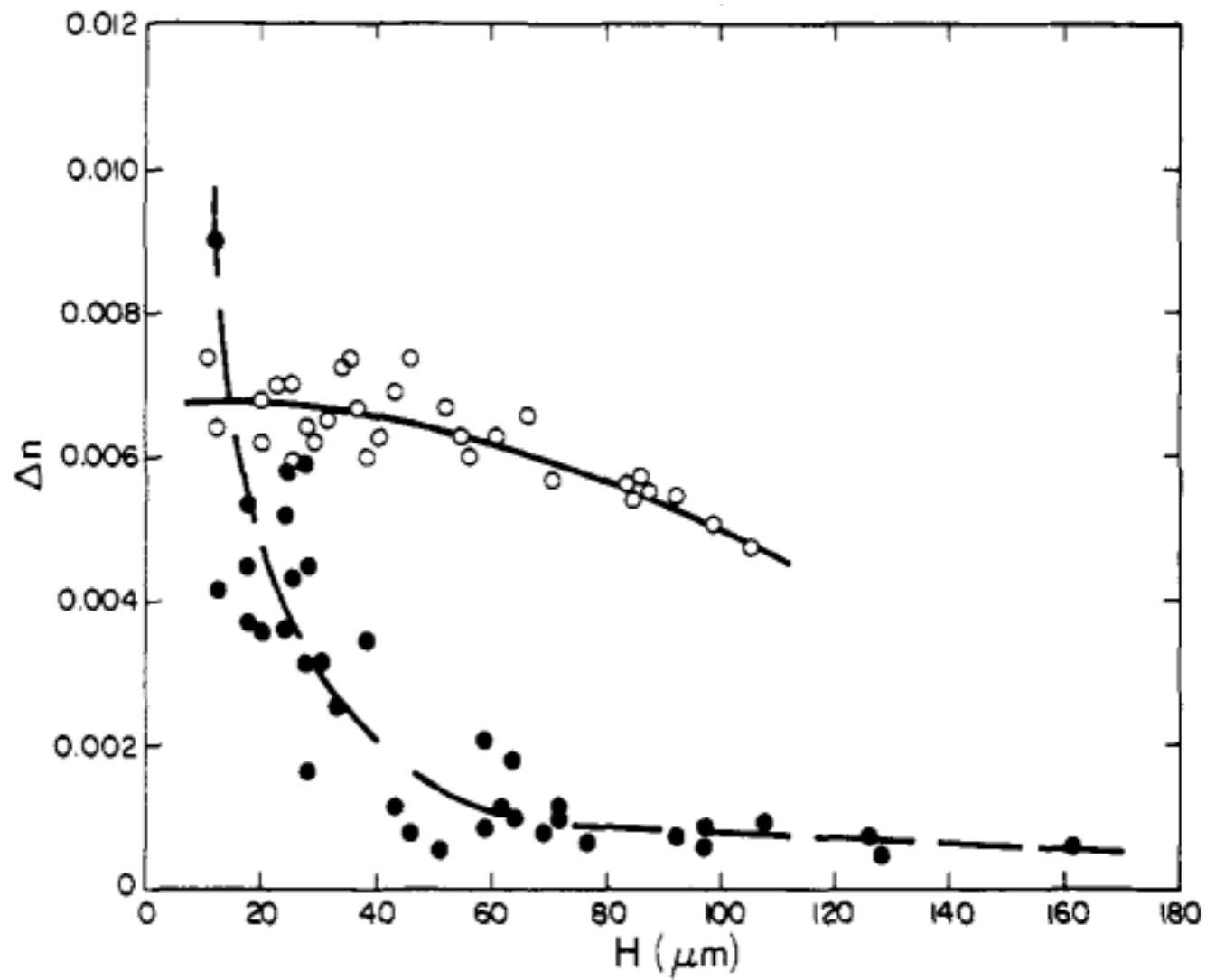

Figure 2.8 Transverse birefringence vs. dry film thickness, showing the effect of casting method for $\mathrm{PCl}$ cast from DCM: $\circ \mathrm{BC}$ method; $\bullet \mathrm{FC}$ method. 


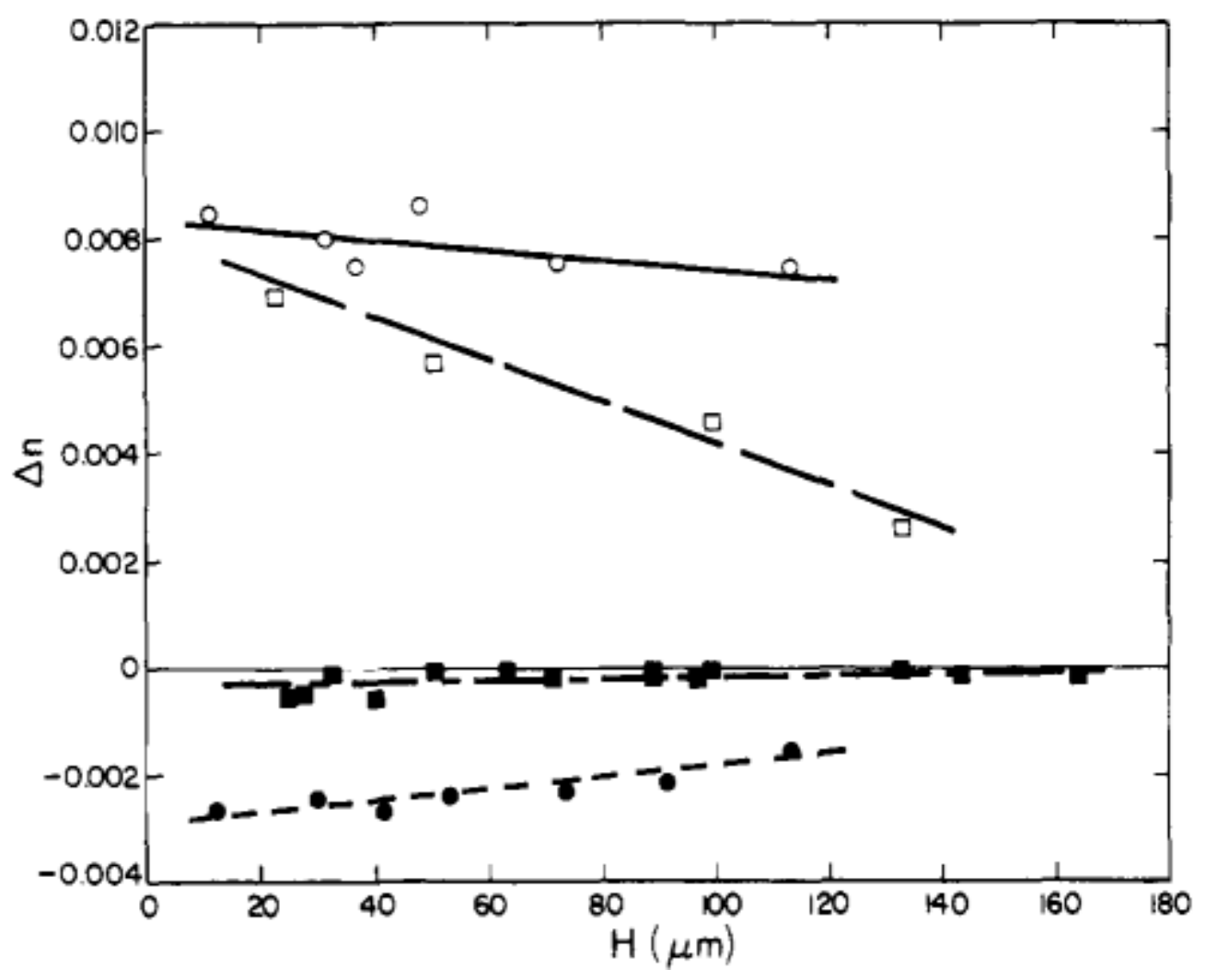

Figure 2.9 Transverse birefringence vs. dry film thickness showing the effect of casting method. TMBPA: ○ BC method, $\square$ FC method. PS: $\bullet$ BC method, $\square$ FC method.

\subsection{Drying process}

Drying process removes solvent from polymer solution to form a solid-behavior film that can sustain a load and peeled from the substrate without any defect. This process controls the structural development of the film and is influenced by drying time, temperature, the mount and the boiling temperature of solvent, polymer-solvent interaction as well as environmental factors, such as humidity, air flow rate etc.

To obtain a uniform and stable film, it is important to figure out the properly operating window depend on the properties of polymer solution and carrier. Po-Ju et 
al. found the operating window of polyimide optical film under different drying condition for the polyethylene terephthalate (PET) and glass substrates, respectively (Figure 2.10 and Figure 2.11). ${ }^{53}$ If the drying rate is too fast or the casting thickness is too thick, bubbles and an irregular and corrugated film surface, the so-called orange peel, appears(Figure 2.12). Because the solvent losses at an extreme rate, a dry polymer skin on the free surface and a fluid solution underneath occur. Continuous evaporation of solvent leads to polymer skin to buckle and form a corrugated surface. ${ }^{54}$

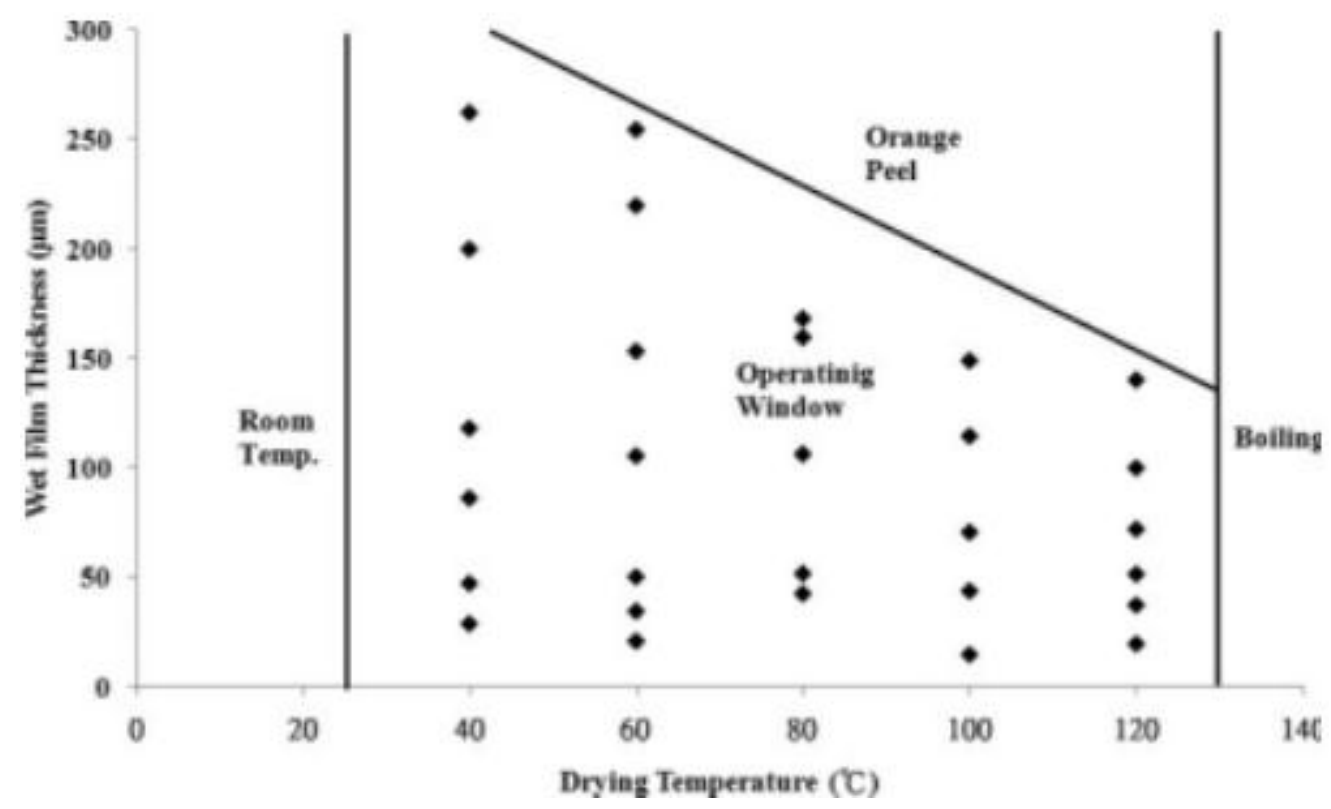

Figure 2.10 Operating window of drying for PET substrate. 


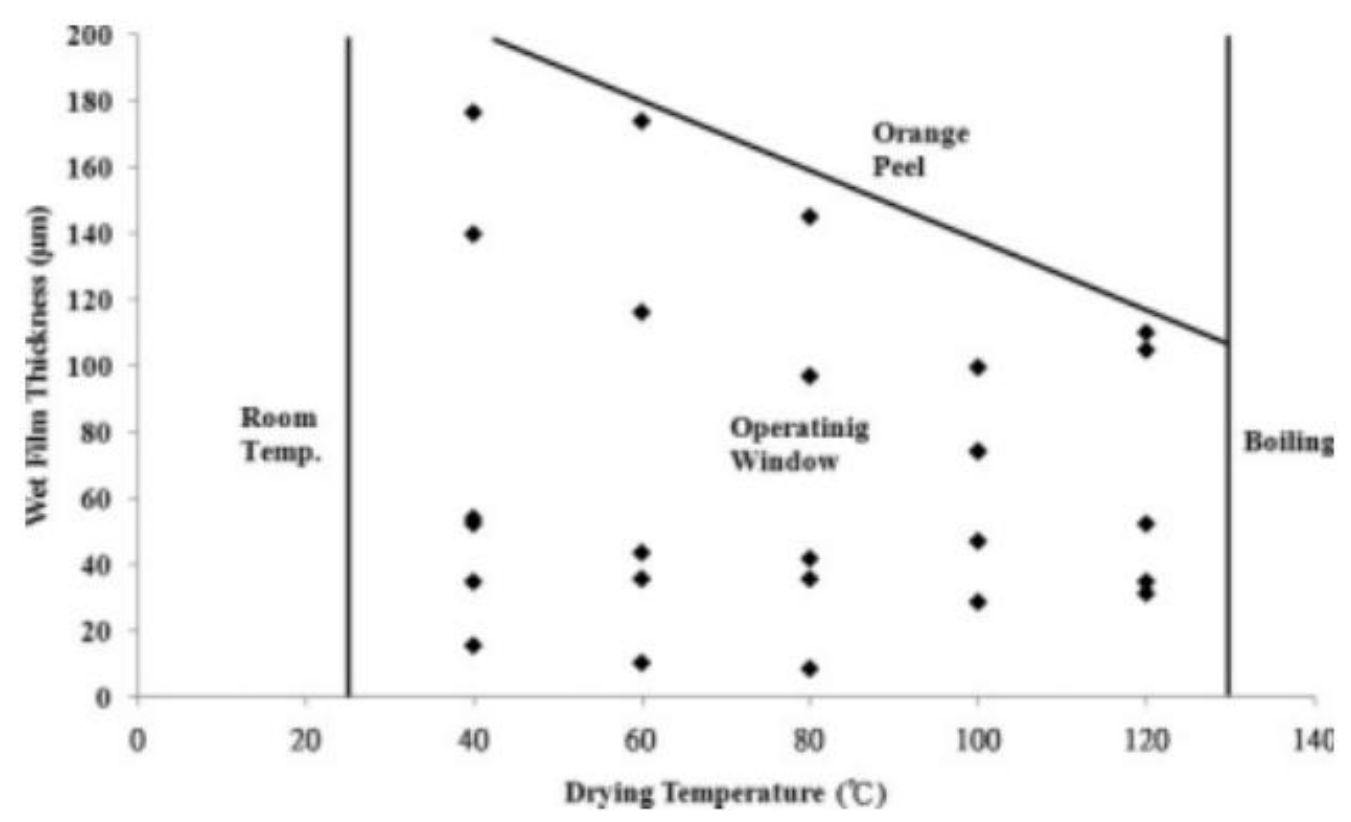

Figure 2.11 Operating window of drying for glass substrate.

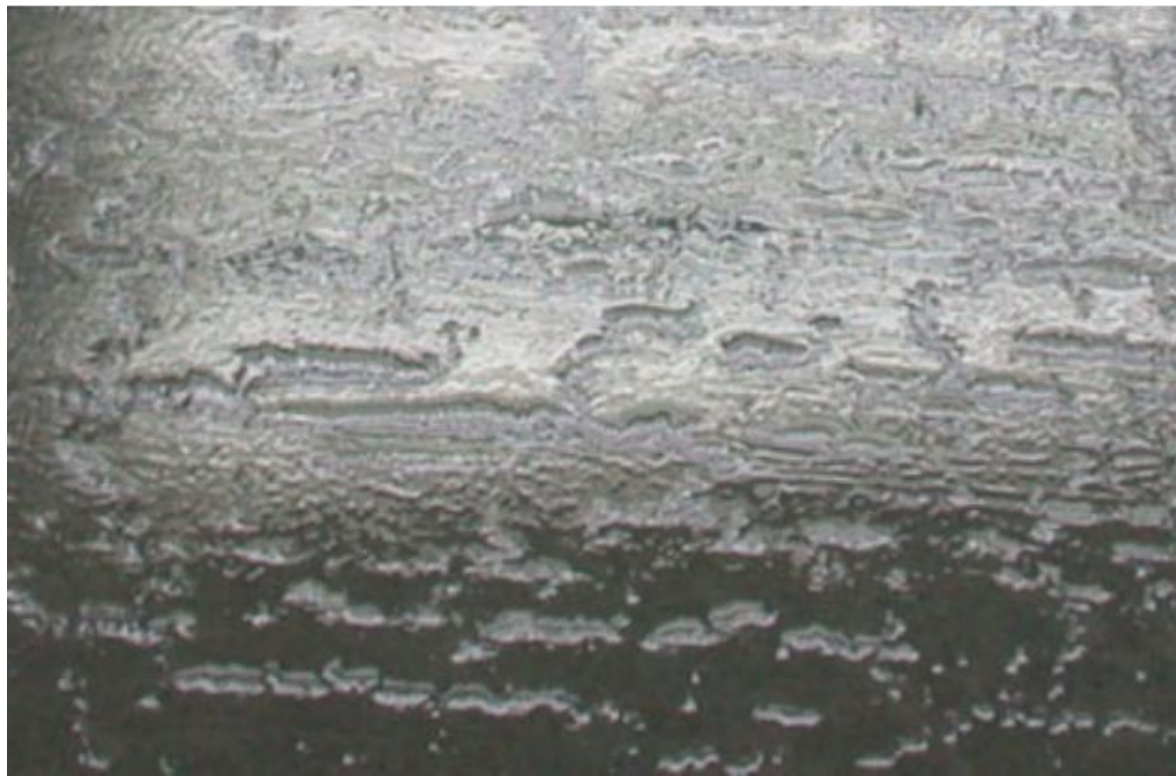

Figure 2.12 Surface appearance of "orange peel". The wet coated film with the thickness $300 \mu \mathrm{m}$ was dried at $80{ }^{\circ} \mathrm{C}$ on glass substrate.

Drying process also effect the final structural development of the polymer film that there is anisotropy in the thickness direction. Coburn and Pottiger ${ }^{52}$ proposed a 
model to give an explanation to this phenomenon. As the solvent evaporate, the concentration of polymer solution changes gradually from dilute to semi-dilute and concentrated solution. Because of the difference between molecular dimensions parallel to the plane and perpendicular to the plane, the structural anisotropy of film is induced. This is also called shrinkage behavior. If the solvent further loss from the film at reduced pressure, while the drying temperature is lower than the glass transition temperature of the polymer, the molecular chains will be frozen and thereby the anisotropic structure will be remained. The condensed film formation and the morphology change of polymer chains during drying process are illustrated in Figure 2.13.

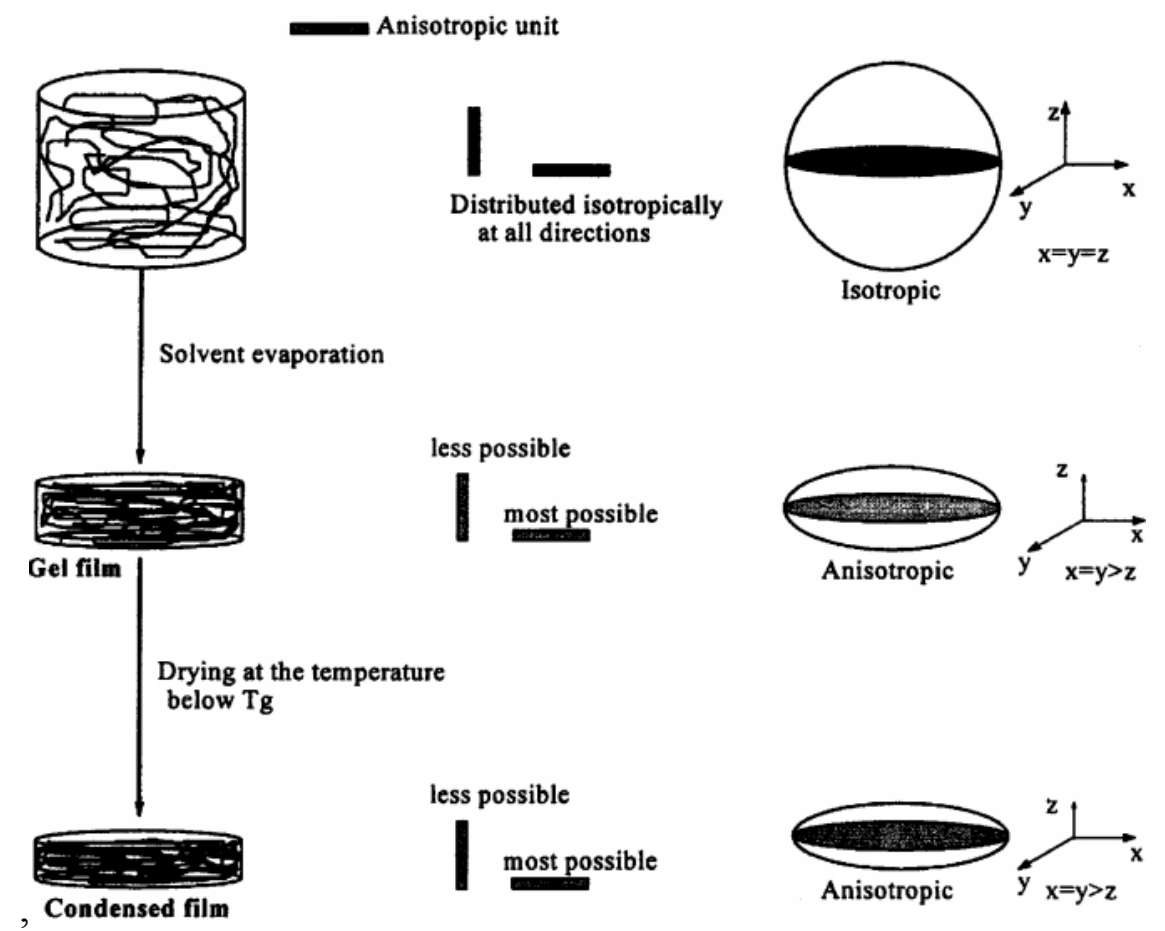

Figure 2.13 Schematic description of polyimide gel film and condensed film formations from its solution. (Three-dimensional axes show macromolecular size comparatively. The slight dark bar depicts anisotropic unit, and the possibility of its position in space is outlined.) 
The volume collapse-induced alignment of the molecular is partially countered by polymer chain relaxation that tends towards randomization. After drying, appreciable solvent still remains in the polymer film that increases the mobility of molecules. Since the entropic driving force is towards to random orientation, the alignment may decrease at some degrees. Casting thickness, temperature, solvent type, molecular weight of polymer, surface energy of substrate, all of these have the influence on this competition. ${ }^{20-21,52,55-57}$

As mentioned in the last section, increasing the initial casting thickness decreases the out-of-plane birefringence. Rising the drying temperature also has very similar effect on decreasing the birefringence in the thickness direction as shown in Figure 2.14. When the drying temperature is closer the final glass transition temperature of polymer-solvent system, the freezing process become slow, and thereby more time stressed chain segments have to relax. ${ }^{50}$ 


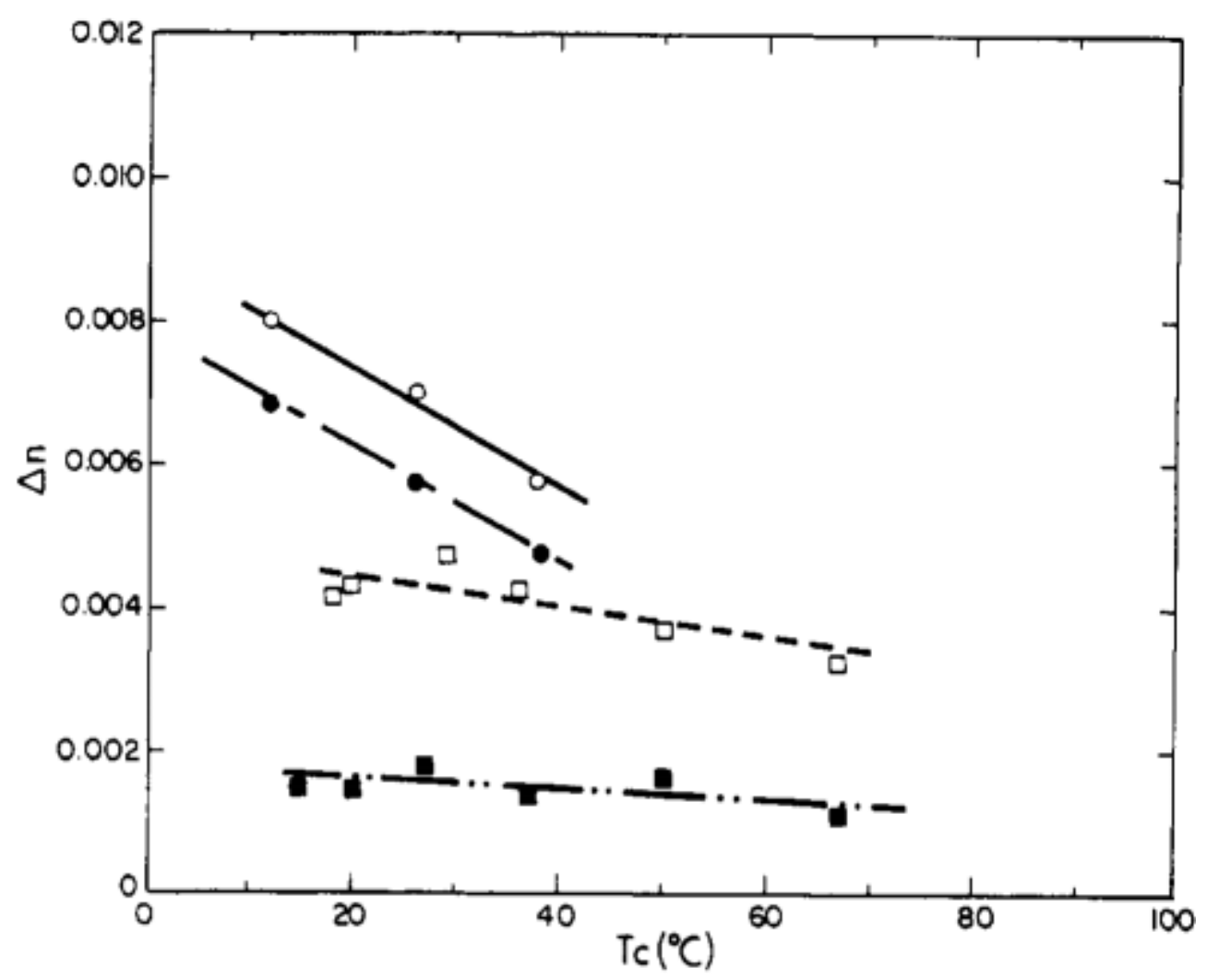

Figure 2.14 Transverse birefringence vs. casting temperature, showing the effect of

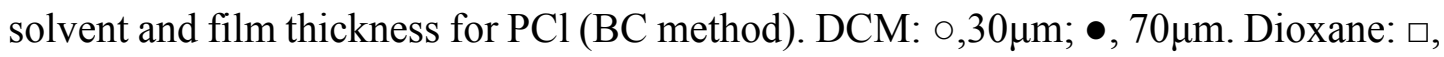
$25 \mu \mathrm{m} ; \mathbf{m}, 50 \mu \mathrm{m}$.

The molecular weight of polymer is one of the factors that effects the alignment of solution cast film. Prest Jr and D. J. Luca ${ }^{21}$ noted that the orientation increases with increasing the molecular weight of polymer (as shown in Figure 2.15). Since higher molecular weight of polymer has more entanglements, it freezes the system sooner while preventing the relaxation of the polymer chains during drying process. $^{20-21}$ 


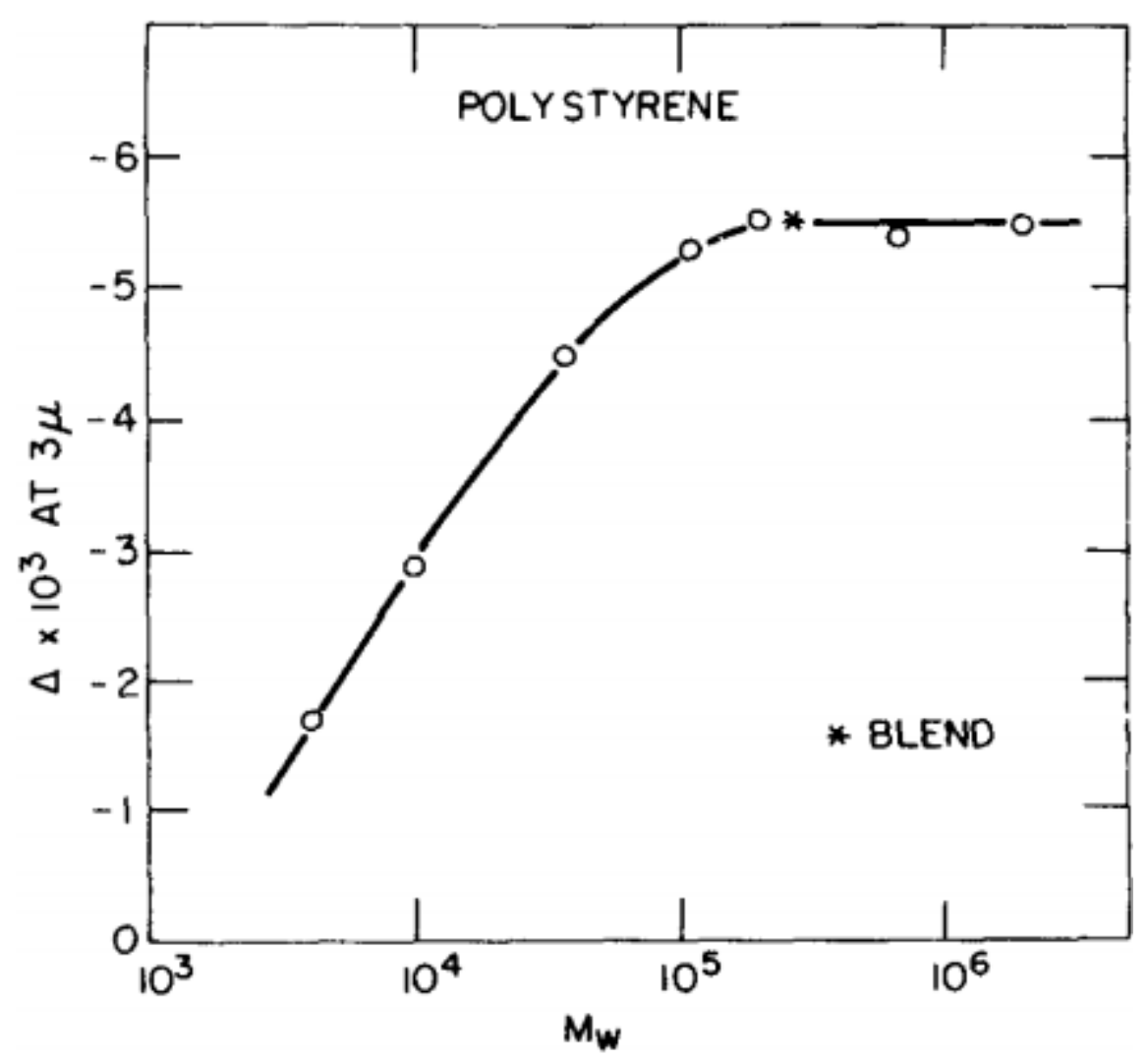

Figure 2.15 Birefringence of the 3- $\mu$ m-thick polystyrene films as a function of the weight average of molecular weight.

Different solvents with various boiling points have influence on the orientation of the film. Figure 2.16 gives us a brief view of the relationship between the birefringence and DCM (boiling point $40^{\circ} \mathrm{C}$ ), tetrahydrofuran $\left(66^{\circ} \mathrm{C}\right)$, p-dioxane $\left(101^{\circ} \mathrm{C}\right)$ and cyclohexanone $\left(155^{\circ} \mathrm{C}\right) .{ }^{50}$ The solvent with higher boiling point produces films with relatively low birefringence due to slowness of evaporation leading to more extensive relaxation of chains. 


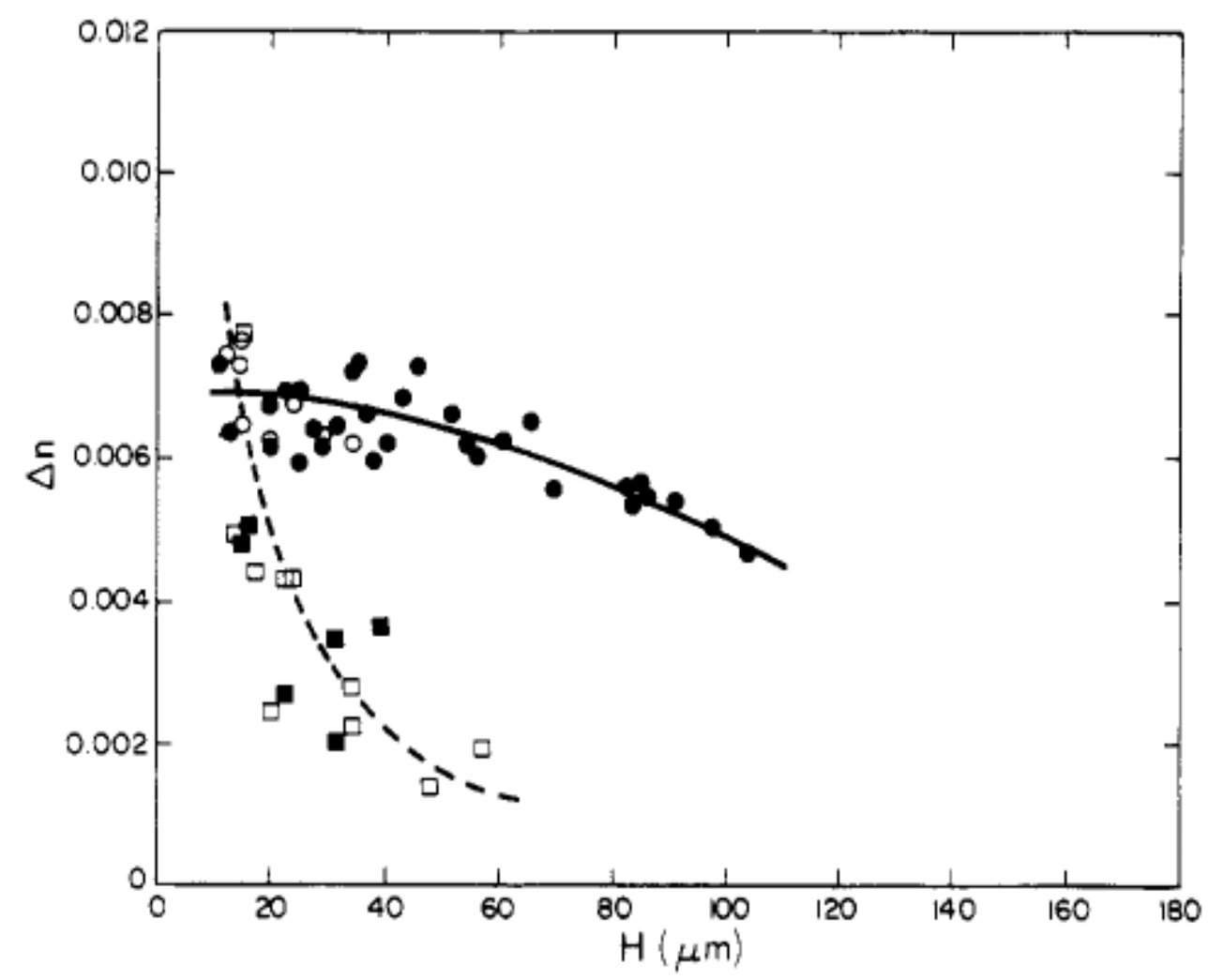

Figure 2.16 Transverse birefringence vs. dry film thickness, showing the effect of casting solvent for $\mathrm{PCl} . \bullet \mathrm{DCM}$; ○ tetrahydrofuran; $\square$ p-dioxane; cyclohexanone.

It was reported that carrier type play an important role on controlling the birefringence in the solid film. ${ }^{55}$ Glass, aluminum, polyethylene and Teflon were used as substrates to evaluate the effect on orientation. The surface energies are $49.4 \mathrm{erg} / \mathrm{cm}^{2}, 49.0 \mathrm{erg} / \mathrm{cm}^{2}, 33.9 \mathrm{erg} / \mathrm{cm}^{2}$ and $20.9 \mathrm{erg} / \mathrm{cm}^{2}$, respectively. Figure 2.17 indicated that the birefringence of the film reduced with decreasing the surface energy of the substrate. This is because that low surface energy substrate impedes the loss rate of solvent which allow molecular chain to relax more. 


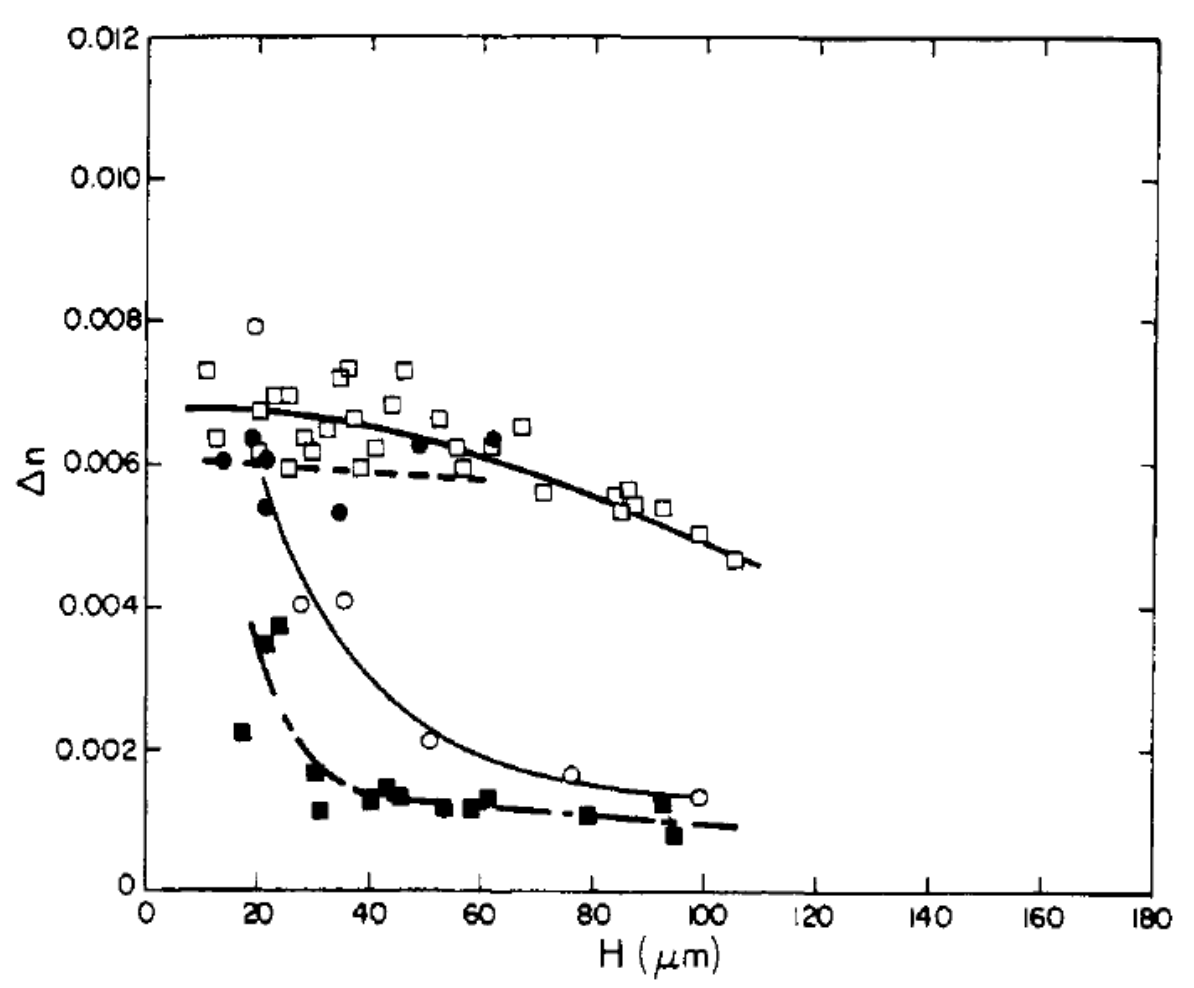

Figure 2.17 Birefringence vs. dry film thickness showing the effect of casting substrate for $\mathrm{PCl}$ casted from DCM $\circ$ polyethylene, $\square$ glass, •aluminum, $\mathbf{\text { Teflon }}$ substrate.

The timing of film removal from the substrate following casting and drying, also affects the development of birefringence. J.S Machell et al. ${ }^{55}$ dried the film at ambient temperature for various times and then peeled it off the substrate and placed it in the oven. They found that the films that were removed from the substrate earlier or prior to complete drying usually showed lower birefringence (in Figure 2.18). The reason is more solvent remained in the film removed early in drying, and this solvent works as kind of plasticizer to enhance relaxation. 


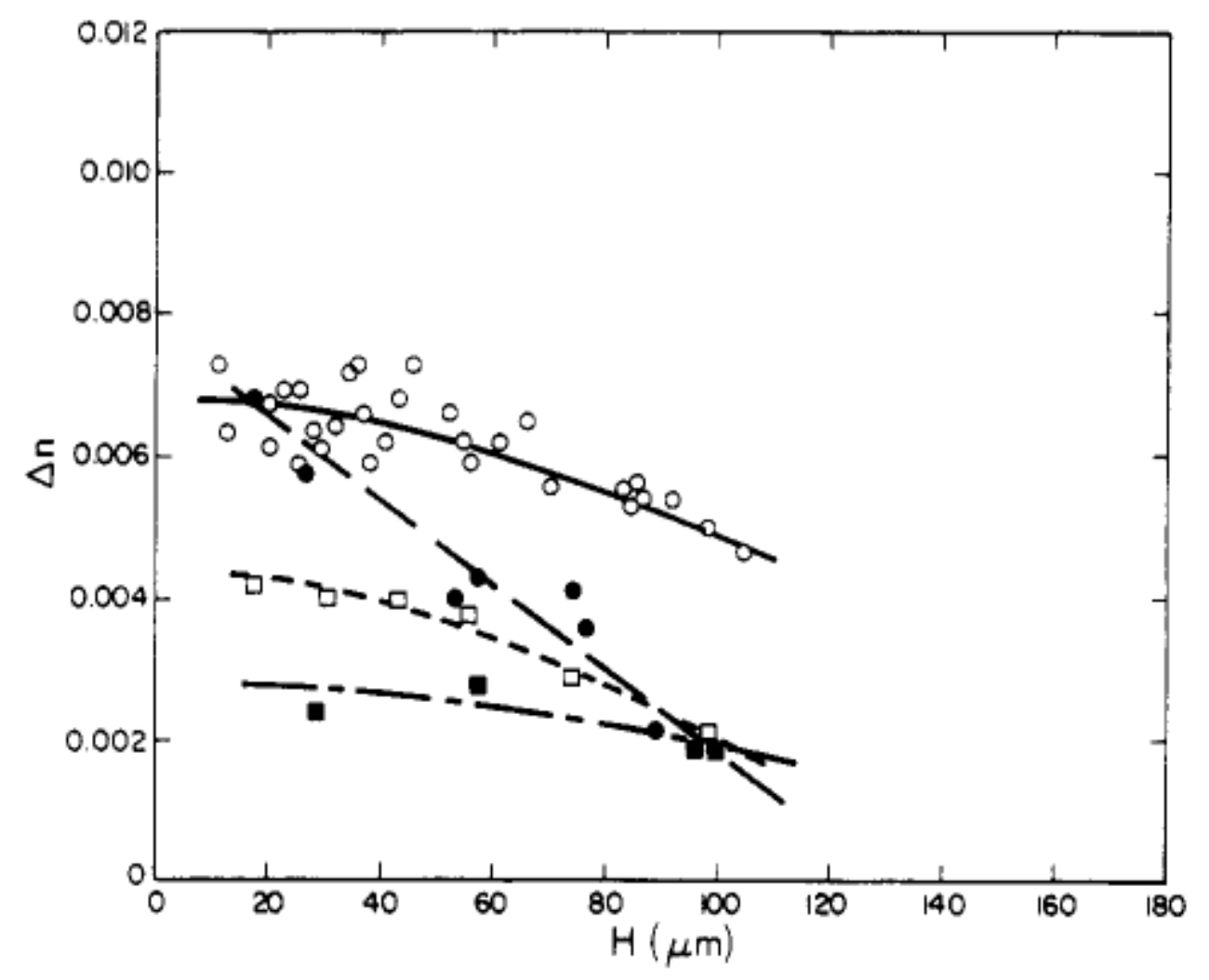

Figure 2.18 Transverse birefringence vs. dry film thickness, showing the effect of film removal from casting substrate for $\mathrm{PCl}, \circ$, removed after complete drying at elevated temperature; $\bullet$, removed after $24 \mathrm{~h}$ at ambient; $\square$, removed after $1.5 \mathrm{~h}$ at ambient; $\mathbf{m}$,removed after $0.5 \mathrm{~h}$ at ambient.

\subsection{Birefringence}

Birefringence is the difference in refractive index between two orthogonal planes of polarization which reflects the level of anisotropy of the system. In a Cartesian frame, three components of the refractive index, $\mathrm{n}_{\mathrm{x}}, \mathrm{n}_{\mathrm{y}}$, and $\mathrm{n}_{\mathrm{z}}$, can be define any polymer film. The solution casting film is isotropic in the in-plane direction ( $\mathrm{x}-\mathrm{y}$ plane, $\left.\mathrm{n}_{\mathrm{x}}=\mathrm{n}_{\mathrm{y}}=\mathrm{n}_{\|}\right)$and thereby the in plane birefringence is equal to zero, 
$\Delta \mathrm{n}_{\mathrm{xy}}=0$. While an anisotropic behavior is detected in the out-of-plane direction ( $\mathrm{y}-\mathrm{z}$ plane, $\mathrm{n}_{\mathrm{z}}=\mathrm{n}_{\perp}$ ), yielding $\Delta \mathrm{n}_{\mathrm{yz}}=\Delta \mathrm{n}_{\mathrm{xz}} \neq 0$.

Because the solution cast film is relatively thin, it's hard to measure these components directly. So, Spence ${ }^{58}$ and Stein $^{59}$ independently developed good methods to solve this problem. The birefringence is measured at some angle $\Phi$ relatively to the normal to the film plane. When the film is rotated about the $\mathrm{X}$ axis, the birefringence of two transverse components is:

$$
\Delta \mathrm{n}_{\mathrm{zy}}=\frac{\Delta \mathrm{n}_{\mathrm{xy}}-\mathrm{R}_{\gamma} \frac{\cos \gamma}{\mathrm{H}}}{(\sin \gamma)^{2}}
$$

$$
\Delta \mathrm{n}_{\mathrm{zx}}=\frac{\Delta \mathrm{n}_{\mathrm{xy}}(\cos \gamma)^{2}-\mathrm{R}_{\gamma} \frac{\cos \gamma}{\mathrm{H}}}{(\sin \gamma)^{2}}
$$

Where $\gamma$ is the refraction angle, and it's denoted as

$$
\gamma=\sin ^{-1}((\sin \emptyset) / \mathrm{n})
$$

Here, $\mathrm{n}$ is the average refractive index

$\mathrm{H}$ is the thickness of the film

$\mathrm{R} \gamma$ is apparent optical retardation from angle $\Phi$.

Since no orientation in the in plane direction $\left(\Delta \mathrm{n}_{\mathrm{xy}}=0\right)$, equation 1 and 2 are identical.

One of the simple birefringence measurement used by A. M. Nasr ${ }^{60}$ is showed in Figure 2.19. The light source of He-Ne laser of $5 \mathrm{mw}$ and $632.8 \mathrm{~nm}$ passes through 
the polymer film, which located between a polarizer and an analyzer. The polarizer and the analyzer are crossed and positioned at $-45^{\circ}$ and $+45^{\circ}$, respectively. The light transmitted through the analyzer is detected by a photodetector.

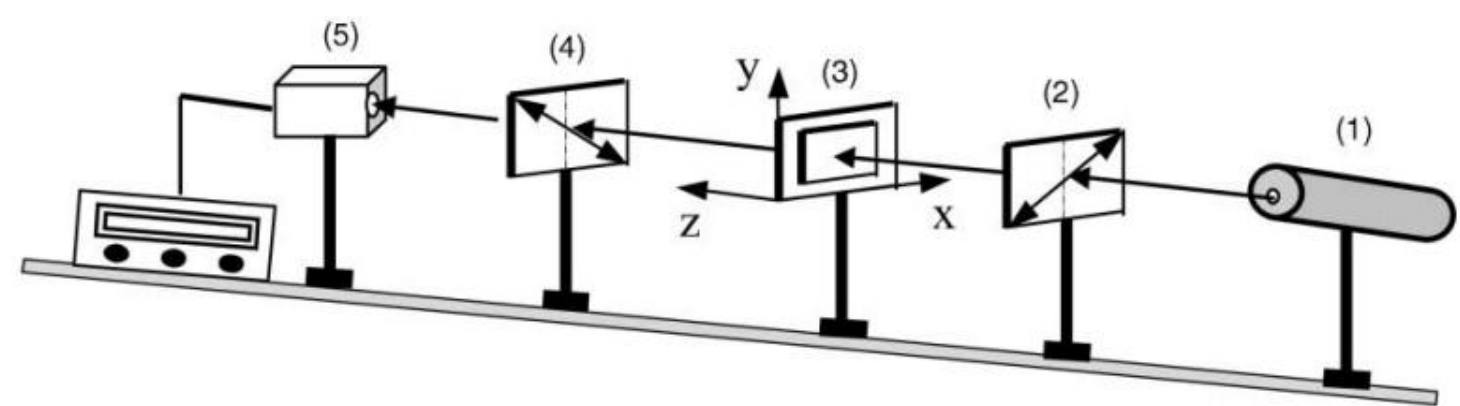

Figure 2.19 Schematic diagram of the set-up for measuring birefringence: (1) He-Ne

laser, $632.8 \mathrm{~nm}$; (2) analyser; (3) sample holder; (4) polarizer; (5) photodetector.

From this method, the $\Delta \mathrm{n}$ can be calculated as the following.

$$
\mathrm{I}=\operatorname{Io} \sin ^{2}\left(\frac{\pi \mathrm{d} \Delta \mathrm{n}}{\lambda}\right)
$$

Where $I_{o}$ is the initial intensity of light before passing through the sample, I is the intensity of light measured by the detector, $\lambda$ is the wavelength, and $d$ is the thickness of the sample.

Based on other methods of measuring birefringence, such as refractive index, optical compensator and photographic fringe methods, Yang further developed spectrophotometric method to determine the birefringence, which involved the distribution of intensity vs. wavelength with a spectrophotometer and compute the optical retardation of the sample. ${ }^{61}$ 
When a polymer film is deformed, the refractive index and stress become anisotropic. Maximum orientation of a given polymer is defined by intrinsic birefringence. Its sign and magnitude depends on the type of monomers are used to form the polymer and their spatial arrangement in the final state. ${ }^{62}$ In the case of rubber and melt state of polymer, ${ }^{63-65}$ the birefringence is only related with the stress through the stress-optical rule since the form birefringence is usually negligible unless regularly repeating macro phases with sufficiently different refractive index is present. This usually occurs in semicrystalline polymer (crystal vs amorphous phase), blends or microphase separated block copolymers. The relationship between the birefringence and the stress can be denoted as the following.

$$
\Delta \mathrm{n}(\mathrm{t})=\mathrm{C} \sigma(\mathrm{t})
$$

Where $\Delta \mathrm{n}$ is the anisotropic part of refractive index tensor, $\sigma$ is the anisotropic part of the stress tensor, and $\mathrm{C}$ is the stress optical coefficient which is independent of the time, the rate of strain or the magnitude of the strain. In the solid state near or below $\mathrm{Tg}$, the polymer exhibits photoelasticity and the magnitude of the birefringence produced is proportional to the stress when the stress is not very large.

$$
\Delta \mathrm{n}=\mathrm{Cp} \sigma
$$

There are some differences between the stress-optical rule and the photoelasticity. First of all, the photoelasticity describes an instantaneous response on the deformation and no effect from the accumulated time. Secondly, the values of 
the proportionality coefficients are different. Generally, $|\mathrm{C}|$ is much bigger than $\left|\mathrm{C}_{\mathrm{p}}\right|$, i.e. the value of $\mathrm{C}$ for polystyrene is $-5.0 * 10^{-9} \mathrm{~Pa}^{-1}$, while its $\mathrm{C}_{\mathrm{p}}$ is $8.81 * 10^{-12} \mathrm{~Pa}^{-1}$. 66

\subsection{Mechanical Behavior during Uniaxial Stretching}

Conventional tensile testing is most frequently used to describe mechanical response for polymer. However, there is only a very small minority of polymer showing uniform extension at a constant stretching rate during stretching experiment. Generally, a non-uniform deformation occurs after initial Hookean elastic behavior. It's inadequate to give a physical interpretation of the quantities derived from the data of engineering stress and strain in this situation.

In order to provide more accurate description of the real mechanical response of the polymer material, true stress and strain is required to measure the mechanical behavior. With the assumption of incompressibility, the expression of true stress and true strain are derived as following.

$$
\mathrm{D}_{0} \mathrm{~W}_{0} \mathrm{~L}_{0}=\mathrm{D}_{\mathrm{t}} \mathrm{W}_{\mathrm{t}} \mathrm{L}_{\mathrm{t}}
$$

$$
\frac{W_{t}}{W_{0}}=\frac{D_{t}}{D_{0}}
$$

$$
\text { True strain }=\frac{\text { Elongation }}{\text { Initial lenght }}=\frac{\mathrm{L}_{\mathrm{t}}-\mathrm{L}_{0}}{\mathrm{~L}_{0}}=\frac{\Delta \mathrm{L}}{\mathrm{L}_{0}}=\left(\frac{\mathrm{W}_{\mathrm{o}}}{\mathrm{W}_{\mathrm{t}}}\right)^{2}-1
$$

$$
\text { True stress }=\frac{\text { Force }}{\text { Cross sectional area }}=\frac{F_{t}}{W_{t} D_{t}}=\frac{F_{t}}{\left[\left(\frac{W_{t}^{2}}{W_{o}}\right) D_{0}\right]}
$$


where; $\mathrm{D}_{0}=$ initial thickness,

$$
\begin{aligned}
& \mathrm{W}_{0}=\text { initial width, } \\
& \mathrm{L}_{0}=\text { initial length, } \\
& \mathrm{D}_{\mathrm{t}}=\text { instantaneous thickness, } \\
& \mathrm{W}_{\mathrm{t}}=\text { instantaneous width, } \\
& \mathrm{L}_{\mathrm{t}}=\text { instantaneous length, } \\
& \mathrm{F}_{\mathrm{t}}=\text { instantaneous force. }
\end{aligned}
$$

Richeton $^{67}$ studied the mechanical behavior of three amorphous polymers: polycarbonate (PC), polymethylmethacrylate (PMMA), and polyamideimide (PAI), respectively. All the samples showed an initial elastic response followed by yield, strain softening and then a dramatic strain hardening. Figure 2.20 depicts the true stress-strain curves for PC, PMMA and PAI with a wide range of strain rates. 

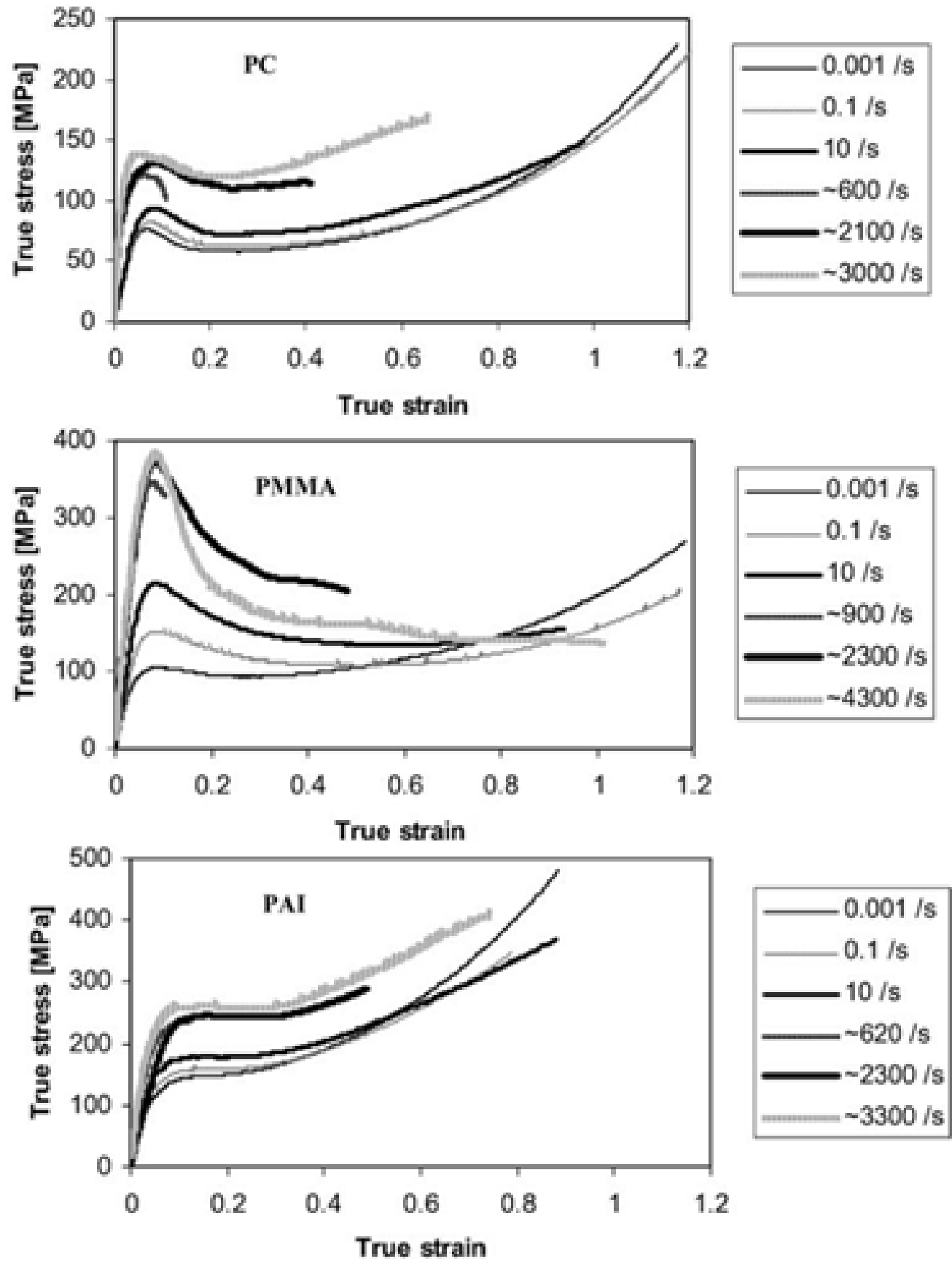

Figure 2.20 Experimental uniaxial compression stress-strain curves for PC, PMMA and PAI at the temperature $25{ }^{\circ} \mathrm{C}$ over a wide range of strain rates. 
2.7 Real-time birefringence measurement

The studies about the changing of the birefringence in the drying and uniaxial stretching process mentioned above were all conducted with off-line characterization technique of the sample at discrete stages. Even though the final properties of the polymer materials were revealed, the material experienced a serious of complex event, including solvent evaporation and molecular chains orientation, were hard to trace all of these simultaneously physical or chemical changes. Therefore, Unsal and Cakmak $^{68}$ designed an instrument which can precisely measure the temporal changes in physical parameters in the drying behavior of polymer film and curing monomers. This real-time instrument is able to follow the weight, thickness, surface temperature, in-plane and out-of-plane birefringence during solvent evaporation and thermal or photocuring in a controlled atmosphere of a polymer film. Drying and imidization of PMDA-ODA film was researched through this novel real-time measurement system by Unsal. ${ }^{69}$

In the case of uniaxial stretching process, Sen and $\mathrm{Cakmak}^{70}$ also designed and built heat setting and uniaxial stretching system that measures birefringence real time. The uniaxial stretching instrument is built with a heating oven to study the mechano-optical behavior at elevated temperatures. The birefringence of the film is obtained while the film is stretched at a constant temperature with both clamps of uniaxial stretching machine moving at the same speed in opposing directions. Through this on-line measurement, the mechano-optical behaviors of polyethylene 
terephthalate, ${ }^{71}$ polypropylene, ${ }^{72}$ polyethylene naphthalate ${ }^{16}$ were investigated under conditions. 


\section{CHAPTER III}

REAL TIME OPTICAL AND MECHANO-OPTICAL STUDIES DURING

DRYING AND UNIAXIAL STRETCHING OF POLYETHERIMIDE FILMS

FROM SOLUTION

\subsection{Introduction}

Polyetherimide (PEI) exhibits excellent thermal, chemical, and mechanical stabilities as well as its good film forming properties. ${ }^{73-76}$ These properties allow it to be used in harsh industrial applications including electronics, automotive and aerospace. ${ }^{77-79}$ The optical properties of solvent-casting polymer films are of great technological importance in a host of optoelectronic system and devices. These properties are commonly affected by the intrinsic optical anisotropy of the polymer chain and by the orientation induced in the casting processing. Rickert et al. ${ }^{17}$ studied that the orientation phenomena of polymer chains was controlled by solution properties, substrate properties and interfacial properties. Cherkasov et al. ${ }^{18}$ studied the alignment behavior of polymer molecular by free casting and found the stiffness of the polymer chain has a great influence on the planar orientation. Cohen and Reich $^{19}$ investigated the effects of the molecular weight and polydispersity on the 
ordering of molecular chain in thin films. Similarly, Prest and Luca ${ }^{20-21}$ focused on the effect of molecular weight, film thickness, solvent, plasticizer content and temperature on the orientation in polymer films.

Because drying process of solvent-cast polymer film is an intricate processing that includes solvent evaporation, thickness reduction, film shrinking and molecular chains orientation, the traditional offline studies are hard to trace all the simultaneously physical and chemical changes during the processing. To deal with this issue, a real-time instrument, which can precisely measure the fast changes in physical parameters in the drying behavior of polymer film and curing monomers, was designed by Unsal et al. ${ }^{68}$. This real-time instrument follows the weight, thickness, surface temperature, in-plane and out-of-plane birefringence during solvent evaporation and thermal or photocuring in a controlled atmosphere of a polymer film, which reveals integrated information in the whole process.

In the case of mechanical and mechano-optical properties of PEI, Nied et al. studied the deformation behavior of PEI in the uniaxial tension process and found a stable necking over a broad temperature range $\left(22.2-204.4^{\circ} \mathrm{C}\right) .{ }^{22} \mathrm{~S}$. Kumar investigated the mechanical and morphological properties of carbon nanofiber reinforced PEI composites material and concluded that carbon nanofiber increases the tensile strength and young's modulus. ${ }^{23}$ Kanuga studied the stress-optical behavior of polyethylene naphthalate (PEN)/PEI blends through using a real-time instrument which tracks the structure development by the measurement of 
birefringence of the polymer film. ${ }^{16}$ We notice that all the processing of these researches need an extremely high temperature range due to the high glass transition temperature of PEI. This strict condition obviously increases the cost when it is applied in the industry. Mixing with solvent can be a good method to decrease the glass transition temperature of polymer ${ }^{80-81}$ and thus the processing temperature.

In this paper, we investigate a real time drying dynamics by tracking birefringence, solid content, surface temperature, thickness, weight, air speed and solvent during drying process of solution casting PEI film. The effects of varying solid content of PEI solution, drying temperature, initial casting thickness, air speed and different kinds of solvent on the birefringence development are systematic research. Also, we study the mechano-optical behavior of PEI film during uniaxial stretching, as well as quantify the influence of solvent N-methyl-2-pyrrolidinone (NMP) on these relationships.

\subsection{Experimental procedures}

In this section, the materials, the solution casting method, the uniaxial tension process, and the characterization techniques applied in this study, are described in detail.

\subsubsection{Materials}

Polyetherimide (Ultem 1000P) was kindly donated by Sabic Company and its density is $1.27 \mathrm{~g} / \mathrm{cm}^{3}$. N-methyl-2-pyrrolidinone (NMP) (CAS Number: 872-50-4, 
boiling point $202^{\circ} \mathrm{C}$ ) and $\mathrm{N}, \mathrm{N}-$ Dimethylacetamide (DMAc) (CAS Number:

127-19-5, boiling point $165^{\circ} \mathrm{C}$ ) were purchased from Sigma-Aldrich Company. Their densities are $1.028 \mathrm{~g} / \mathrm{cm}^{3}$ and $0.937 \mathrm{~g} / \mathrm{cm}^{3}$, respectively.

\subsubsection{Solution casting by Dr. Blade}

The PEI solution was cast on a smooth surface of a glass substrate by using a motorized drawdown coater and a commercial 3" wide casting blade (Figure 3.1). The initial length was 7"and the initial width was 3".
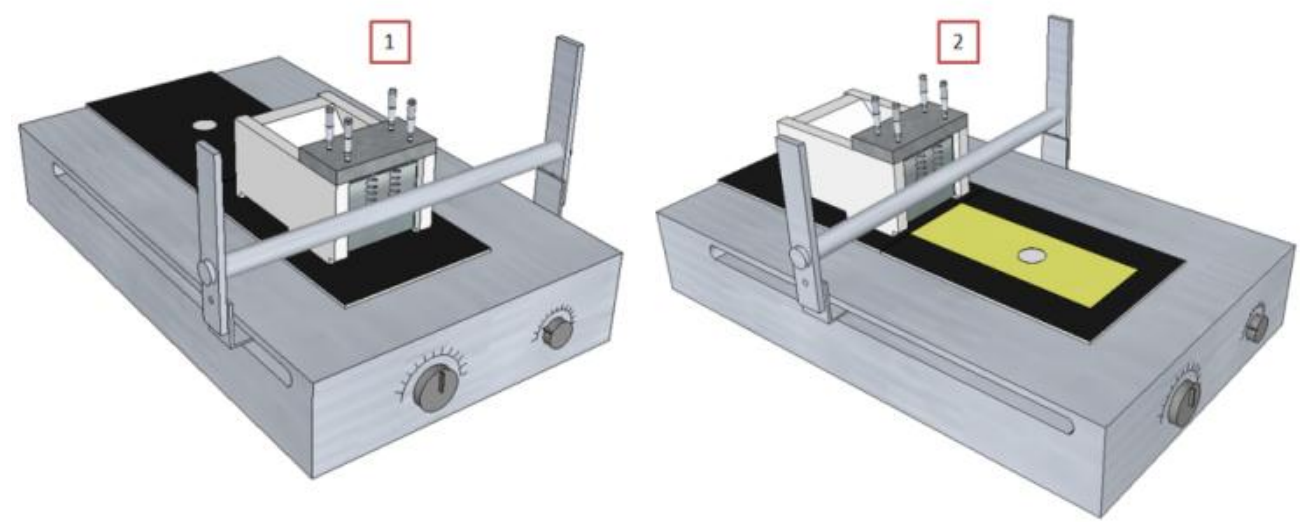

Figure 3.1 Casting procedure with Dr. Blade: before (1) and after casting (2).

\subsubsection{Drying apparatus and drying process}

The real-time measurements system ${ }^{68}$ used in this experiment was showed in Figure 3.2. It consists of a hot air blower, wind tunnel shaped frame with three adjustable vertical baffles, a balance, several sensors for tracking changes including in-plane and out-of-plane, thickness and temperature. The temperature varies from 
room temperature to $500^{\circ} \mathrm{C}$ and the air speed varies from 0 to $4.5 \mathrm{~m} / \mathrm{s}$ by adjusting the parameters of hot air blower.

Through using spectral birefringence method, ${ }^{82-98}$ the temporal in-plane and out-of-plane birefringence is calculated by $0^{\circ}$ and $45^{\circ}$ retardation values. The in-plane birefringence $\Delta \mathrm{n}_{12}$ is calculated by Stein's equation: ${ }^{59}$

$$
\Delta n_{12}=\frac{R_{0}(t)}{d(t)}
$$

(1)

Also, the out-of-plane birefringence $\Delta \mathrm{n}_{23}$ :

$$
\Delta n_{23}=-\frac{1}{d(t)}\left[\frac{R_{0}(t)-R_{\phi}(t) \sqrt{1-\frac{\sin ^{2} \phi}{\bar{n}^{2}}}}{\frac{\sin ^{2} \phi}{\bar{n}^{2}}}\right]
$$

(2)

where $\mathrm{d}(\mathrm{t})$ is the instantaneous thickness. $\mathrm{R}_{0}(\mathrm{t})$ and $\mathrm{R}_{\Phi}(\mathrm{t})$ are the instantaneous $0^{\circ}$ retardations (at $546 \mathrm{~nm}$ ) and $\Phi^{\circ}$ retardations (in this case, $\Phi^{\circ}$ is $45^{\circ}$ ), respectively. $\overline{\mathrm{n}}$ is the average refractive index of the drying solution, and it is estimated linearly through the concentration change:

$$
\overline{\mathrm{n}}=n_{\text {polymer }} \chi_{\text {polymer }}+n_{\text {solvent }} \chi_{\text {solvent }}
$$

where $\mathrm{n}_{\text {polymer }}$ is the refractive index of polymer (here the refractive index of PEI at $546 \mathrm{~nm}$ is 1.66 ), $\mathrm{n}_{\text {solvent }}$ is the refractive index of solvent (here the refractive indices of NMP and DMAc at 546nm are 1.47 and 1.44 , respectively), $x_{\text {polymer }}$ is the solid content in solution, and $x_{\text {solvent }}$ is the solvent content in solution. 


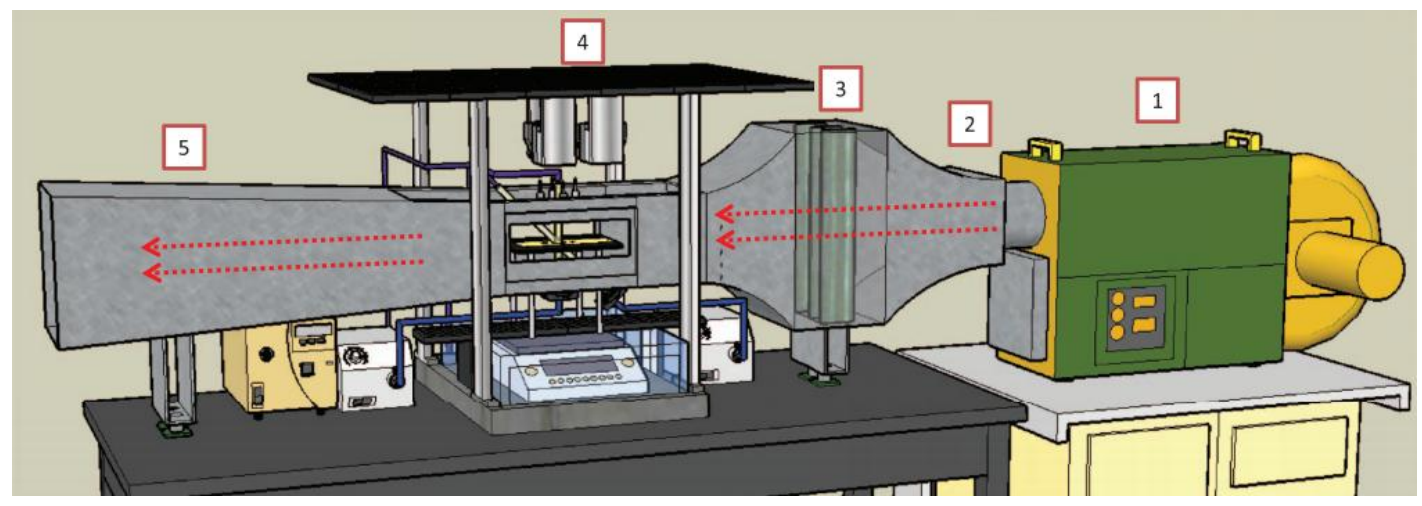

Figure 3.2 Real-time solution drying measurement instrument (1 Hot air blower, 2 connection of blower to the tunnel, 3 vertical baffles, 4 drying sample and sensor location, 5. open end of the tunnel).

PEI solution was cast on a glass substrate at room temperature. And then it was quickly placed inside the preheated wind tunnel and data acquisition was begun. The air speed and the temperature were kept constant during the whole dry processing.

3.2.4 Dumbbell shape film preparation and stretching apparatus

PEI film with $50 \mu \mathrm{m}$ thickness was peeled off from the substrate after several hours drying at $60^{\circ} \mathrm{C}$ and then was cut into dumbbell shape sample by a custom made trimming knife mold with dimensions shown in Figure 3.3 (a). The sample was mounted between the clamps of the real-time mechano-optical measurement system (Figure $3.3(\mathrm{~b}))^{70}$ and preheated for 10 minutes before stretching. The deformation behavior was investigated in $100^{\circ} \mathrm{C}$ to $150^{\circ} \mathrm{C}$ temperatures at $2 \mathrm{~mm} / \mathrm{min}$ to $200 \mathrm{~mm} / \mathrm{min}$ stretching rates. 

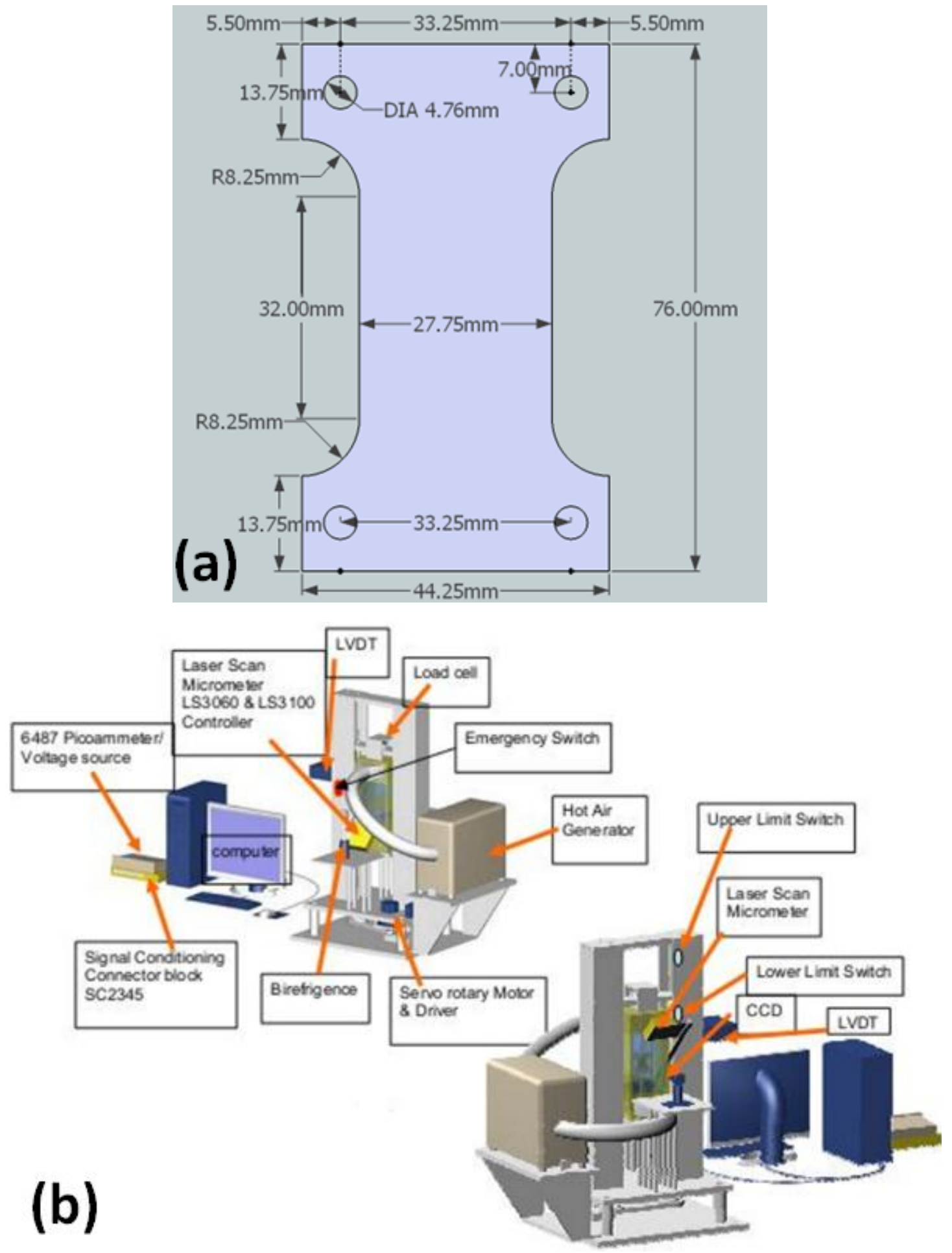

Figure 3.3 (a) Dumbbell shape of testing sample, and 3.3 (b) Scheme of uniaxial stretch-birefringence machine. 


\subsubsection{Rheology}

The rheological tests were run on a Bohlin Gemini HR Nano 200 by using a cone and plate $4^{\circ}$ incline, $40 \mathrm{~mm}$ diameter measuring geometry $(\mathrm{CP} 4 / 40)$ at room temperature. The shear rate was between $0.011 / \mathrm{s}$ and 1000 1/s.

\subsubsection{DSC and TGA}

Differential scanning calorimetry (DSC) data of sample was measured by a differential scanning calorimeter (TA Instruments DSC Q200) under nitrogen atmosphere. All the samples were heated from $-50^{\circ} \mathrm{C}$ to $270^{\circ} \mathrm{C}$ at the heating rate of $10^{\circ} \mathrm{C} / \mathrm{min}$. Solid content of the sample was measured by a thermo gravimetric analyzer (TGA) (TA Instruments Q50) under nitrogen atmosphere. The samples were heated from $40^{\circ} \mathrm{C}$ to $470^{\circ} \mathrm{C}$ at the heating rate of $20^{\circ} \mathrm{C} / \mathrm{min}$.

\subsection{Result and discussion}

In this section, the effects of solid content, drying temperature, casting thickness, air speed and solvent type on in-plane and out-of-plane birefringence in drying, as well as effects of solvent content, stretching temperature and stretching rates on birefringence during stretching were systematically studied.

\subsubsection{Overview of drying process}

The PEI and NMP were mixed by a centrifugal mixer and the solid contents of solution were $17 \%, 21 \%, 25 \%$, and $30 \%$, respectively. Figure 3.4 shows a 
rheological behavior of PEI/NMP solution at room temperature. A linear increasing of viscosity is observed when increasing the solid content of solution which indicates that the mobility of polymer chain decreases as solid content increases. The glass transition temperature (Tg) of samples with different solvent contents is shown in Figure 3.5. The polymer exhibits a gelatinous state with very low Tg when the solvent content is above $30 \%$ which indicates that polymer chains are highly mobile. After more solvent evaporate, the polymer solidifies with an increasing in $\mathrm{Tg}$.

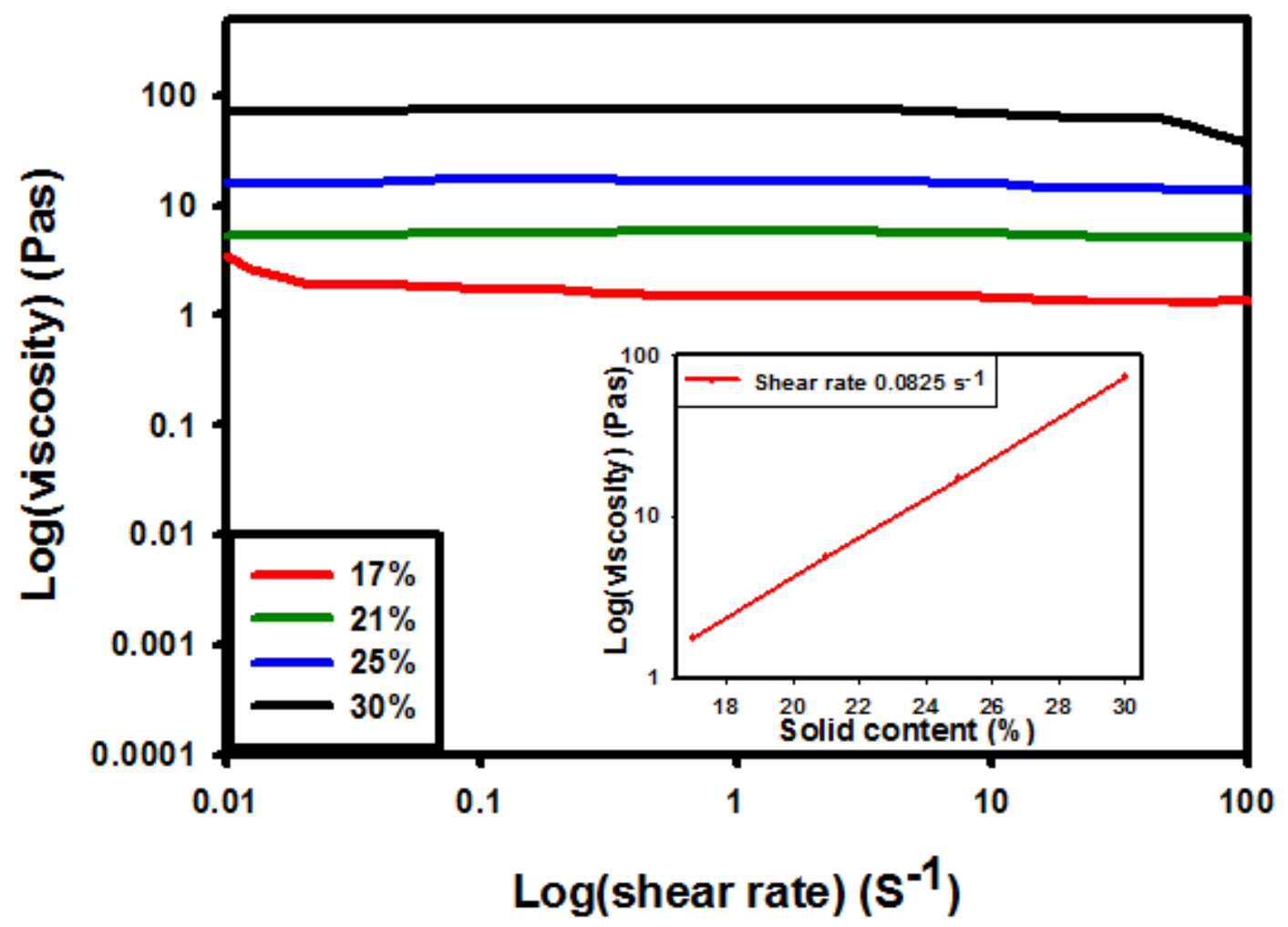

Figure 3.4 Rheology behavior of PEI-NMP with various solid contents at room temperature. (Inset figure: $\log \left(\right.$ viscosity) vs. solid content at shear rate $0.0825 \mathrm{~s}^{-1}$.) 


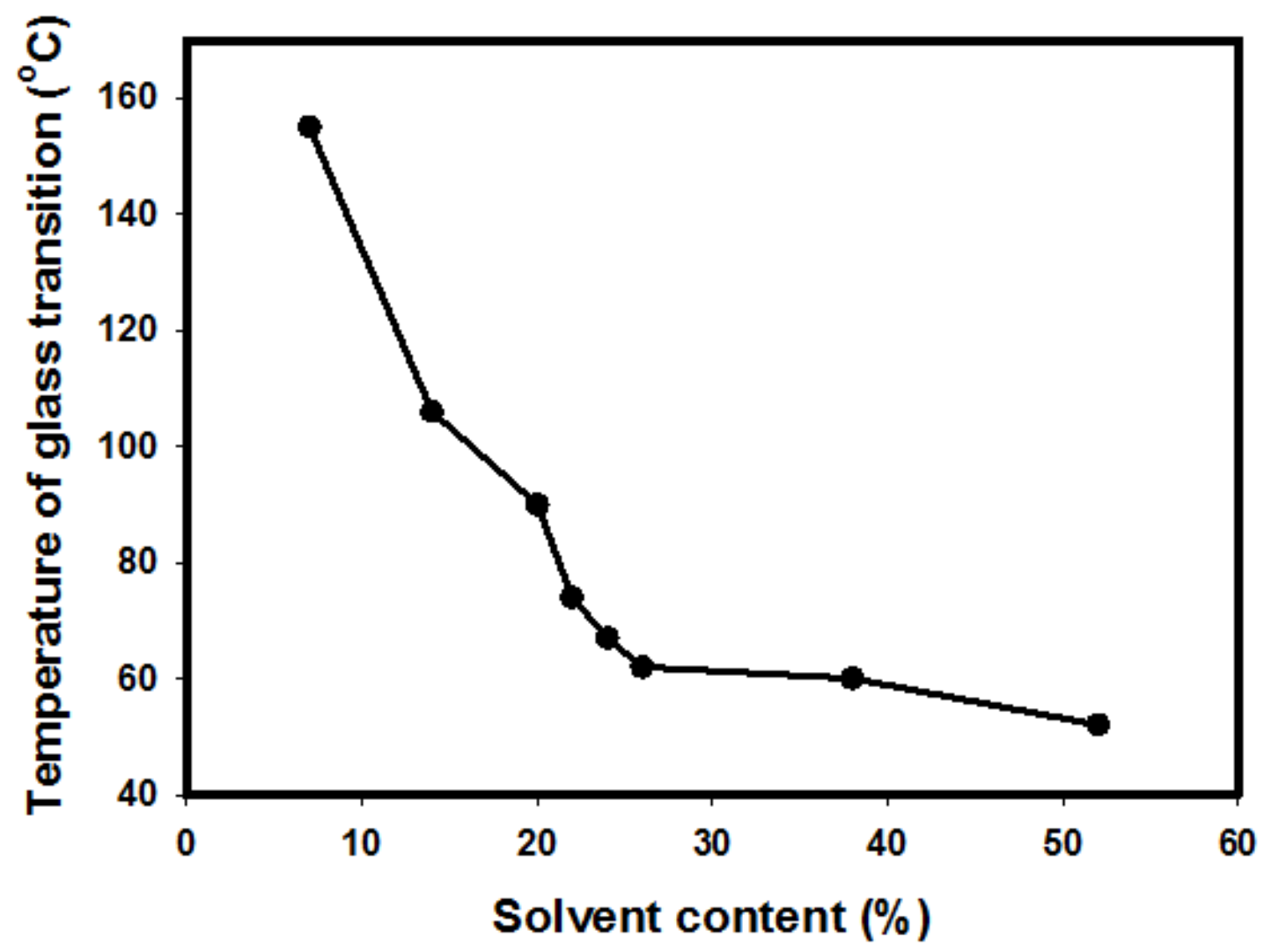

Figure 3.5 Temperature of glass transition vs. solvent content of PEI solution.

Drying is a very complex process which contains a concentration gradient and a birefringence gradient since the solvent diffuses from interior of the cast solution to solution-air interface along the thickness direction of wet coating. ${ }^{99-102}$ As the result of a rapid evaporation of solvent near the film's surface and a slow diffusion of solvent molecules from interior to the top surface, a solid skin layer may form on the top of film surface that may act as a barrier entrapping the residual solvent. Besides, a gradient of solvent loss rate along the machine direction makes the film thickness non uniform for some period time. Since the drying front develops along the air flow direction traveling from upstream to downstream, the thickness reduces first at upstream edge and this profile propagates towards the downstream edge. ${ }^{103}$ Additionally, there is a slight temperature decrease due to evaporative cooling at the 
early stages of drying. All of these phenomena affect the orientation behavior during drying.

The real-time weight, thickness, temperature, in-plane and out-of-plane birefringence data as a function of time with $17 \%$ and $30 \%$ initial solid content of PEI/NMP drying experiment are shown in Figure 3.6 (a) and 3.6 (b), respectively. The surface temperature values remain nearly constant through the whole drying process after it reaches a plateau. A thickness reduction and weight loss is observed because of solvent evaporation. In-plane birefringence remains zero throughout the complete drying process indicating that there is a random in-plane chain orientation. Beyond a critical solvent loss, the out of plane birefringence start increases and begin to level off as preferential orientation of the axes of the polymer chains in the film plane. This phenomenon can be explained as follows: $:^{20-21,104-110}$ a shrinkage develops within the thickness direction when a solution-cast film is drying. This leads to alignment of polymer chains parallel to the surface of the substrate. As the solvent evaporates, the film is vitrified when $\mathrm{Tg}$ passes through the environment temperature. The molecules are frozen, and thus the anisotropic structure of the film is retained. 

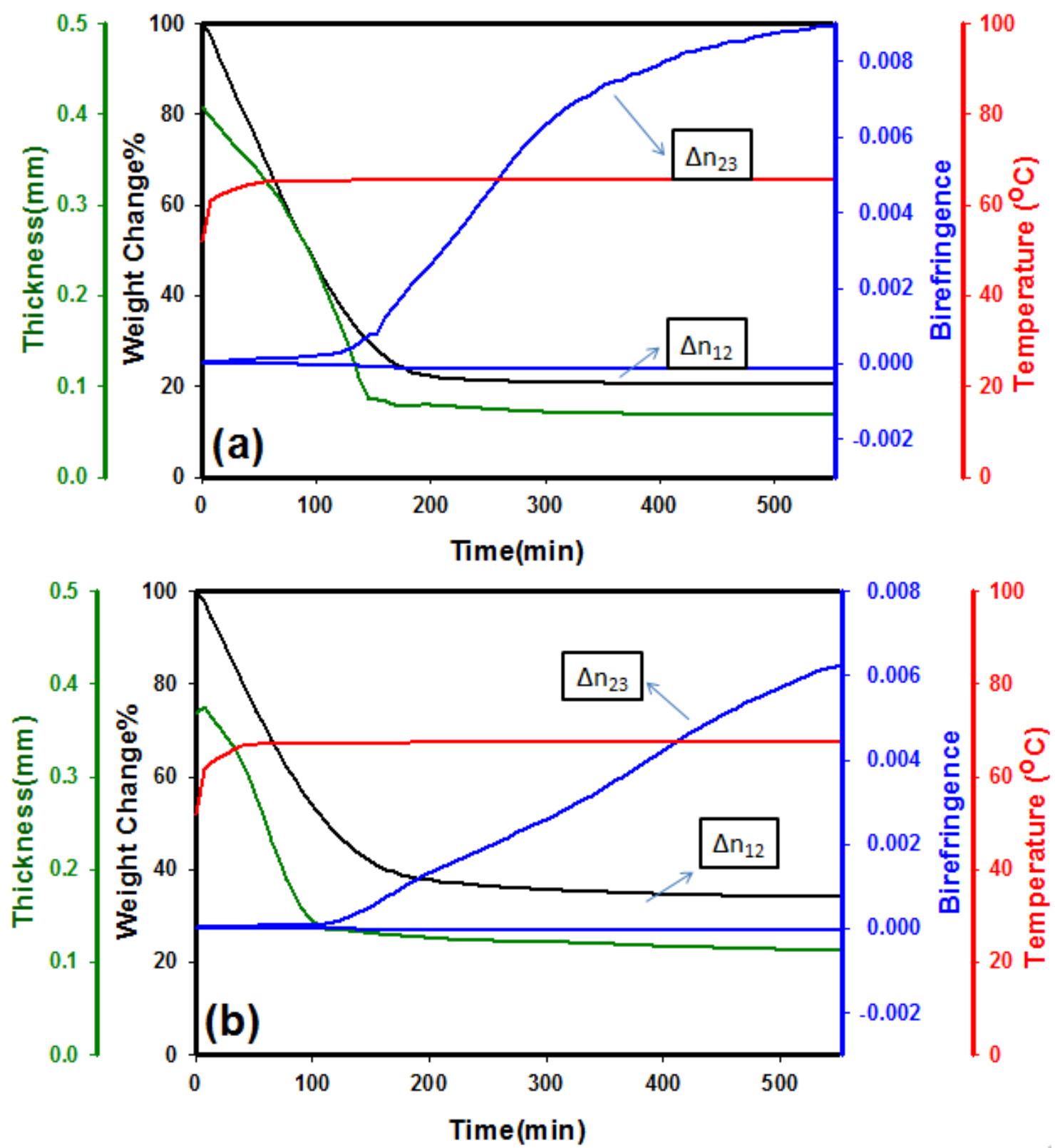

Figure 3.6(a) The whole drying process traced by real-time measurements system of

PEI-NMP with $17 \%$ solid content and $750 \mu \mathrm{m}$ initial thickness drying at $65^{\circ} \mathrm{C}$ and $0.5 \mathrm{~m} / \mathrm{s}$ air speed, and 3.6(b) $30 \%$ solid content.

\subsubsection{Solid content effect in drying process}

As shown in Figure 3.7, decrease of polymer concentration in the initial solution lead to increase the final out-of-plane birefringence. 


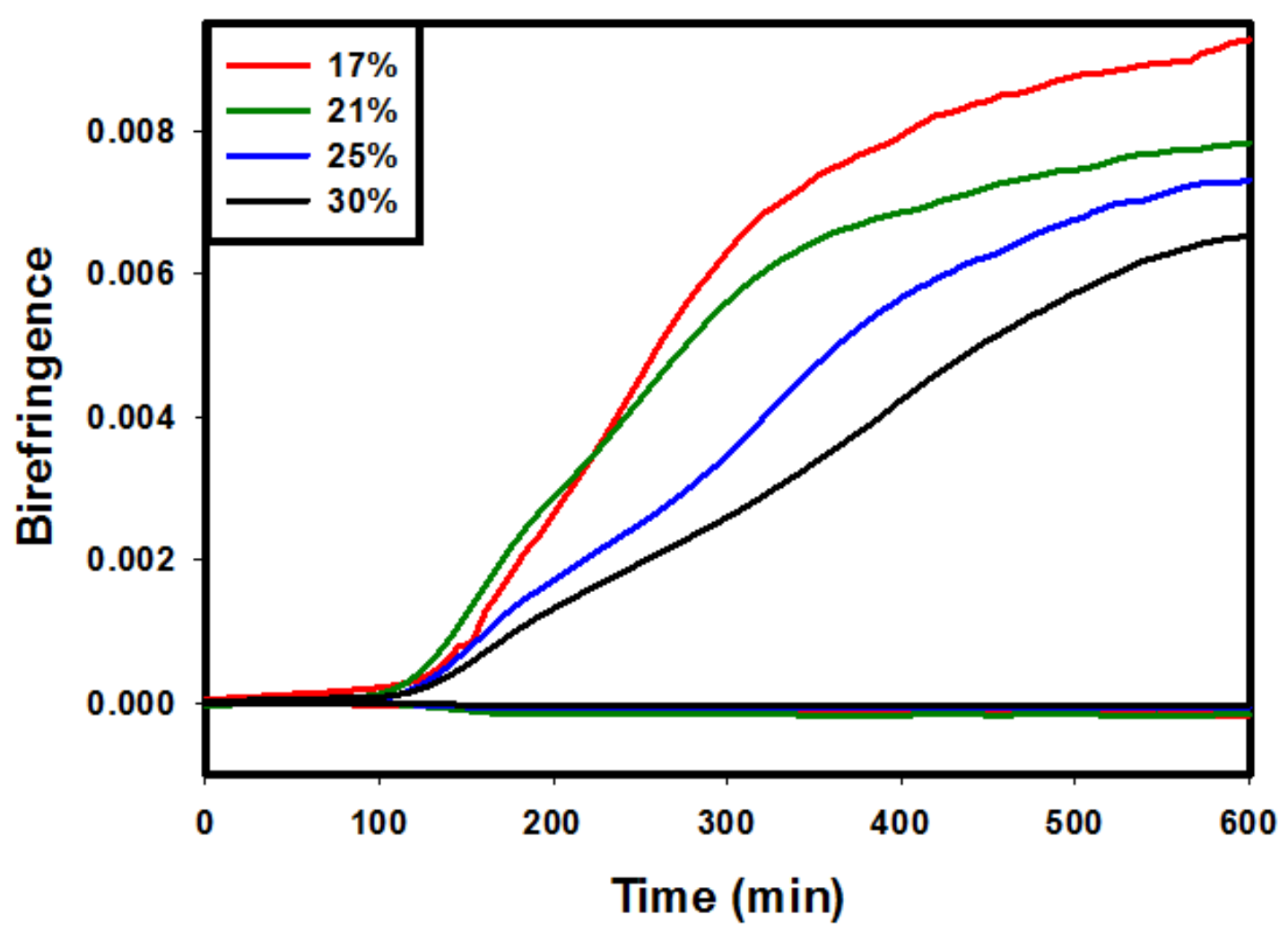

Figure 3.7 Solid content effects on in-plane and out-of-plane birefringence behavior of

PEI-NMP with $750 \mu \mathrm{m}$ initial thickness drying at $65^{\circ} \mathrm{C}$ and $0.5 \mathrm{~m} / \mathrm{s}$ air speed.

\subsubsection{Drying temperature effect in drying process}

Figure 3.8(a) and 3.8(b) show the effect of drying temperature on out of plane birefringence. The PEI film dried at lower temperature has lower out-of-plan birefringence at the initial stage of drying. But the out-of-plane birefringence rises rapidly after certain time and reaches ultimately to a high value. Both of the samples with initial thickness at $300 \mu \mathrm{m}$ and $750 \mu \mathrm{m}$ exhibit crossovers in temporal evolution of out-of-birefringence during drying process. This may be because that increasing drying temperature creates a solid skin layer at the coating-air interface quickly that suppresses the diffusion of remnant solvent to the top surface. When solvent exists in 
the vicinity of polymer chains below the solid skin layer, chains relax towards isotropic state. As the result of this phenomenon, counterintuitively, higher temperature actually slows the entire long-term drying process and thereby reduces the ultimate out-of-plane birefringence of the film. Figure 3.9(a) and 3.9(b) gives us a view of the changes of out-of-plane birefringence, solid content and glass transition temperature of PEI-NMP with $300 \mu \mathrm{m}$ and $750 \mu \mathrm{m}$ initial thickness in drying at $65^{\circ} \mathrm{C}$ and $110^{\circ} \mathrm{C}$, respectively. The solid content and glass transition temperature increase rapidly and keep at high value when drying at high temperature. The ultimate values of out-of-plane birefringence, solid content, $\mathrm{Tg}$ and different value between $\mathrm{Tg}$ and $\mathrm{T}_{\text {drying }}$ of PEI film is list in Table 3.1. Another explanation of drying at higher temperature results a decreasing final value of out-of-plane birefringence can be given as the following: A fast-evaporating solvent yields high out-of-plane birefringence initially. After the crossover, the Tg of sample drying at $65^{\circ} \mathrm{C}$ keeps on increasing and finally reaches the plateau at $130.1^{\circ} \mathrm{C}(300 \mu \mathrm{m}$ initial thickness $)$ and $90.8^{\circ} \mathrm{C}(750 \mu \mathrm{m}$ initial thickness), which are much higher than drying temperature. The difference values between $\mathrm{Tg}$ and $\mathrm{T}_{\text {drying }}$ are $65.1^{\circ} \mathrm{C}(300 \mu \mathrm{m})$ and $25.8^{\circ} \mathrm{C}$ $(750 \mu \mathrm{m})$, respectively. However, in the case of drying at $110^{\circ} \mathrm{C}$, the ultimate $\mathrm{Tg}$ are just $145.9^{\circ} \mathrm{C}(300 \mu \mathrm{m})$ and $110.0^{\circ} \mathrm{C}(750 \mu \mathrm{m})$, which are closer, or even equal to drying temperature. The difference values (drying at $\left.110^{\circ} \mathrm{C}\right)$ are $35.9^{\circ} \mathrm{C}(300 \mu \mathrm{m})$ and $0^{\circ} \mathrm{C}(750 \mu \mathrm{m})$, respectively. In this situation, the mobility of polymer chain at high drying temperature is more favorable and thereby leading to remarkable relaxation with low value of out-of-plane birefringence. 

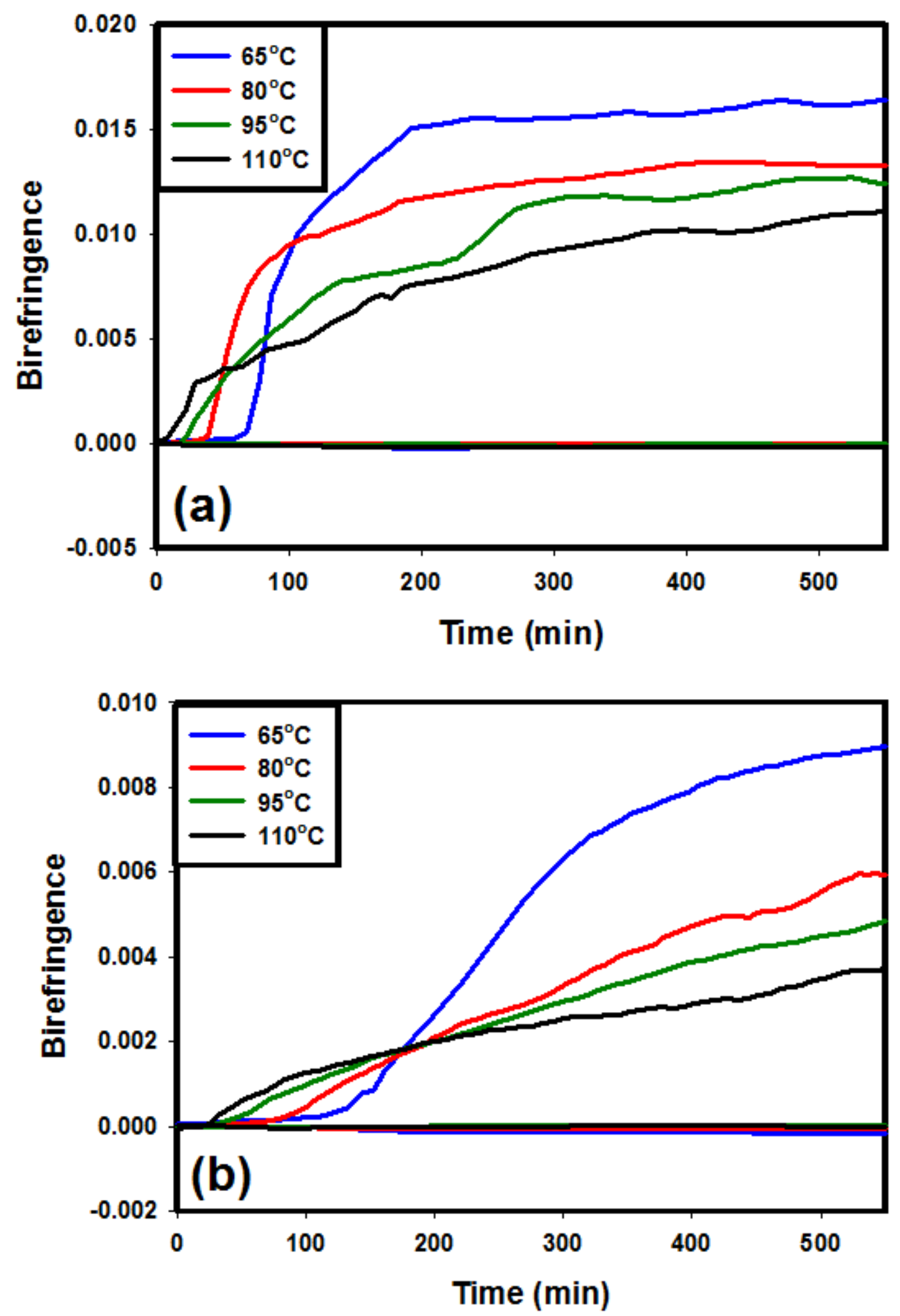

Figure 3.8(a) Temperature effects on in-plane and out-of-plane birefringence behavior of PEI-NMP with $17 \%$ solid content and $300 \mu \mathrm{m}$ initial thickness drying at $0.5 \mathrm{~m} / \mathrm{s}$ air speed, and 3.8(b) $750 \mu \mathrm{m}$ initial thickness. 


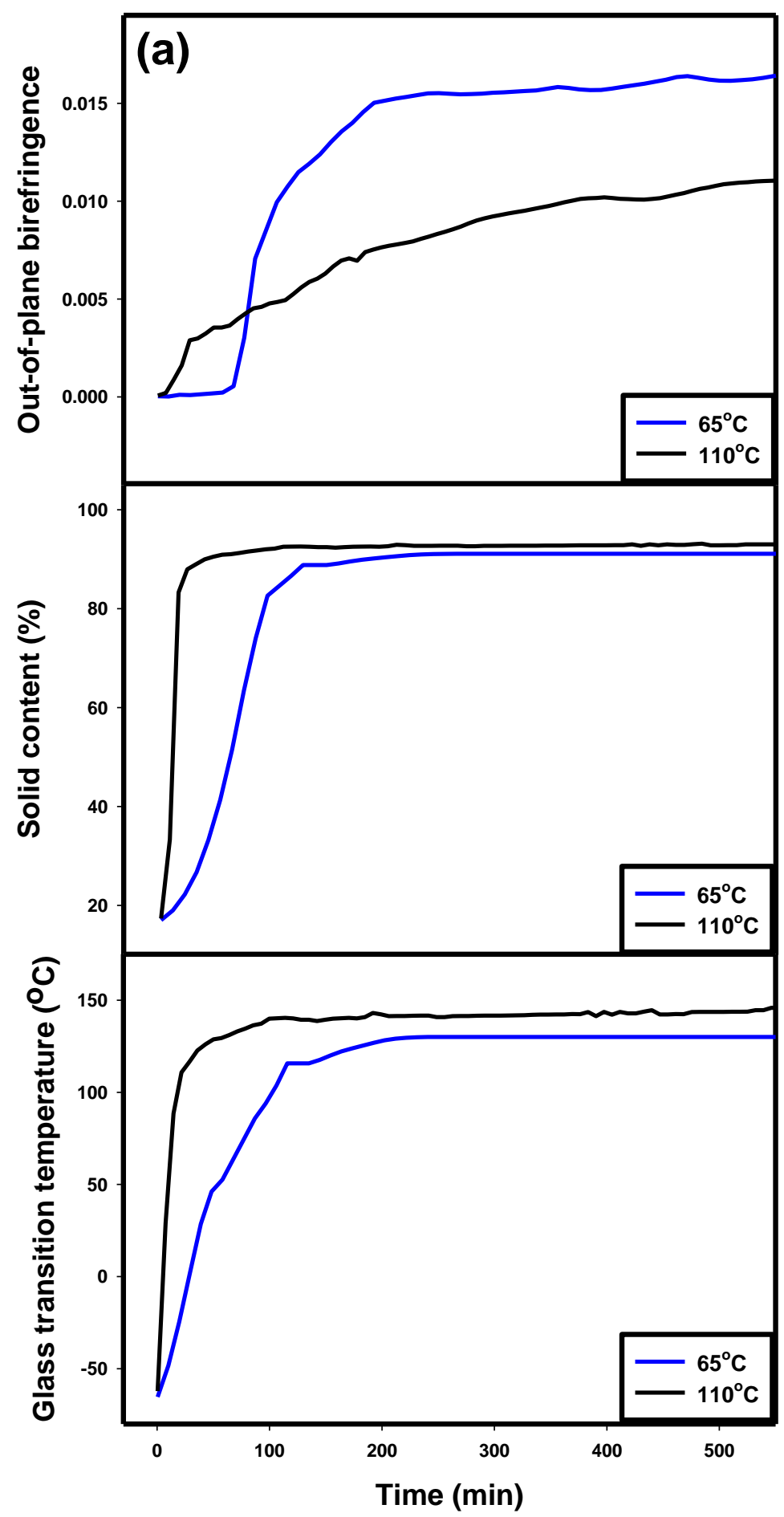




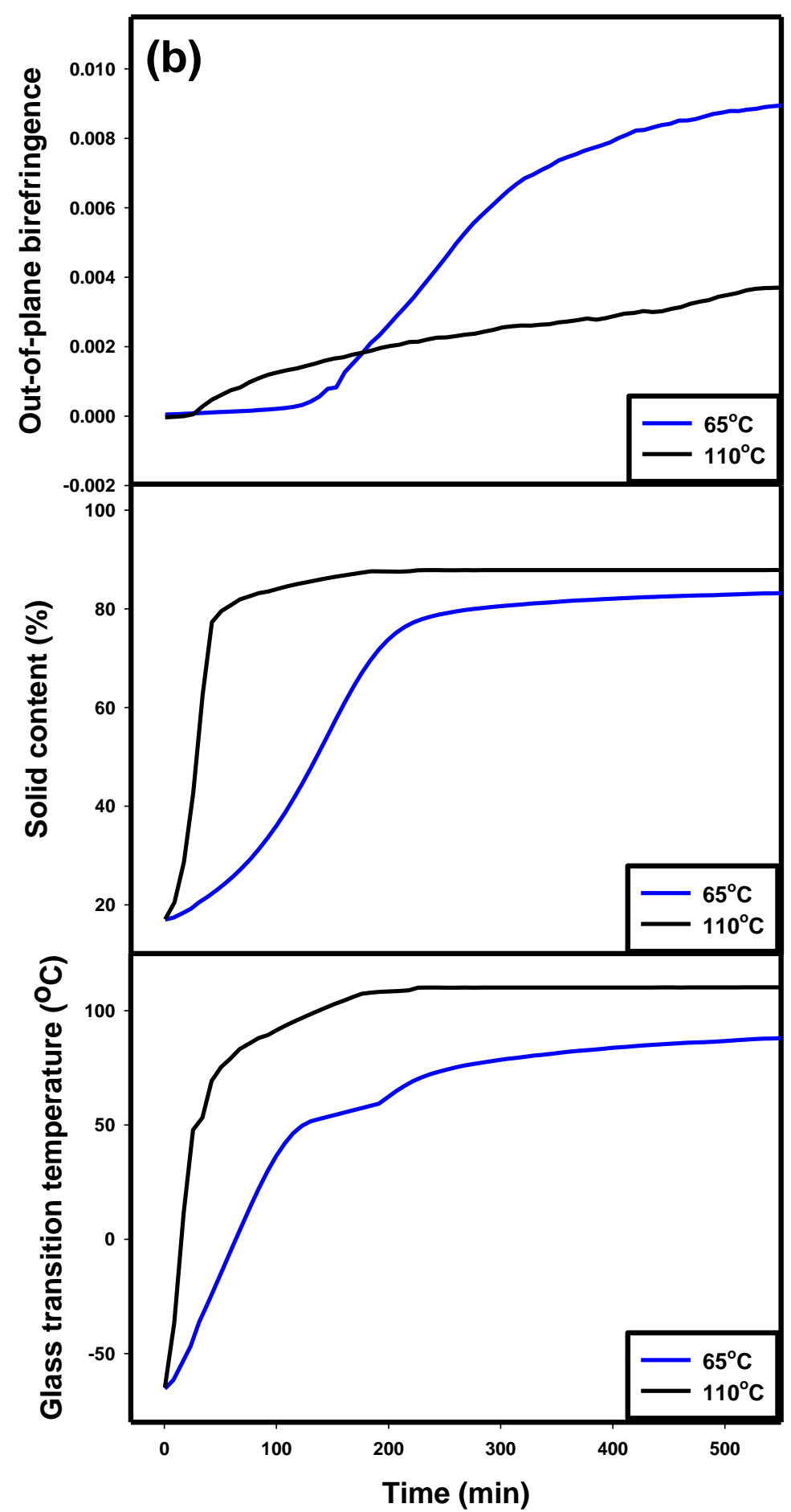

Figure3.9 (a) The changes of out-of-plane birefringence, solid content and glass transition temperature of PEI-NMP with $17 \%$ solid content and $300 \mu \mathrm{m}$ initial thickness drying at $0.5 \mathrm{~m} / \mathrm{s}$ air speed and various temperatures, and 3.9(b) $750 \mu \mathrm{m}$ initial thickness. 
Table 3.1 The ultimate values of out-of-plane birefringence, solid content, Tg and different value of PEI film with $17 \%$ initial solid content drying at $0.5 \mathrm{~m} / \mathrm{s}$ air speed.

\begin{tabular}{|c|c|c|c|c|c|}
\hline Initial & Drying & Ultimate & Solid & Tg of & Difference \\
thickness & temperature & out-of-plane & content & sample after & value between \\
\hline$\mu \mathrm{m})$ & $\left({ }^{\circ} \mathrm{C}\right)$ & birefringence & after drying & drying $\left({ }^{\circ} \mathrm{C}\right)$ & Tg and $\mathrm{T}_{\text {drying }}$ \\
& & & $(\%)$ & 130.1 & 65.1 \\
\hline \multirow{2}{*}{300} & 65 & 0.0151 & 91.1 & 145.9 & 35.9 \\
\cline { 2 - 6 } & 110 & 0.0122 & 93.3 & 90.8 & 25.8 \\
\hline 750 & 65 & 0.0096 & 83.9 & 110.0 & 0 \\
\hline
\end{tabular}

Since the temperature affects the drying rate of solution, the out-of-plane birefringence with actual solid content is correlated by removing the differences in solvent content at different times at these temperature as shown in Figure 3.10(a) and 3.10(b), respectively. The out-of-plane birefringence begins to increase rapidly after the average solid content reaches nearly $60 \%(300 \mu \mathrm{m})$ and $40 \%(750 \mu \mathrm{m})$. The samples dried at low temperatures usually have high values of out-of-plane birefringence at a given solid content. 

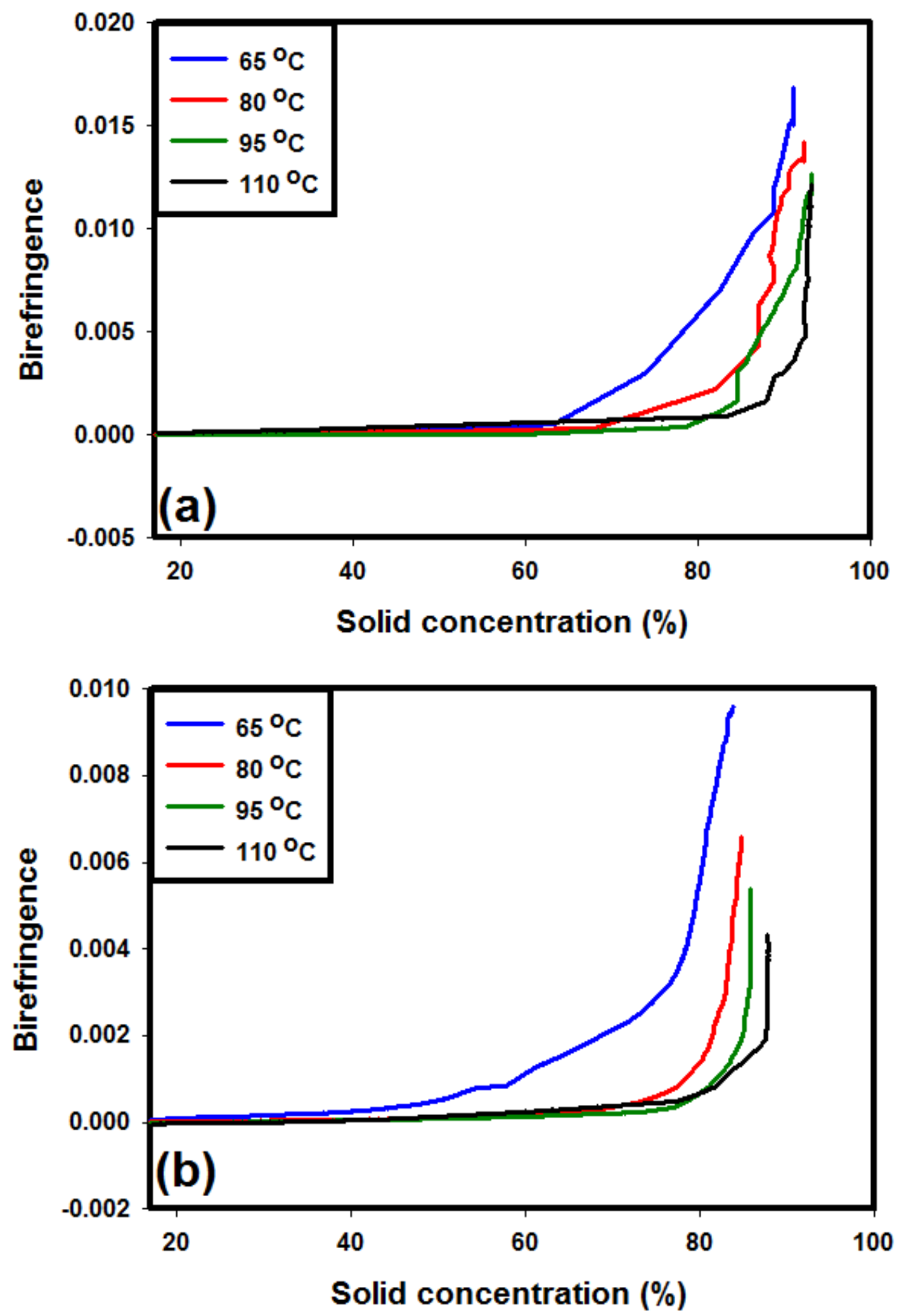

Figure 3.10(a) The out-of-plane birefringence vs. solid content of PEI-NMP with 17\% solid content and $300 \mu \mathrm{m}$ initial thickness drying at $0.5 \mathrm{~m} / \mathrm{s}$ air speed and vary temperatures, and 3.10(b) $750 \mu \mathrm{m}$ initial thickness. 
Figure 3.11 gives us a clear view of the initial time of out-of-plane birefringence increase at different drying temperature for $300 \mu \mathrm{m}$ and $750 \mu \mathrm{m}$ thickness samples. It is observed that the out-of-plane birefringence value of PEI film with small initial thickness and high dry temperature increases earlier.

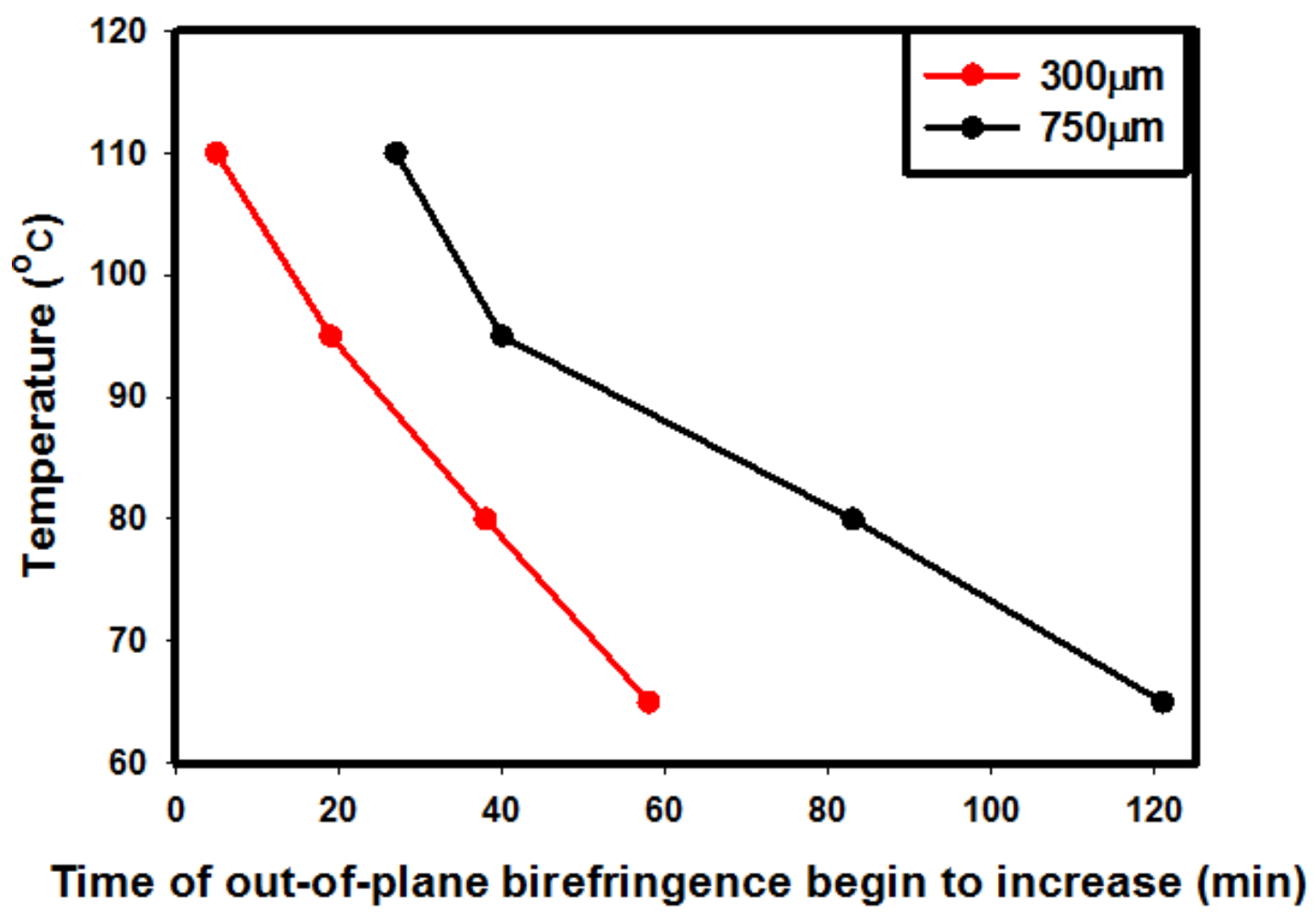

Figure 3.11 Temperature vs. time of out-of-plane birefringence begin to increase of PEI-NMP with $17 \%$ solid content and different initial thickness drying at $0.5 \mathrm{~m} / \mathrm{s}$ air speed.

\subsubsection{Casting thickness effect in drying process}

The effects of the casting thickness are investigated by using three different thicknesses, $750 \mu \mathrm{m}, 500 \mu \mathrm{m}$ and $300 \mu \mathrm{m}$, respectively (Figure 3.12). It is observed that out-of-plane birefringence of the thicker sample increases slower and leveling 
off at a lower value due to the slow rate of solvent loss during drying. This slower freezing-in process leads chains to take more relaxed conformation prior to vitrification.

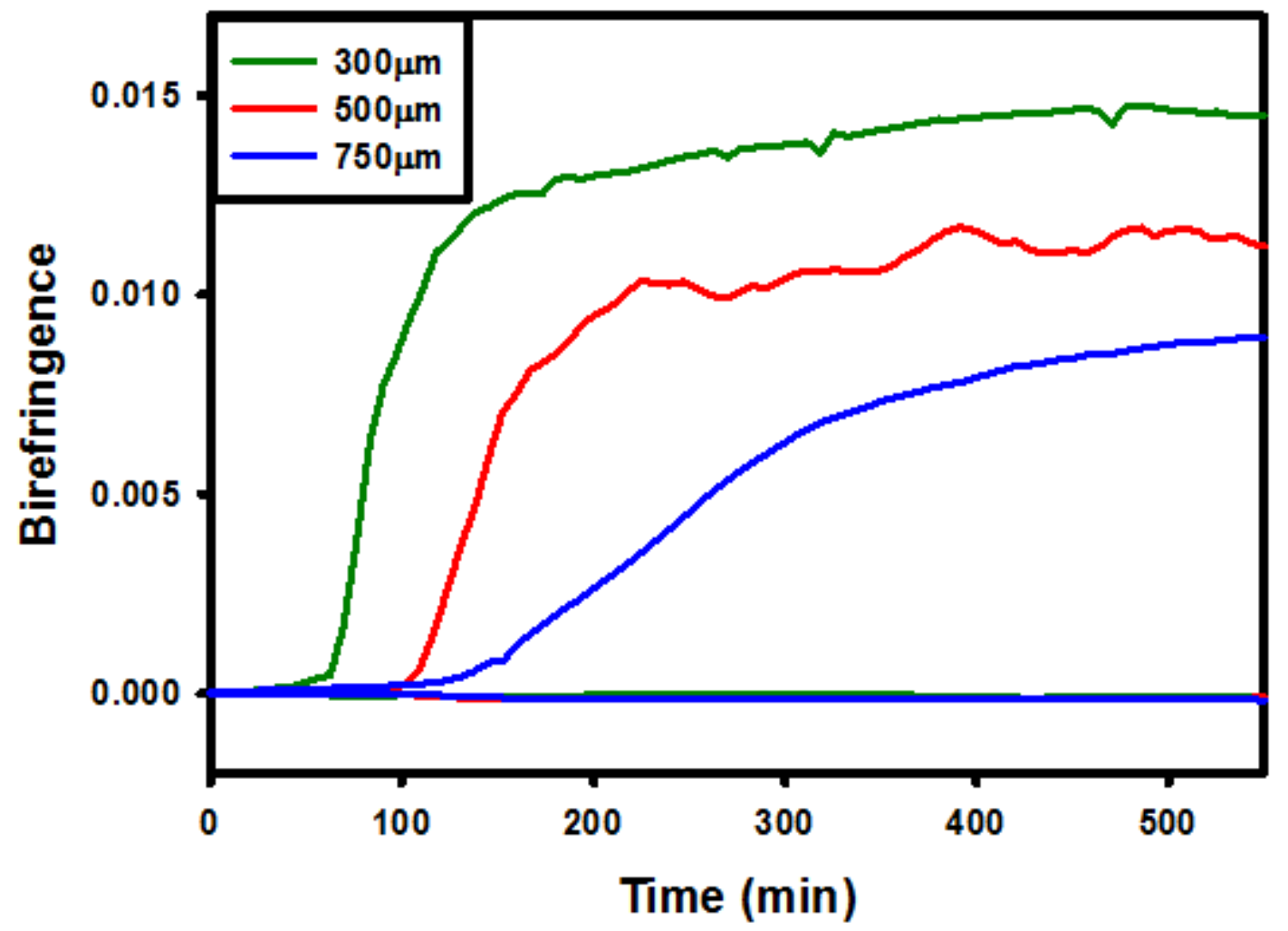

Figure 3.12 Thickness effects on in-plane and out-of-plane birefringence behavior of PEI-NMP with $17 \%$ solid content drying at $65^{\circ} \mathrm{C}$ and $0.5 \mathrm{~m} / \mathrm{s}$ air speed.

\subsubsection{Air speed effect in drying process}

We also studied the influence of air speed to the birefringence during drying. $0.5 \mathrm{~m} / \mathrm{s}, 0.65 \mathrm{~m} / \mathrm{s}, 0.8 \mathrm{~m} / \mathrm{s}$ and $1.0 \mathrm{~m} / \mathrm{s}$ are used in this study. Figure 3.13 shows that the out-of-plane birefringence increases with increasing the air speed blowing the surface of the casting solution. This is because a fast air speed freezes the aligned 
molecular chains in the thickness direction rapidly, and meanwhile prevents the relaxation of the polymer segments.

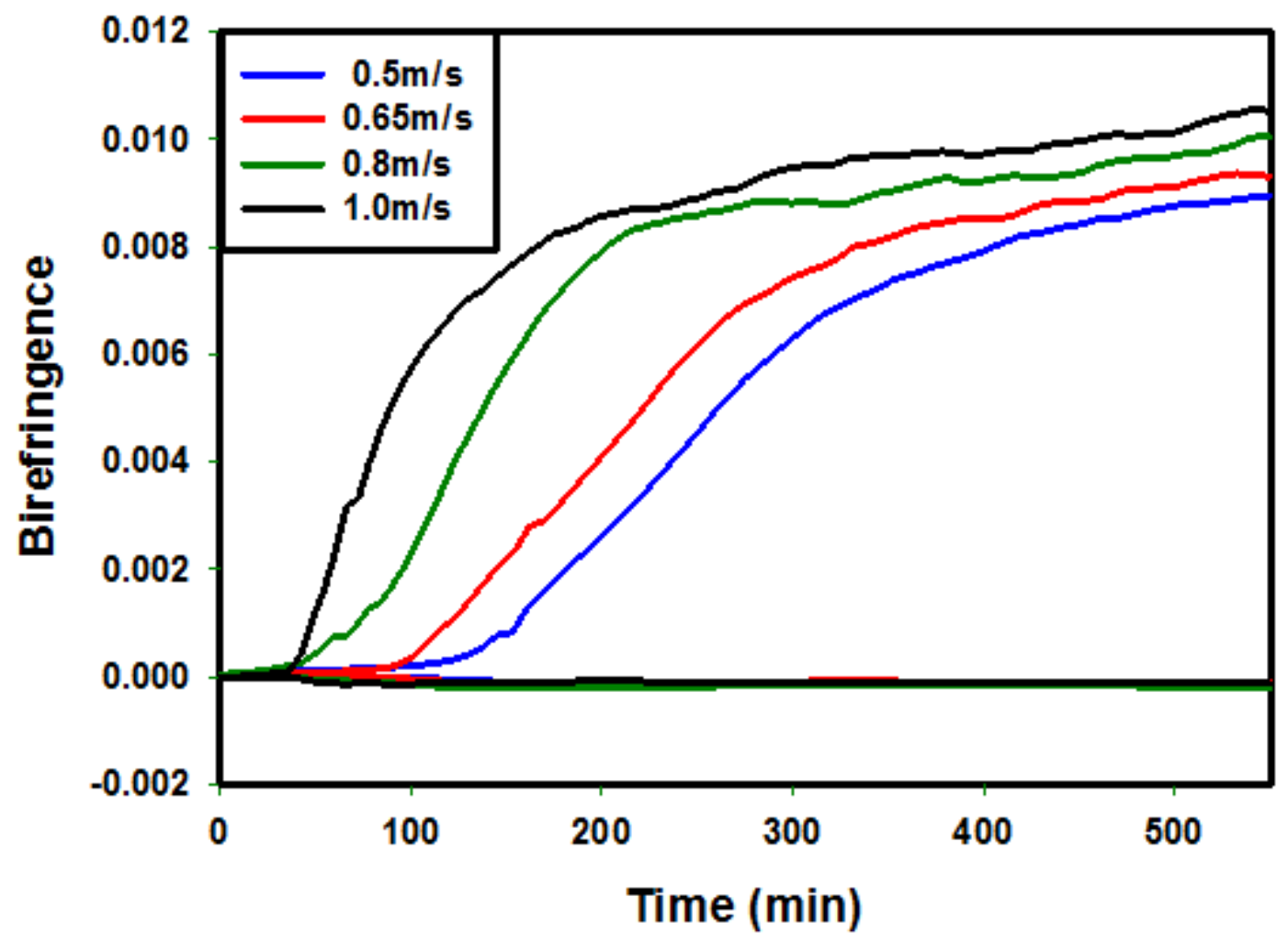

Figure 3.13 Air speed effects on in-plane and out-of-plane birefringence behavior of

PEI-NMP with $17 \%$ solid content and $750 \mu \mathrm{m}$ initial thickness drying at $65^{\circ} \mathrm{C}$.

\subsubsection{Solvent effect in drying process}

DMAc is chosen as another solvent to study the solvent effect in the process.

Generally, boiling point and solubility parameter are the two most important solvent characters which affect the orientation behavior of solution casting film. The solubility parameters of DMAc and NMP are $10.8 \mathrm{cal}^{1 / 2} \mathrm{~cm}^{-3 / 2}$ and $11.3 \mathrm{cal}^{1 / 2} \mathrm{~cm}^{-3 / 2}$, respectively. Since the solubility parameters are very close, the boiling point plays a 
key role in determining the plasticizing power of solvent. In Figure 3.14, it is found that the solvents produce films of different degrees of orientation, and a slow-evaporating solvent NMP yields a lower out-of-plane birefringence. Since more NMP solvent is remained at the given time, chain relaxation is more favorable which decreases the preferential orientation of polymer chains.

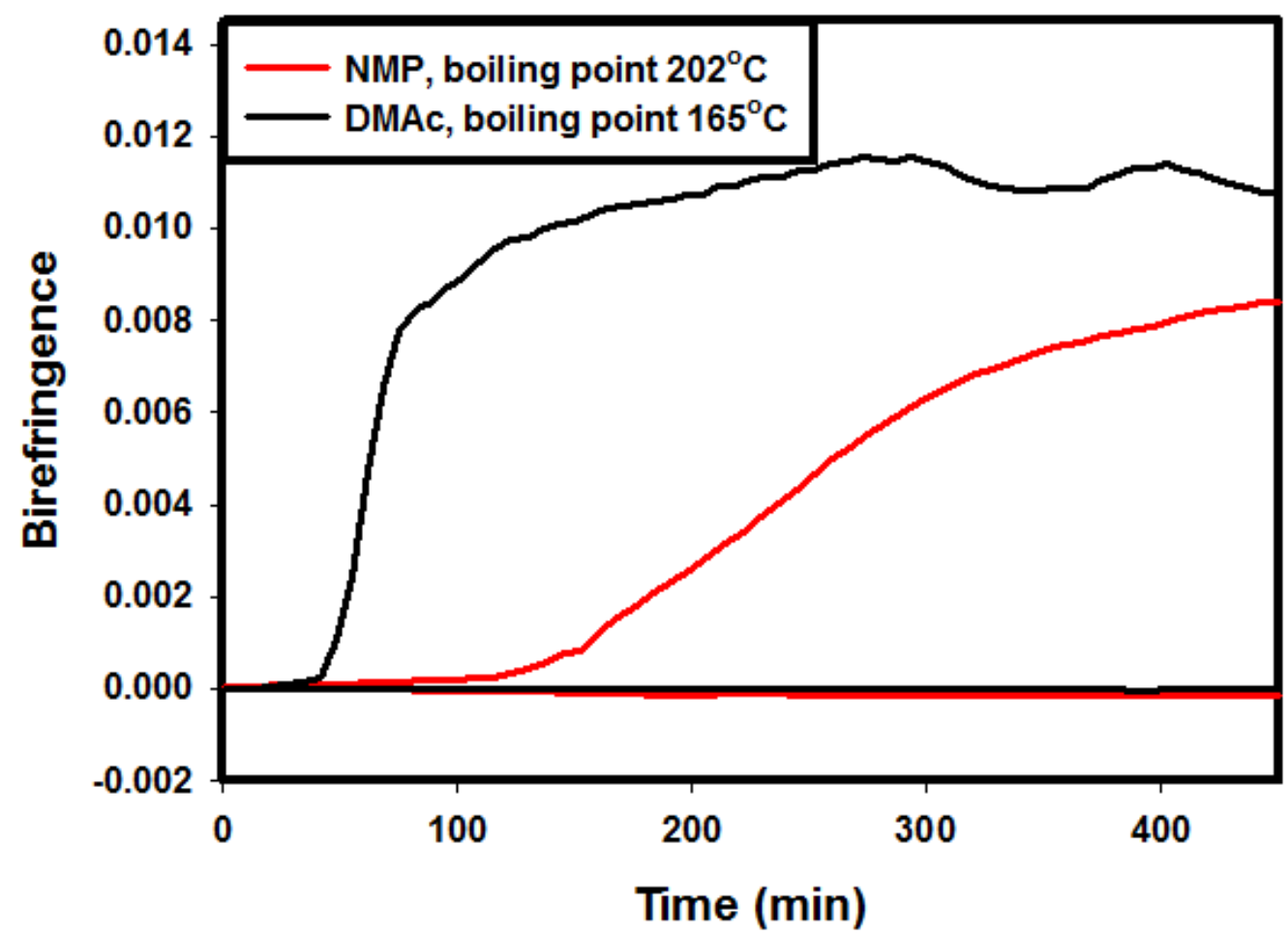

Figure 3.14 Solvent effects on in-plane and out-of-plane birefringence behavior of PEI-NMP with $17 \%$ solid content and $750 \mu \mathrm{m}$ initial thickness drying at $65^{\circ} \mathrm{C}$ and $0.5 \mathrm{~m} / \mathrm{s}$ air speed.

\subsubsection{Overview of uniaxial stretching}

In the uniaxial stretching process, the real-time thickness, cross-sectional area, retardation of the PEI dumbbell-shaped film, as well as the force load on the sample 
are tracked by a mechano-optical on-line measurement system. Therefore, the relationship between true strain and true stress, birefringence and true stress, birefringence and true strain of the PEI films can be obtained.

\subsubsection{Solvent content effects on mechano-optical properties}

The change of remnant solvent concentration directly influences the Tg and consequently deformation behavior. In addition, the solvent concentration does not remain constant during stretching. In order to investigate this effect, we stretched a film cast from $17 \%$ concentration solution to a series of deformations and analyzed the remaining solvent concentration after the stretching to a series of deformations followed by rapid having TGA as well as DSC experiments to determine solvent level and Tg. This is shown in Figure 3.15. The results indicate that about 3\% of solvent evaporate during the preheating and the solvent level further decreases as the stretching proceeds. Thus this material undergoes an increase in Tg during the stretching process. Since we stretch PEI film at $130^{\circ} \mathrm{C}$, the material behaves as if it is approaching its $\mathrm{Tg}$ as the deformation proceeds as it increases from $98^{\circ} \mathrm{C}$ to $120^{\circ} \mathrm{C}$ which is still below the stretching temperature. After the true strain reaches 1.6, the rate of solvent loss becomes very small and solvent content levels off at $12 \%$. 


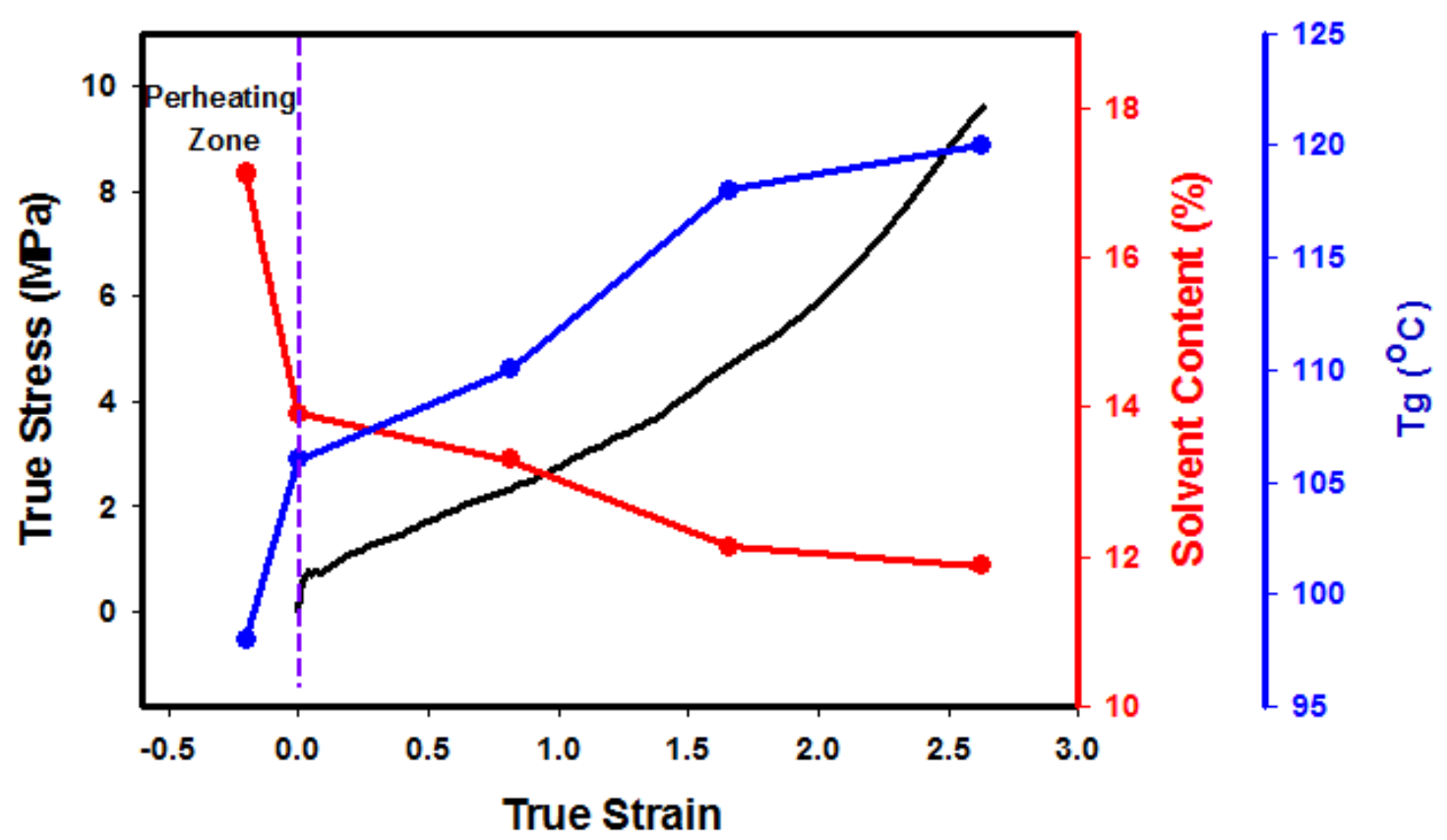

Figure 3.15 The change of solvent content and Tg during stretching for PEI film with

$17 \%$ initial solvent contents stretched at $130{ }^{\circ} \mathrm{C}$ and $10 \mathrm{~mm} / \mathrm{min}$ stretching speed.

In order to further investigate the effects of solvent content on the mechano-optical behavior, we stretched the PEI films at $130^{\circ} \mathrm{C}$ and $10 \mathrm{~mm} / \mathrm{min}$ at different solvent contents. The true stress and true strain plots is shown in Figure 3.16, and the solvent content of each sample before and after stretching is measured by TGA and listed in the table in figure 3.16. 


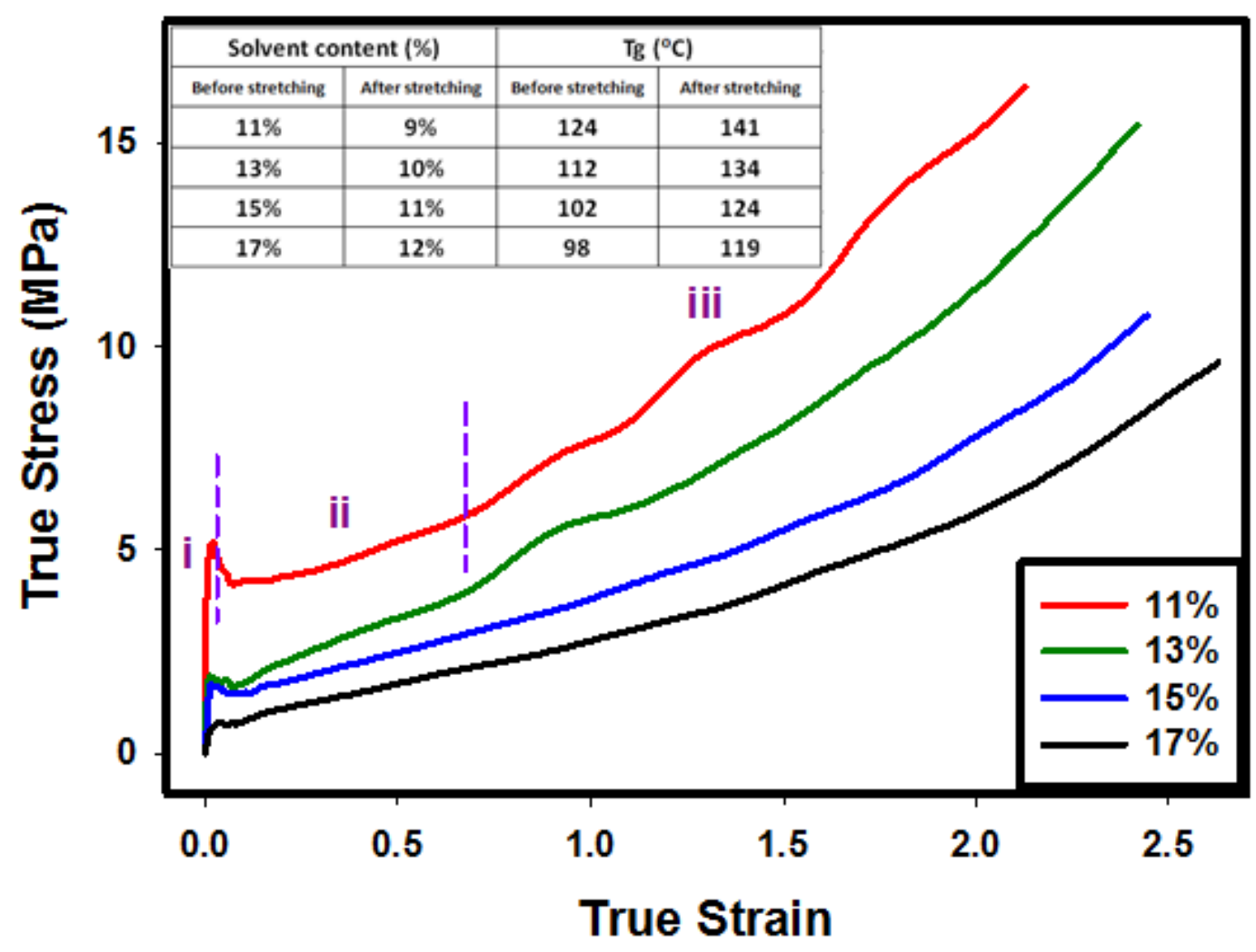

Figure 3.16 True stress-strain plots of PEI films with various solvent contents stretched at $130^{\circ} \mathrm{C}$ and $10 \mathrm{~mm} / \mathrm{min}$ stretching speed.

Yielding phenomenon is one of the most important mechanical performance characteristics which control the deformation behavior during the film stretching. Generally, there is a drop on the stress value after yielding. The phenomenon is controlled by processing conditions, such as solvent content and temperature. Figure 3.16 shows that increasing the solvent content decreases the yielding values.

There are three regimes of true stress-strain relationship during the stretching process of PEI film (Regime i, Regime ii and Regime iii as shown in Figure 3.16): a significant increase of stress before yielding, also called elastic regime; a relatively mild increase after yielding and a steep rise after strain hardening. When the PEI 
films with high solvent content are stretched, the stress values at all strain levels decrease, including the stress at the yield point and the stress at strain hardening onset (Figure 3.17).

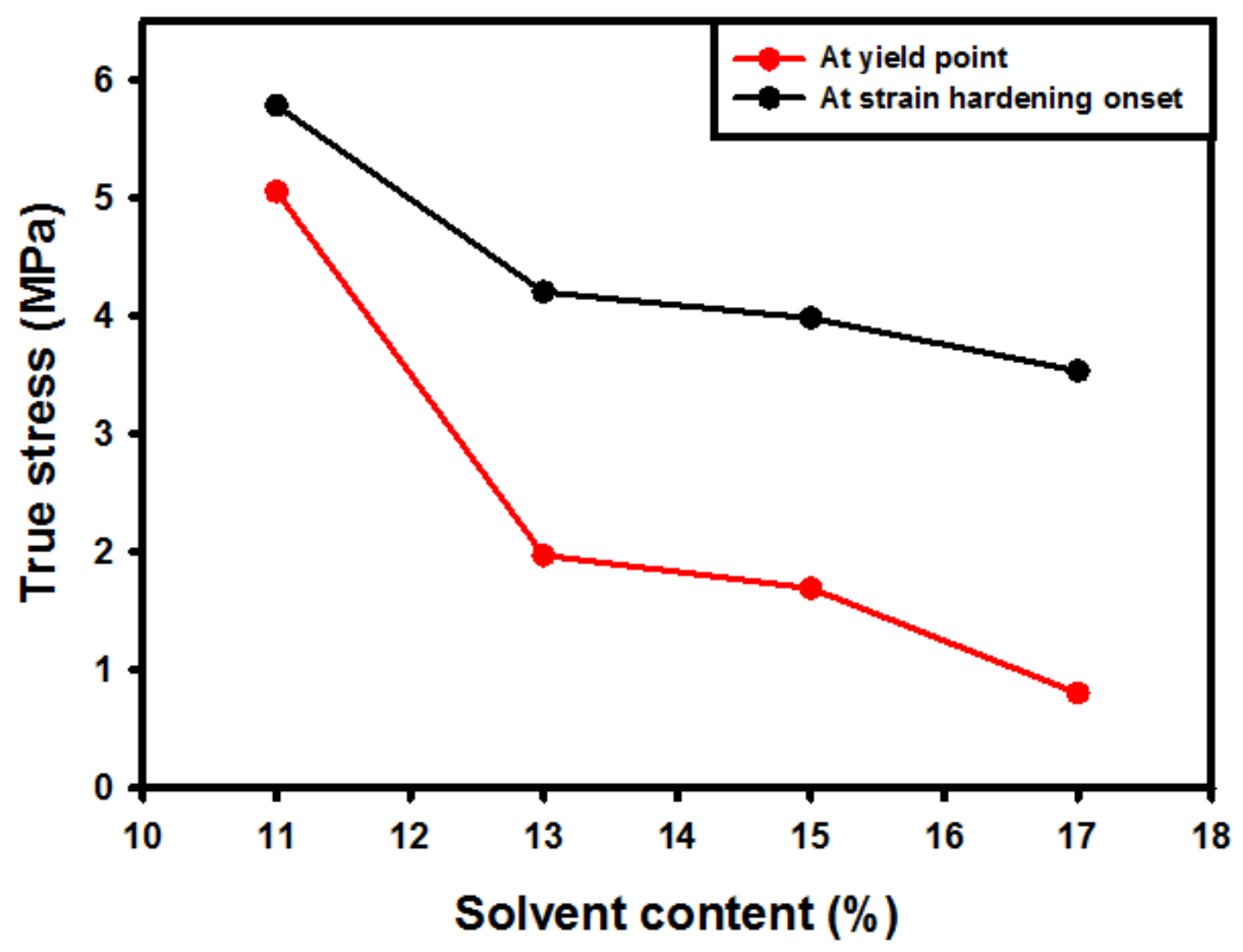

Figure 3.17 True stress at yield point and strain hardening onset at various solvent contents.

Figure 3.18 gives us a view of the relationship between birefringence and true stress behavior of PEI with various solvent contents. For each of the birefringence vs. true stress curve, it exhibits a linear elastic regime (Regime i) before yielding. And then a notable increase of birefringence with little change in stresses occurs in Regime ii. As further deformation of the PEI film takes place (in Regime iii), the birefringence gradually reaches a plateau while a significant increase in true stress is observed. 


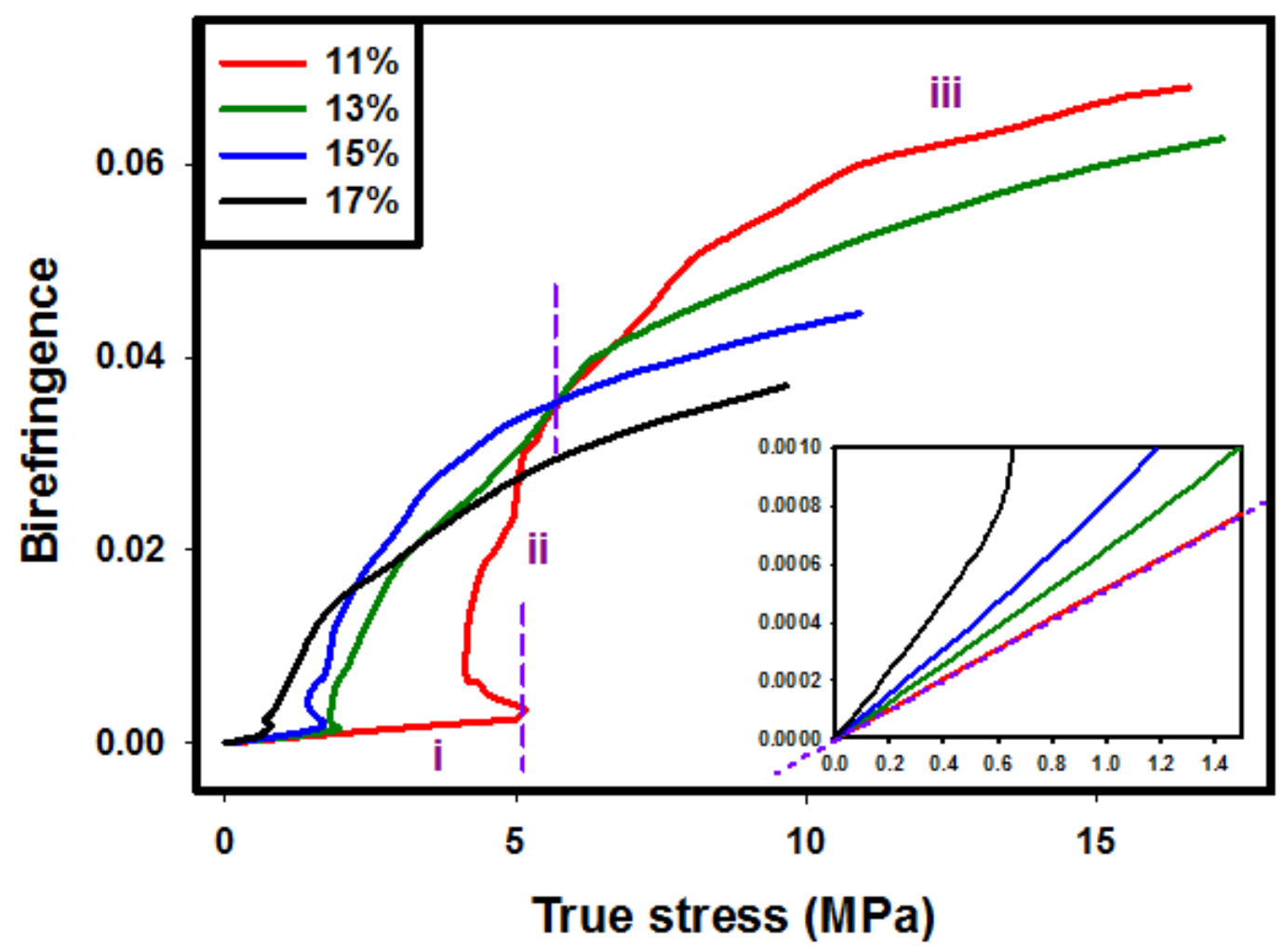

Figure 3.18 Birefringence-true stress plot for PEI film with various solvent contents stretched at $130{ }^{\circ} \mathrm{C}$ and $10 \mathrm{~mm} / \mathrm{min}$ stretching speed. (Inset figure: magnification of initial regime).

Comparing the birefringence and true stress plots with different solvent content, we notice that the birefringence of the film with high solvent content increases rapidly when the given true stresses is small. But as the true stress further processes, it increases slower and finally reaches at a lower value. This is because the $\mathrm{Tg}$ of high solvent content PEI film is low. The mobility of molecular is relatively high at stretching temperature and therefore forming the orientation along the machine direction quickly at the initial time. But on the other hand, the PEI films with high solvent content could only reach low final birefringence levels as the chains experience more relaxation. In Figure 3.19, the birefringence is plotted as a function 
of the true strain for PEI films with different solvent contents. With increasing the true strain, the birefringence increases for each sample which indicates that the alignment of polymer chain take place along the stretching direction. The birefringence exhibits a lower value at given true stain values as remnant solvent content increases.

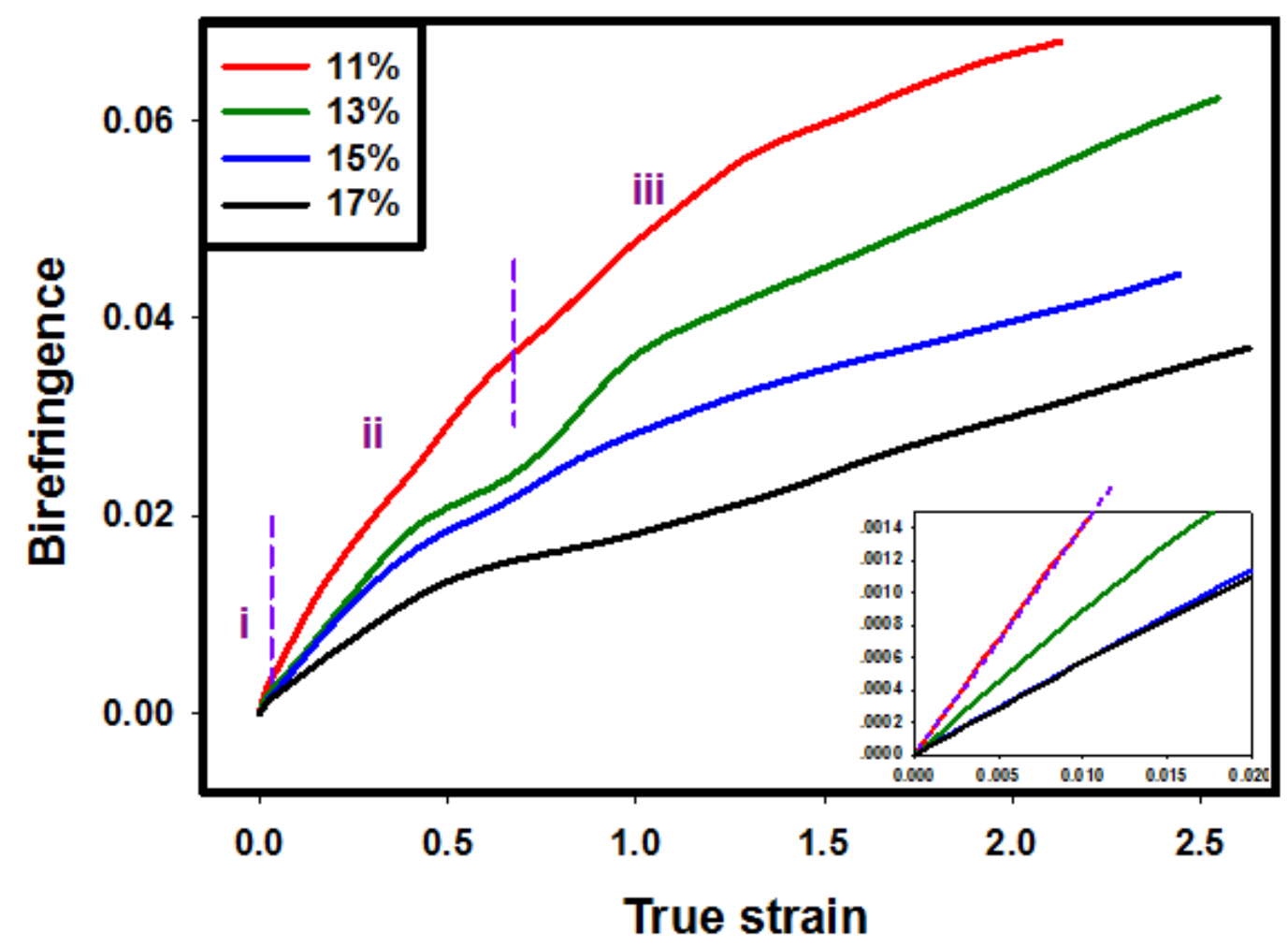

Figure 3.19 Birefringence-true strain plot for PEI film with various solvent contents stretched at $130{ }^{\circ} \mathrm{C}$ and $10 \mathrm{~mm} / \mathrm{min}$ stretching speed. (Inset figure: magnification of initial regime).

The photoelastic constant and strain optical constant is obtained from the slope of the linearity on birefringence-true stress plot and birefringence-true strain plot are plotted as a function of temperature in Figure 3.20. The strain optical constant decreases with increasing the solvent content while the photoelastic constant behaves 
the opposite way. Because of the relaxation effects introduced by solvent, the birefringence decreases at the given true strain value. On the other hand, the true stress increases significantly with low solvent content at given true strain, and the birefringence merely increased little within a big change in true stress. So the photoelastic constant increased with increasing solvent content.

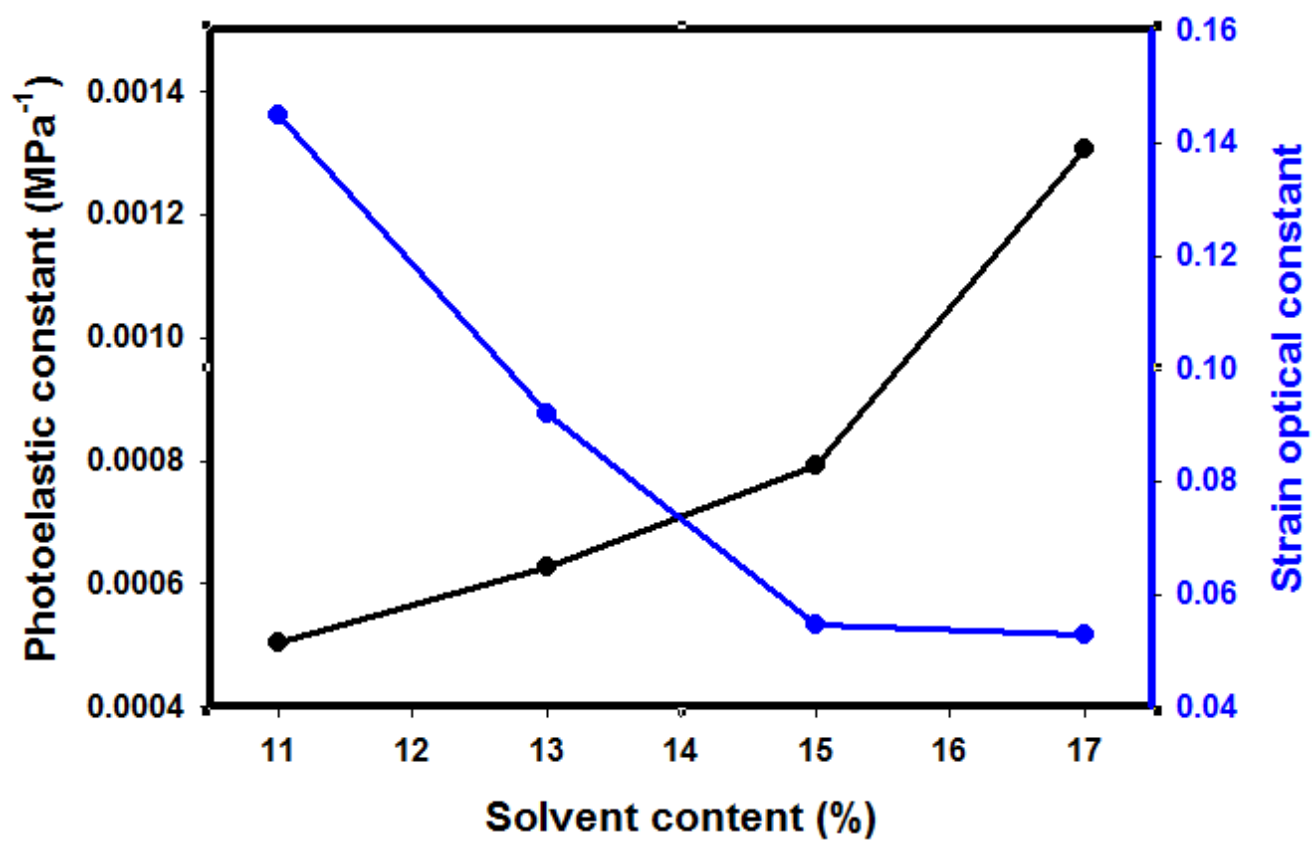

Figure 3.20 Photoelastic constant and strain optical constant of Regime i at various solvent contents.

\subsubsection{Temperature effects on mechano-optical properties}

PEI has a very high $\mathrm{Tg}$ around $210^{\circ} \mathrm{C}$ and it will bring a difficulty to stretch the film at such high temperature by using on-line measurement system. Therefore, part of solvent is remained in the PEI film to decrease the Tg so that we can investigate the temperature effects on the mechano-optical properties. 
Figure 3.21 shows the mechanical behaviors for PEI films which contain 17\% solvent stretched at different temperatures $\left(100^{\circ} \mathrm{C}, 110^{\circ} \mathrm{C}, 120^{\circ} \mathrm{C}, 130^{\circ} \mathrm{C} 140^{\circ} \mathrm{C}\right.$ and $150^{\circ} \mathrm{C}$, respectively) when the stretching speed is $10 \mathrm{~mm} / \mathrm{min}$. In the case of sample stretched at $100^{\circ} \mathrm{C}$, strain-hardening occurs at the very early stage of deformation and the slope of the true strain-stress curve increases dramatically after that. This is because continued losing solvent raise the $\mathrm{Tg}$ from below the stretching temperature to above the stretching temperature. The polymer chains are nearly frozen. Therefore, the film breaks at a very high stress value. When the stretching temperature is below $120^{\circ} \mathrm{C}$, all the PEI films demonstrates typical glassy polymer tensile curves with obvious yielding. However, the PEI films stretched above $130^{\circ} \mathrm{C}$ shows a transition from plastic-like behavior to rubbery-like behavior with no apparently sharp yielding after photoelastic regime is observed. When the temperature reaches $150^{\circ} \mathrm{C}$, the PEI film exhibits an entirely rubber-like behavior without any yielding. 


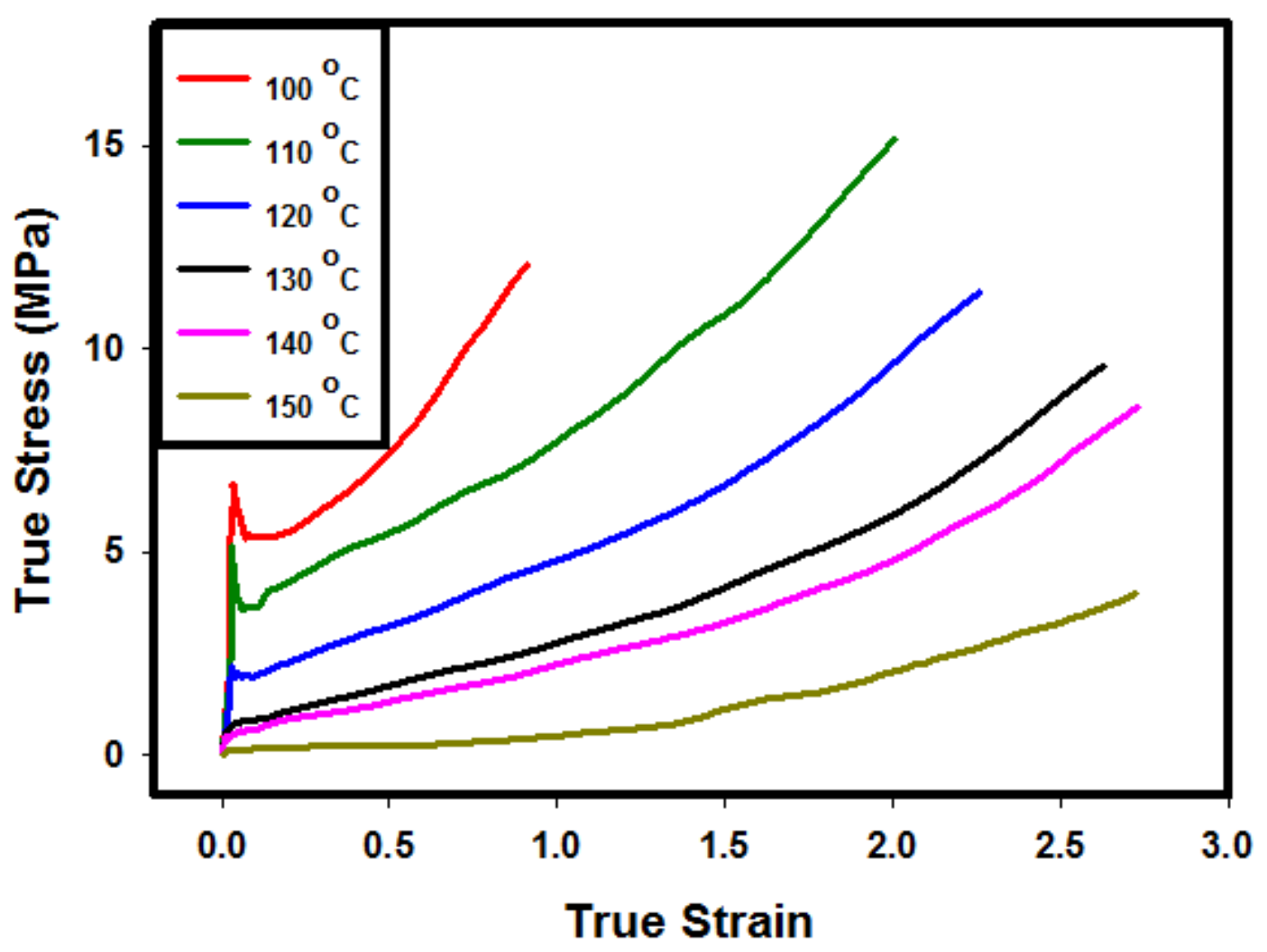

Figure 3.21 True stress-true strain plots for PEI films with 17\% solvent content stretched at $10 \mathrm{~mm} / \mathrm{min}$ stretching speed with various temperatures.

Figure 3.22 shows the relationship between birefringence and true stress of PEI films stretched at different temperatures. It indicates that the birefringence does not increase significantly until the stress value reaches the yield point when the stretching temperature is below $140^{\circ} \mathrm{C}$. However, the PEI film stretched at $150^{\circ} \mathrm{C}$ shows an increase birefringence as the true stress processed. After that, the birefringence increases rapidly due to the large plastic deformation and then it almost leveling off after strain hardening. At the initial stretching, high stretching temperature leads to high orientation value because the mobility of molecular chains is relatively extensive and these chains form the aligned structure rapidly. 


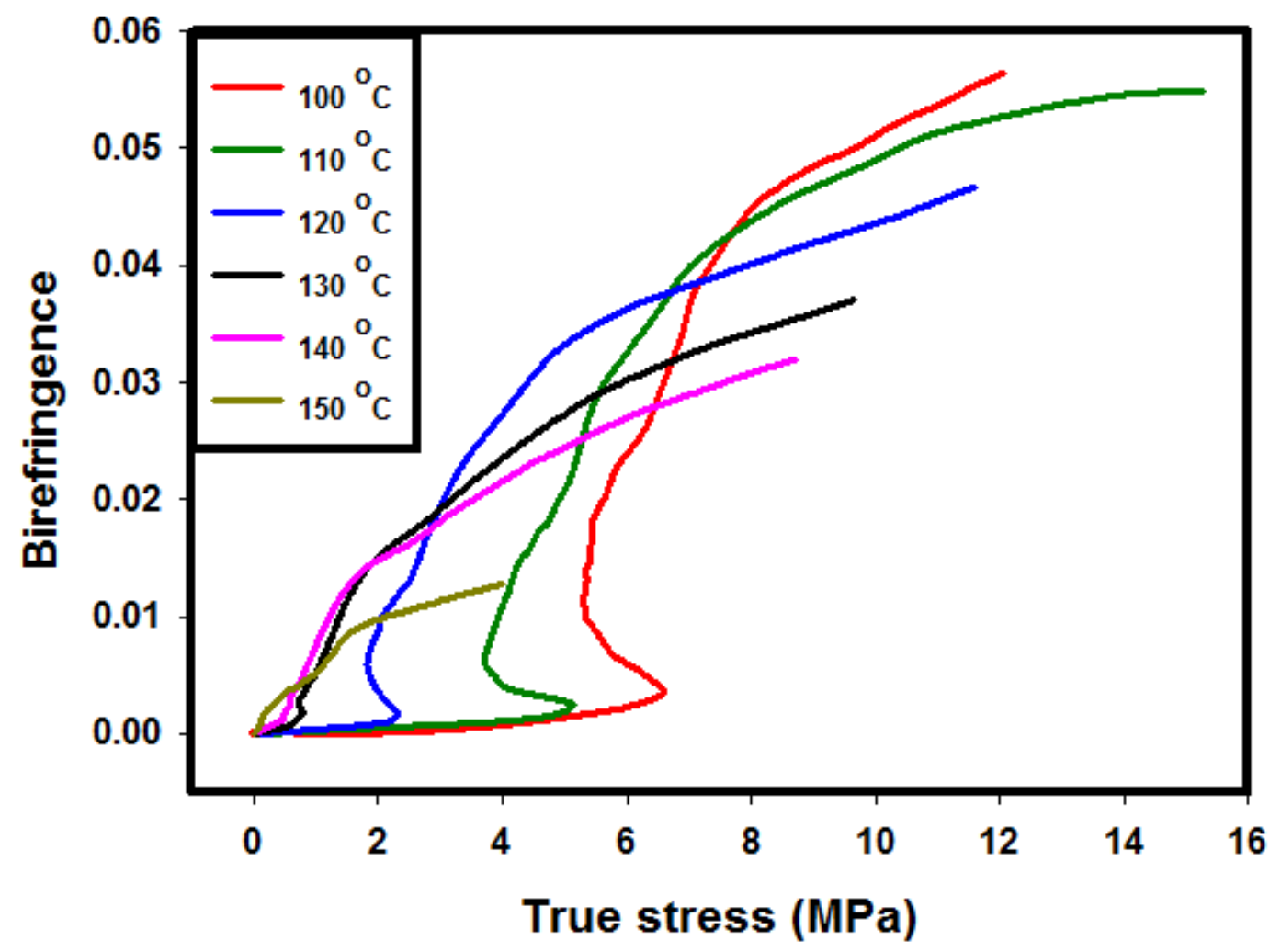

Figure 3.22 Birefringence-true stress plots for PEI films with $17 \%$ solvent content stretched at $10 \mathrm{~mm} / \mathrm{min}$ stretching speed with various temperatures.

The effect of temperature on the true strain vs. birefringence plot is showed in Figure 3.23. There is a continuous increase of birefringence as the true strain processes due to the orientation of molecular. The birefringence of PEI films stretching at high temperature reveals a low values because of the remarkable polymer chain relaxation at high temperature. 


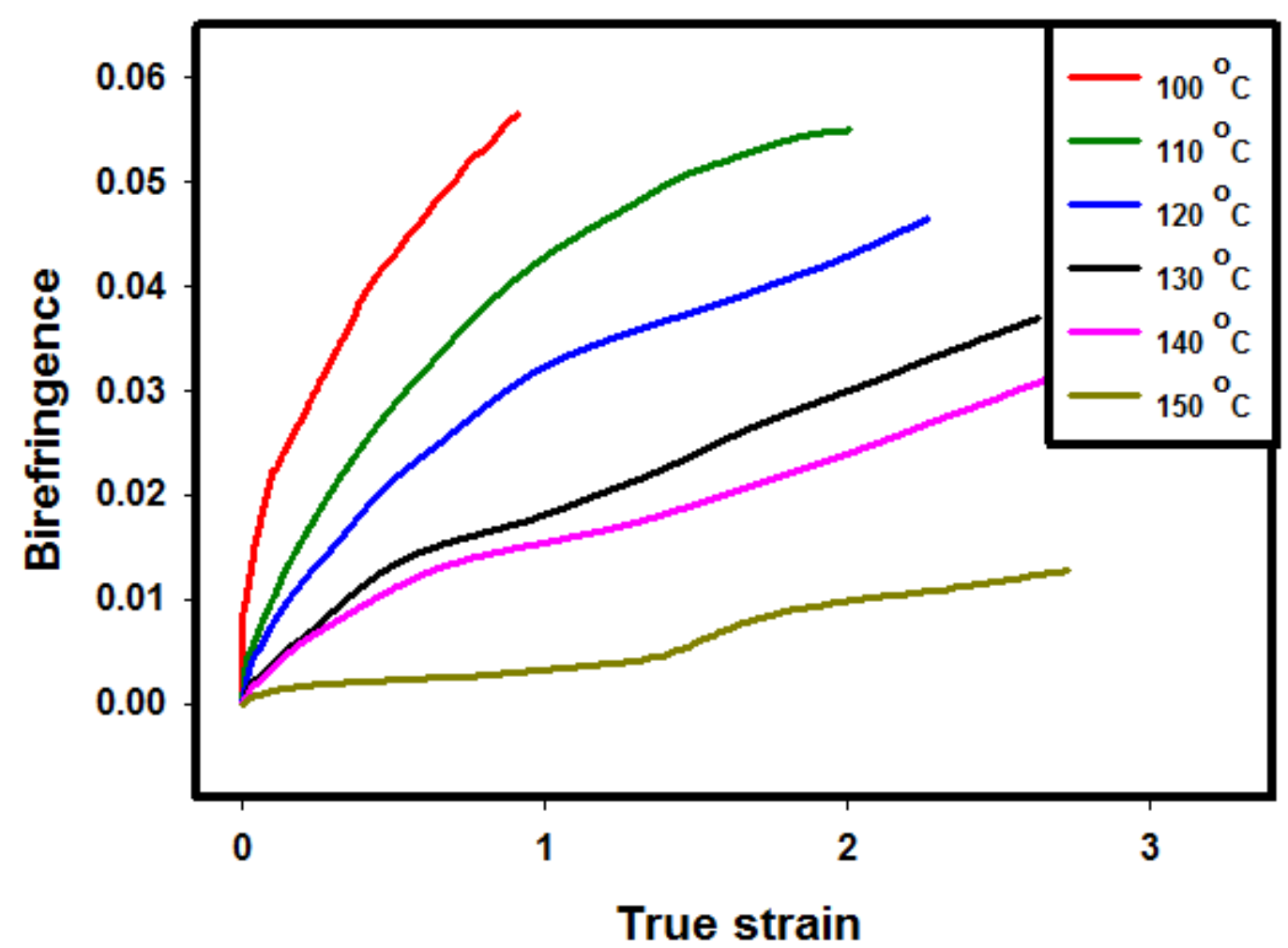

Figure 3.23 Birefringence-true strain plots for PEI films with 17\% solvent content stretched at $10 \mathrm{~mm} / \mathrm{min}$ stretching speed with various temperatures.

\subsubsection{Stretching speed effects on mechano-optical properties}

The effect of stretching speeding on the mechanical properties is also investigated in Figure 3.24. The PEI films with $12 \%$ solvent content stretched at $140^{\circ} \mathrm{C}$ with stretching speed at $2 \mathrm{~mm} / \mathrm{min}, 20 \mathrm{~mm} / \mathrm{min}$ and $200 \mathrm{~mm} / \mathrm{min}$, all show a plastic behavior with yielding. Comparing with stretching rate at $20 \mathrm{~mm} / \mathrm{min}$ and $200 \mathrm{~mm} / \mathrm{min}$, low stretching speeding has lower true stresses at the given true strain compared. This is because at the lower speed, the relaxation rate is more comparable to the stretching rate during deformation. We also notice that the slope of strain and stress curve of $2 \mathrm{~mm} / \mathrm{min}$ stretching speed increases dramatically after strain 
hardening due to large amount of solvent loss induced by long-time stretching process.

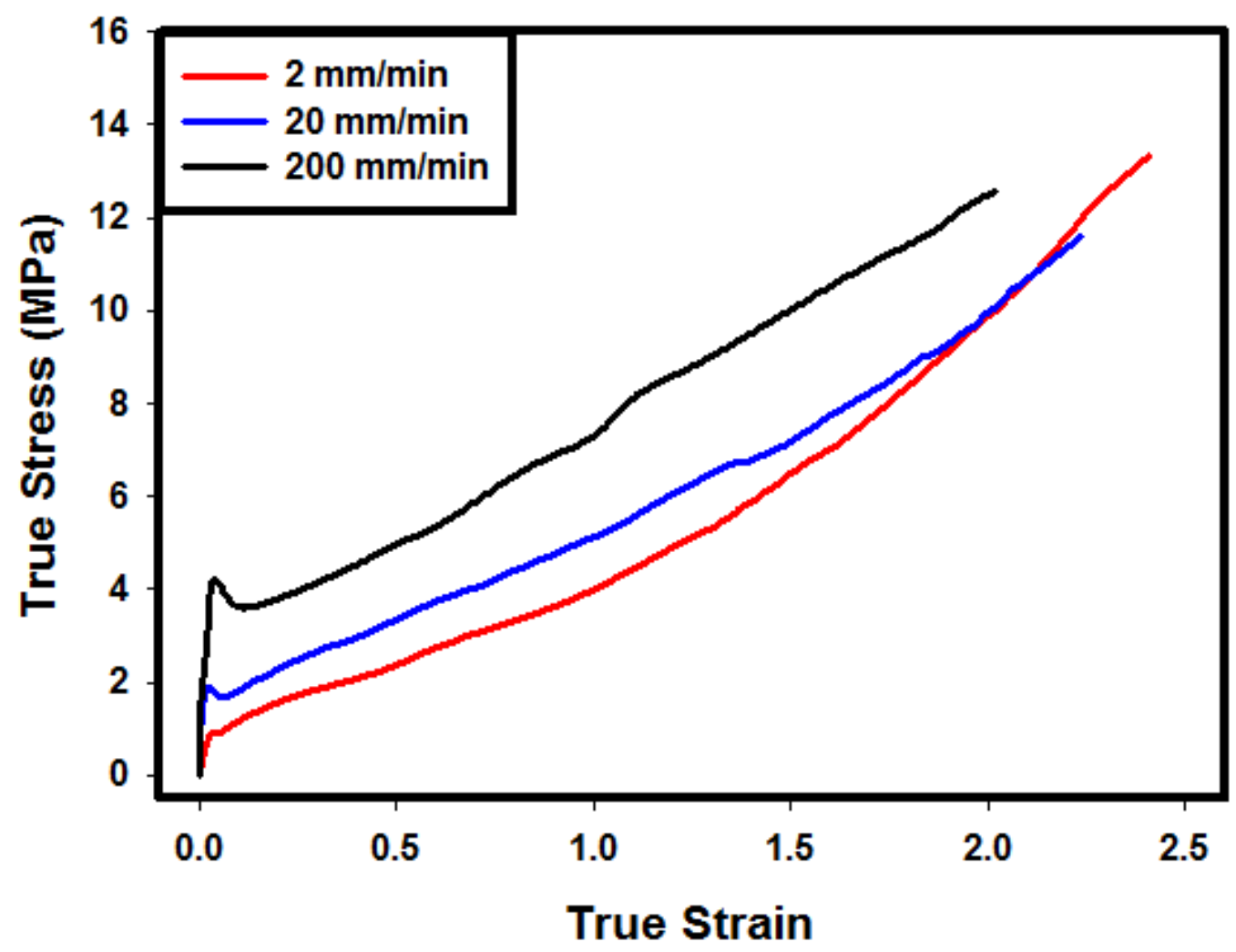

Figure 3.24 True stress-true strain plots for PEI films with $12 \%$ solvent content stretched at $140^{\circ} \mathrm{C}$ with various stretching speeds.

Figure 3.25 shows the birefringence vs. true stress curve of PEI stretched at the various stretching rates. The birefringence increases significantly after the stress processed to a starting point and its slope gradually levels off ultimately. Increasing the stretching rate shifts the starting point to higher stress levels due to the time is too limited for polymer chains to orientate following the stretching direction which produces a "delay phenomenon". The limited time also prevents the chain relaxation and fixes the chain structure with high alignment degree. 


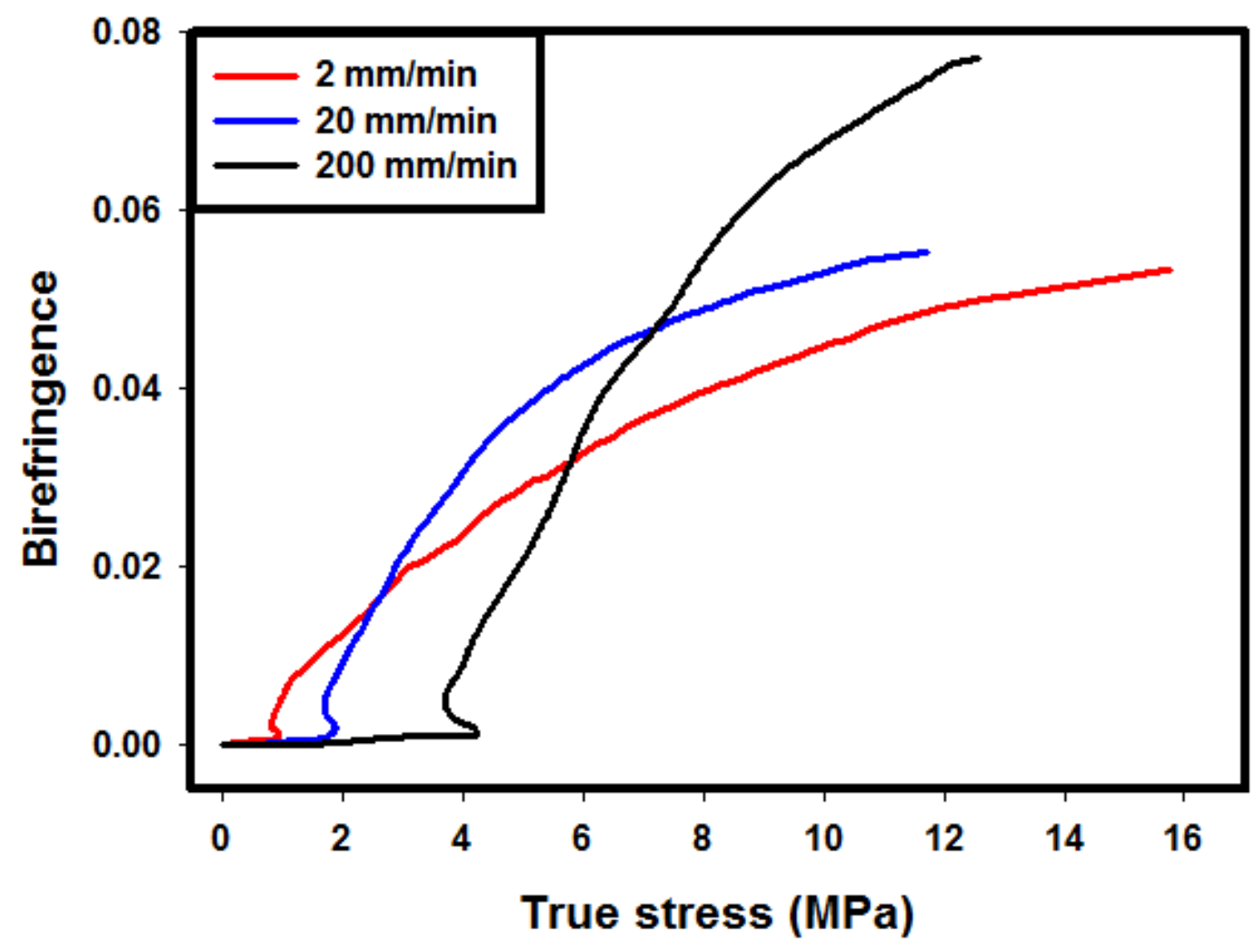

Figure 3.25 Birefringence-true stress plots for PEI films with $12 \%$ solvent content stretched at $140{ }^{\circ} \mathrm{C}$ with various stretching speeds.

The birefringence increases with increasing the true strain as shown in Figure 3.26. Since there is much more time for molecular relaxing before ending the experiment, the PEI film with low stretching speed has a relatively low value of birefringence. 


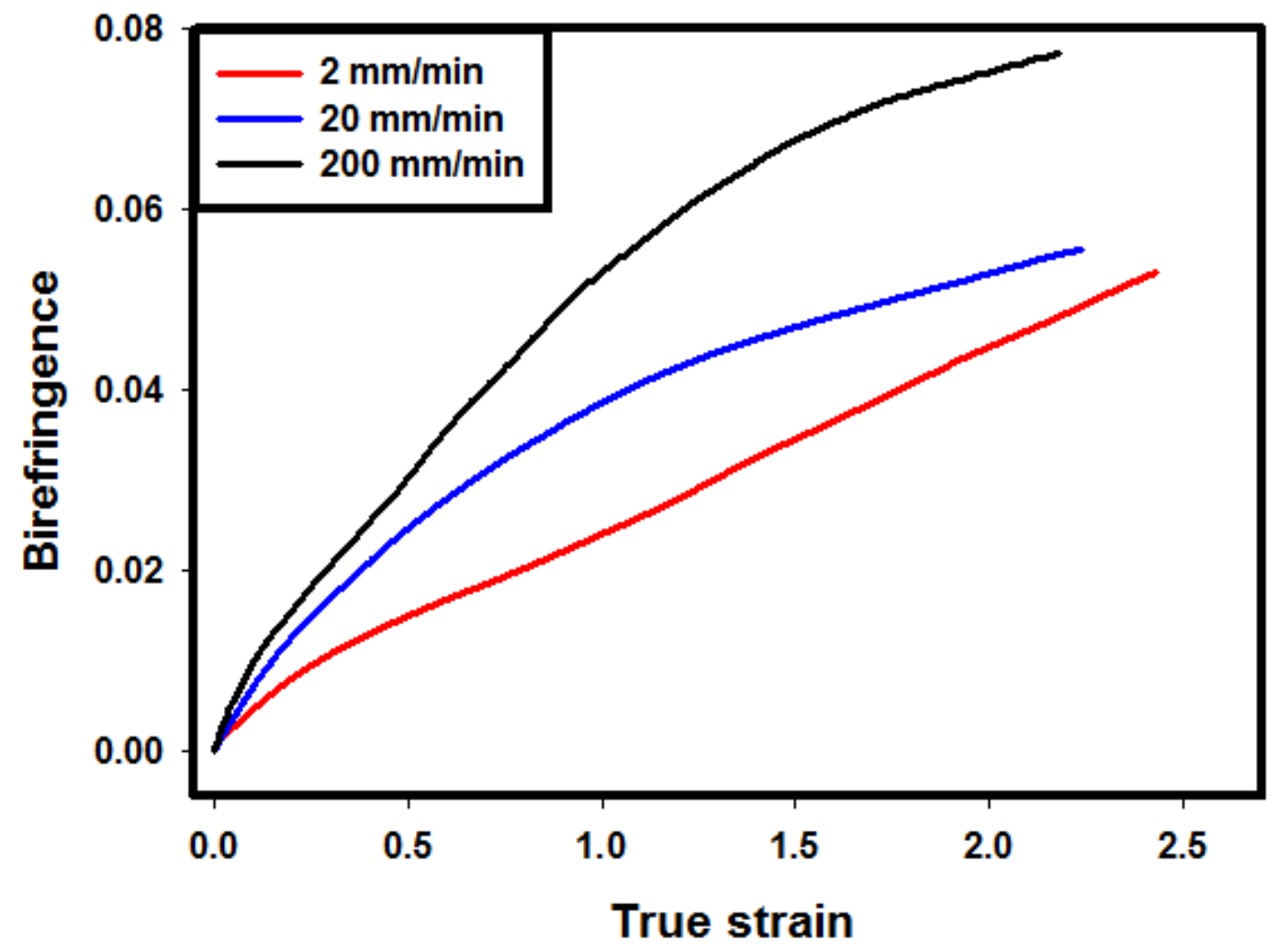

Figure 3.26 Birefringence-true strain plots for PEI films with $12 \%$ solvent content stretched at $140^{\circ} \mathrm{C}$ with various stretching speeds. 


\section{CHAPTER IV}

\section{CONCLUSIONS}

The structure development and optical properties of PEI from film formation to stretching was observed in real-time. As drying proceeds by solvent diffusion, the solution goes through vitrification. The polymer chain becomes oriented with an increasing birefringence in the out-of-plane direction while remaining randomly oriented in the film plane direction during drying. The degree of alignment in out-of-plane direction is affected by the properties of polymer solution and the parameters of drying. Low solid content of polymer solution, low boiling-point solvent, high drying temperature, large film thickness and rapid air speed, all result a high value of out-of-plane birefringence due to strongly fixing of the aligned structure and suppressed molecular chain relaxation.

Addition of solvent successfully decreases the glass transition temperature so that allows PEI film to be stretched at low temperatures. Generally, enhancing the solvent content, rising the stretching temperature, and reducing the stretching rate decrease the true stresses value at the given true strains. The deformation behavior of PEI film transfers from plastic-like to rubber-like when the stretching temperature or the solvent content is high enough. A relatively lower oriented structure is developed 
under higher temperature, faster stretching speed and more solvent content because of the more chain relaxation. 


\section{REFERENCES}

(1) Mittal, K. L. (ed) Polyimides: Stnthesis, characterization and applications, 1\&2. Plenum, NY (1984).

(2) Ghosh, M. K.; Mittal, K. L. (ed) Polyimides: Stnthesis, characterization and applications. Marcel Dekker (1996).

(3) Takehoshi, T. Synthesis of Polyimides, in Polyimides: Fundamentals and Applications, Ghosh, M. K. and Mittal, K. L. (Editors), Wiley and Sons, 1996, 7,

(4) Sgroog, C. E. Prog. Polym. Sci, 1991, 16, 561.

(5) Takehoshi, T.; Kochanowski, J. E.; Malleno, J. S.; Webber, M.J. J. Polym. Sci. Polym. Symp. 1986, 74, 93.

(6) Chen, B. K.; Fang, Y. F.; Cheng, J. R. Macromol. Symp. 2006, 242, 34.

(7) Kumar Sen, S.; Maji, S.; Dasgupta, B.; Chatterjee, S; Banerjee, S. J. of Applied Polymer Science 2009, 113,1550.

(8) Flaim, T.; Wang, Y.; Mercado, R. Optical system design 2003, 5250.

(9) Patil, O.; Shaffer, T.; Bodige, S.; Dalrymple D. C. "Partidga. Ethanol stable polyetherimide membrance for aromatics separation," US Pat. No. 0108605 A1 assigned to Exxon mobile Research and Engineering Company, 2010, May.

(10) Orlicki, J.; Thompson, J.; Markoshi, L. J. Polym. Sci. A1. 2002, 40, 936.

(11) Hsiao S. H.; Huang, P.C. J. of Pol. Research, 1997, 4, 183.

(12) Thompson, D. S.; Markoski, J. L.; Moore, J, S. Macromolecules 1999, 32, 4764.

(13) Wang, D. H.; Cheng, S. Z. Polymer 2007, 48, 2572.

(14) Bagheri-Tar, F.; Sahimi, M.; Tsotsis, T. T. Ind. Eng. Chem. Res. 2007, 46, 3348 .

(15) Alesbury, C. K. Polyetherimide. US. Pat. No. 4960837, assigned to Pierli general plc, 1990, Oct. 
(16) Kanuga. K. Doctoral Thesis in The University of Akron. "A fundamental study on the non-linear mechano-optical behavior of polyethylene naphthalate, its blends with polyetherimide and its nancomposites," 2006.

(17) Rickert, S. E.; Balik, C. M.; Hopfinger, A. J. Adv. Colloidlnterface Sci. 1979, $11,149$.

(18) Cherkasov, A. N.; Vitovskava, M. G.; Bushin, S. V. Visoko mol. Soedin., Ser:A. 1976, 18, 1628.

(19) Cohen, Y.; Reich, S. J. Polym. Sci., Polym. Phys. Ed. 1981, 19, 599.

(20) Prest, W. M., Jr.; Luca, D. J. J. Appl. Phys. 1979, 50, 6067.

(21) Prest, W. M., Jr.; Luca, D. J. J. Appl. Phys. 1980, 51, 5170.

(22) Nied, H. F.; Stokes, V. K.; Ysseldyke, D. A. Polymer Engineering and Science 1987, 27, 101.

(23) Kumara, S.; Ratha, T.; Mahalinga, R.N. Mat. Sci. Eng. B-Solid. 2007, 141, 61-70.

(24) Johnson. R. O.; Burlhis, H. S.; Thermoplastic Resin. J. Poly. Sci. Pol. Sym. 1983, 70, 129.

(25) www.sabic-ip.com.

(26) Ibeh, C. C. Thermoplastic Materials. Properties, Manufacturing Methods and Applications. 2010.

(27) Thomas, S.; Visakh, P. M. Hangbook of Engineering and Specialty Thermoplastocs. Volume 4 Nylons. 2010.

(28) Mzabi, N. American J. of Engineering and Applied Sciences. 2009, 2(1), 120.

(29) Merdas, I. Thomonette. F.; Verdu, J. J. Appl. Polym. Sci. 2000, 77, 1439.

(30) Merdas, I. Thomonette. F.; Verdu, J. J. Appl. Polym. Sci. 2000, 77, 1455.

(31) Margolis, J. Engineering Plastics. Handbook. 2006.

(32) Guggenheim, T. L.; Odle, R. R.; Venkataraman, K. Production of low color polyetherimide. US. Pat. No. 0292128A1, Sabic Innovative Plastics, 2009, Nov.

(33) Gao, C.; Zhang, S.; Gao, L. J. Appl. Polym. Sci. 2004, 92, 2415.

(34) Takehoshi, T.; Kochaniwskli. J. method for making polyetherimides and products produced thereby, US. Pat. No. 3905942, assigned to G.E. 1975. Sept.

(35) Takehoshi, T. Method for making polyetherimides. US. Pat. No. 3833544, assigned to G.E. 1974. Sept. 
(36) Williams, F. J.; Klopfer, H. J. Method for making polyetherimides using a sodium chloride or ferric sulfate catalyst, US. Pat. No. 3998840, assigned to G.E. 1976. Dec.

(37) Takehoshi, T. Method for making polyetherimides. US. Pat. No. 4324882, assigned to G.E. 1982. April.

(38) Takehoshi, T.; KochaniwskIi, J. method for making polyetherimides. US. Pat. No. 3803085, assigned to G.E. 1974. April.

(39) Takehoshi, T.; KochaniwskIi, J. method for making polyetherimides. US. Pat. No. 3833546, assigned to G.E. 1974. Spet.

(40) Takehoshi, T.; KochaniwskIi, J. method for making polyetherimides. US. Pat. No. 4011198, assigned to G.E. 1977. Mar.

(41) Williams, F. G. Polyetherimides and method for preparation, US. Pat. No. 3933749, assigned to G.E. 1976. Jan.

(42) Wirth, J. G.; Heath, D. R. Process for making polyetherimide, US. Pat. No. 3787364, assigned to G.E. 1974. Jan.

(43) Williams, F. G. Method for preparing polyetherimides, US. Pat. No. 3847869, assigned to G.E. 1974.

(44) Takehoshi, T.; Kochaniwskli, J. J. Polym. Sci. Polym. Chem. 1980, 18, 3069.

(45) White, D. M.; Takehoshi, T.; Williams, F. G. J. Polym. Sci. Polym. Chem. 1981, 19, 1635.

(46) Wirth, J. G.; Heath, D. R. US. Pat. No. 3838079, assigned to G.E. 1974.

(47) Takehoshi, T. Method for making polyetherimides. US. Pat. No. 3847870, assigned to G.E. 1974. Nov.

(48) Takehoshi, T. Method for making polyetherimides. US. Pat. No. 4024110, assigned to G.E. 1977. May.

(49) Odle, R. R.; Guggenheim, T. L.; Swatos, W. J. Method for preparation polyetherimides. US. Pat. No. 6498224, assigned to G.E. 2002. Dec.

(50) Machell, J. S.; Greener, J. Macromolecules 1990, 23, 186-194.

(51) Greener, J.; Lei, H.; Elman, J.; Chen, J. J. Soc. Inf. Disp. 2005, 13, (10), 835-839.

(52) Coburn, J. C., Pottiger Michael T., Thermal Curing in Polyimide Films and Coatings. Marcel Dekker, Inc.: New York, 1996.

(53) Chen, P. J.; Liu, T. J. American Institute of Chemical Engineers, 2010, 56, (3), 790 .

(54) Pauchard, L.; Allain, C. Europhys Lett. 2003, 62, 897-903. 
(55) Machell, J. S.; Greener, J.; Contestable, B. A. Macromolecules 1990, 23, (1), 186-94.

(56) Greener, J.; Lei, H.; Elman, J.; Chen, J. J. Soc. Inf. Disp. 2005, 13, (10), 835-839.

(57) Coburn, J. C.; Pottiger, M. T.; Noe, S. C.; Senturia, S. D. J. Polym. Sci., Part B: Polym. Phys. 1994, 32, (7), 1271-83.

(58) Spence. J. J. Phvs. Chem. 1939, 43, 865.

(59) Stein, R. S. J. Polym. Sci. 1957, 24, 383.

(60) Nasr, A. M. Polymer Testing 2002, 21, 303-306.

(61) Yang, H. H.; Chouinard, M. P.; Lingg, W. J. J. Polym. Sci. A2. 1982, 20, 981-987.

(62) Tsvetkov, V.N. In Newer Methods of Polymer Characterization. Ke, B., Ed; Interscience: New York, 1964; Chapter 14.

(63) Treloar, L. R. G. The Physics of Rubber Elasticity, 2nd ed.; Oxford University Press: Oxford, 1958.

(64) Wales. J.L. S. The Application of Flow Birefringence to Rheological Studies of Polymer Melts; Delft University Press: Delft, The Netherlands, 1976.

(65) Janeschitz-Kriegl, H. Polymer Melt Rheology and Flow Birefringence; Springer-Verlag: Berlin, 1983.

(66) Gurnee, E. F.; Patterson, L. E.; Andrews, R. D. J. Appl. Phys. 1955, 1106.

(67) Richeton, J.; Ahzi, S.; Vecchio, K. S. International Journal of Solids and Structures 2006, 43, 2318-2335.

(68) Unsal, E.; Drum, J.; Yucel, O.; Nugay, I.; Cakmak, M. Review of Scientific Instruments 2012, 83, 025114.

(69) Unsal, E. Doctoral Thesis in The University of Akron. "Integrate real time studies to track all physical and chemical changes in polyimide film processing," 2013.

(70) Sen, Z.; Cakmak, M. Macromol. Symp. 2002, 185, 149-166.

(71) Martins, C. I.; Cakmak, M. Polymer 2007, 48, 2109-2123.

(72) Koike, Y.; Cakmak, M. Polymer 2003, 44, 4249-4260

(73) Scroog, C. E. Macromol. Rev. J. Polym. Sci. 1976, 2, 161.

(74) Arnold, C. Macromol. Rev. J. Polym. Sci. 1979, 14, 265.

(75) Hergenrother, P. M.; Wakelyn, N. T.; Havens, S. J. J. Polym. Sci. 1987, 25, 1093. 
(76) Vandezande, P.; Gevers, L.; Vankelecom, I. Che. Soc. Rev. 2008, 37, 365-405.

(77) St. Clair, A. K.; St. Clair, T. L. US. Patent 4, 603, 061, 1986.

(78) St. Clair, A. K.; St. Clair, T. L.; Slemp, W.; Ezzell, K. S. Optically transparent/colorless polyimides; Langley Res. Cent.,Natl. Aeronaut. Space Adm.,Hampton, VA, USA., 1985,41.

(79) Misawa, Y.; Kinjo, N.; Hirao, M.; Numata, S.; Momma, N. IEEE Transactions on Electron Devices. 1987, 34, 621-627.

(80) Kim, J. Y.; Kim, Y. D. J. Appl. Polym. Sci. 1999, 71, 431-438.

(81) Oksanen, C. A; Zografi, G. Pharmaceutical Research. 1990, 7, (6), 654-657.

(82) Koike, Y.; Sen, T. Z.; Cakmak, M. Annu. Tech. Conf. - Soc. Plast. Eng. 2002, $60,1550-1555$.

(83) Koike, Y.; Cakmak, M. Polymer 2003, 44, 4249-4260.

(84) Kanuga, K.; Cakmak, M. Macromolecules 2005, 38, 9698-9710.

(85) Kanuga, K.; Cakmak, M. Polymer 2007, 48, 7176-7192.

(86) Sen, T. Z. Ph. D. thesis, The University of Akron, 2003.

(87) Pluta, M. Polymer 1992, 33, 1553-1555.

(88) Hongladarom, K.; Burghardt, W. Macromolecules 1994, 27, 483-489.

(89) Hongladarom, K.; Burghardt, W.; Baek, S.; S., C.; Magda, J. J. Macromolecules 1993, 26, 772-784.

(90) Hongladarom, K.; Secakusuma, V.; Burghardt, W. Journal of Rheology 1994, 38,1505 .

(91) Beekmans, F.; De Boer, A. P. Macromolecules 1996, 29, 8726-8733.

(92) Galay, J.; Cakmak, M. J. Polym. Sci. Pol. Phys. 2001, 39, 1147-1159.

(93) Galay, J.; Cakmak, M. J. Polym. Sci. Pol. Phys. 2001, 39, 1107-1121.

(94) Venkatesvaran, H.; Cakmak, M. Polym. Eng. Sci. 2001, 41, 341-357.

(95) Martins, C. I.; Cakmak, M. Polymer 2007, 48, 2109-2123.

(96) Hassan, M. Ph. D. thesis, The University of Akron, 2004.

(97) Cakmak, M.; Hassan, M. K.; Unsal, E.; Martins, C. I. Rev. Sci. Instrum. 2012, 83, 123901 .

(98) Bicakci, S.; Cakmak, M. Polymer 2002, 43, 2737-2746.

(99) Doumenc, F.; Guerrier, B. Langmuir 2010, 26 (17), 13959-13967.

(100) Shojaie, S.; Krantz, W. J. Membr. Sci. 1994, 94, 255-280. 
(101) Shojaie, S.; Krantz, W. J. Membr. Sci. 1994, 94, 281-198.

(102) Yucel, O.; Unsal, E.; Cakmak, M. Macromolecules 2013, 46, 7112-7117.

(103) Eguchi, Y.; Unsal, E.; Cakmak, M. Macromolecules 2013, 46, 7488-7501.

(104) Sosnowski, T. P.; Weber, H. P. Appl. Phys. Lett. 1972, 21, 310-311.

(105) Cherkasov, A. N.; Vitovskaya, M. G.; Bushin, S. V Vysokomol. Soedin., Ser. A 1976, 18, 1628-1634.

(106) Machell, J. S.; Greener, J.; Contestable, B. A. Macromolecules 1990, 23, 186-194.

(107) Nasr, A. Polymer Testing 2002, 21, 303-306.

(108) Greener, J.; Lei, H.; Elman, J.; Chen, J. J. Soc. Inf. Disp. 2005, 13, 835-839.

(109) Greener, J.; Lei, H.; Rao, Y.; Elman, J. F. IDMC 2007, 402-405.

(110) Chen, P. J.; Liu, T. J.; Wu, P. Y.; Tseng, C. F.; Leu, C. M. AIChE Journal 2010, 56, 790-800. 